\title{
Performance
}

No.1737

December 2020

\section{The UK's great demand and supply recession}

Nick Jacob

Giordano Mion 


\begin{abstract}
We revisit UK's poor productivity performance since the Great Recession by means of both a suitable theoretical framework and firm-level prices and quantities data for detailed products allowing us to both measure demand, and its changes over time, and distinguish between quantity total factor productivity (TFP-Q), i.e., the capacity to turn inputs into more physical output (number of shirts, liters of beer), and what we call revenue total factor productivity (TFP-R), i.e., productivity calculated using revenue (or value-added) as a measure of output and so the capacity to turn inputs into more revenue. This in turn allows us to measure how changes in TFP-Q, demand and markups ultimately affected revenue TFP, as well as labour productivity, over the Great Recession. Our findings suggest that the poor UK firms' productivity performance post-recession is due to both a weakening of demand and a decreasing TFPQ pushing down sales, markups, revenue TFP and labour productivity.
\end{abstract}

Key words: Total factor productivity (TFP), revenue TFP, prices, demand, great recession, United Kingdom.

JEL codes: D24; L11; E01; O47; O52

This paper was produced as part of the Centre's Growth Programme. The Centre for Economic Performance is financed by the Economic and Social Research Council.

\title{
Acknowledgements
}

We are grateful to Jagjit Chadha, Stephen Millard and seminars participants at the Bank of England and University of Sussex. The paper contains statistical data from ONS which are Crown copyright and reproduced with the permission of the controller of HMSO and Queen's Printer for Scotland. The use of the ONS statistical data does not imply the endorsement of the ONS in relation to the interpretation or analysis of the data. This work uses research datasets which may not exactly reproduce National Statistics aggregates. Copyright of the statistical results may not be assigned, and publishers of this data must have or obtain a license from HMSO. The ONS data in these results are covered by the terms of the standard HMSO license.

Nick Jacob, University of Sussex. Giordano Mion, University of Sussex, CESifo, NIESR/ESCoE and Centre for Economic Performance, London School of Economics.

Published by

Centre for Economic Performance

London School of Economics and Political Science

Houghton Street

London WC2A 2AE

All rights reserved. No part of this publication may be reproduced, stored in a retrieval system or transmitted in any form or by any means without the prior permission in writing of the publisher nor be issued to the public or circulated in any form other than that in which it is published.

Requests for permission to reproduce any article or part of the Working Paper should be sent to the editor at the above address.

(c) N. Jacobs and G. Mion, submitted 2020. 


\section{Introduction}

The Covid-19 pandemic has forced a number of countries to shut down large parts of the economy leaving millions of people at home and many businesses at risk of bankruptcy. Detailed data on the economic consequences of this crisis are only beginning to be available while a climate of general uncertainty dominates the discussions related to how best address such economic consequences in both the short and the long term. Meanwhile, governments are putting in place large rescue packages that will severely affect the public debt to GDP ratio; a ratio that is already high everywhere because the world has not yet completely recovered from the previous crisis, i.e., the 2008 Great Recession; a recession we have not fully understood yet. In this paper we revisit, with the help of new data and a suitable framework, the impacts of the Great Recession on output and productivity for the UK. In doing so, we provide a number of new insights that we believe could be useful to better understand how the Great Recession has affected countries other than the UK as well as to inform the current discussions on the Covid-19 crisis.

Nine years after the end of the Great Recession in the UK, labour productivity has barely returned to the level it reached on the eve of the downturn at the end of 2007 (Office for National Statistics, 2018b). Output per hour worked grew just $1.8 \%$ between the start of 2008 and the end of 2017: had it grown at its 1994-2007 trend, it would have been $19.6 \%$ higher. $^{1}$ This poor performance is a puzzle. A sustained period of little to no labour productivity growth following a recession is indeed rare in the UK's historical record. ${ }^{2}$ Furthermore, the productivity slowdown has occurred despite a buoyant labour market, ${ }^{3}$ and the UK's experience is widely judged to have been worse than most of its EU and OECD peers. ${ }^{4}$ Despite many complementary explanations have so far been put forward, little attention has been paid to the role of demand and markups as well as to the crucial distinction between quantity total factor productivity (TFP-Q), i.e., the capacity to turn inputs into more physical output (number of shirts, liters of beer), and what we call revenue total factor productivity (TFP-R), i.e., productivity calculated using (price-index deflated) revenue or value-added as a measure of output and so the capacity to turn inputs into more revenue/value-added.

Regarding the role of demand, the problem is that without actual data on products' prices and quantities it is not possible to measure demand and its changes over time and

\footnotetext{
${ }^{1}$ Our period of analysis ends in 2013 and at that point, output per hour was $1.7 \%$ lower than at the end of 2007. Had it grown at its 1994-2007 trend rate, it would have been $14.4 \%$ higher.

${ }^{2}$ Four years after the end of the recessions that began in 1973, 1980 and 1990, labour productivity was between $5 \%$ and $15 \%$ higher than its previous peak (Grice, 2012).

${ }^{3}$ See, for example, Bryson and Forth (2016) and Pessoa and Van Reenen (2014).

${ }^{4}$ See, for example, OECD (2018) and Office for National Statistics (2018a). There is evidence that the productivity slowdown in the US and major European economies pre-dates the financial crisis (Cette et al., 2016) but the UK experience, as documented by Office for National Statistics (2018b), shows a marked slowdown of the productivity growth trend in the recovery from the 2008-9 recession.
} 
so assess whether, and to what extent, a fall in demand might have contributed to the UK productivity slowdown. For example, if revenues increase less than the price index one might well conjecture that the underlying unobservable quantities sold have decreased, but it would not be possible to establish whether the decrease in quantities is simply due to price changing, and firms moving along the same demand curve, or the underlying demand curve firms face has changed. At the same time, the unavailability of data on products' prices and quantities does not allow to properly distinguish between quantity TFP and revenue TFP. To be more specific, both macro and micro productivity studies use price indices to deflate nominal sales, or valueadded, in order to measure output and its changes over time. Besides the usual caveats of aggregation bias and the presence of substantial price heterogeneity across firms, the issue with this approach is that actual price changes do not correspond to price index changes due to, for example, the imputation of part of actual price changes to quality improvements to products or changes to the specification of a product. Therefore, standard price-index deflated nominal values still contain a price measure and that is why we label productivity measures obtained with this approach as revenue-TFP measures.

In this paper we provide novel evidence that the poor UK firms' productivity performance post-2008 is due to both a weakening demand and a sluggish TFP-Q growth pushing down sales, markups and revenue TFP, as well as labour productivity. More specifically, in the first part of our analysis we focus on manufacturing firms and use information on firm-level prices and quantities for detailed products, coming from the UK Prodcom dataset, as well as inputs over the period $2003-2013^{5}$ to measure firm-level quantity TFP by building upon the frameworks developed in De Loecker et al. (2016) and Forlani et al. (2016). This allows us to further quantify firm-level markups, as well as firm-level demand and its changes over time and, while aggregating-up the information at the manufacturing industry-level, compare the evolution of TFP-Q, markups and demand before and after 2008. Finally, we exploit two exact decompositions for TFP-R and labour productivity to show how changes in TFP-Q, markups and demand have affected the two productivity measures. Our results strongly indicate that both a slowing down of demand and a decline in quantity TFP, and the related markups fall, are behind the decline in revenue TFP and labour productivity in manufacturing. Furthermore, we show that the difference between actual price changes and price index changes, that we label 'real price changes', reflect more than just quality improvements to products and actually widened post-2008, in response to the increasing production costs generated by a lower TFP-Q, so helping to contain the fall in TFP-R.

In the second part of our analysis, we instead consider service industries and estimate a restricted version of the model due to the absence of reliable and meaningful information on

\footnotetext{
${ }^{5}$ We consider the time frame 2003-2013 in our analysis for better comparability with previous studies on the UK productivity puzzle.
} 
prices and quantities. In doing so we find, for those measures that are common to both the full and restricted versions of the model, very similar patterns to those obtained for manufacturing. These findings, along with the absence of noticeable differences in capital stock investments patterns between manufacturing and services industries, lead us to conjecture that both demand and TFP-Q are also responsible for the poor revenue TFP and labour productivity performance of UK service industries.

We believe that our results are important for at least two reasons. First, they are informative about the long-term impacts of the Great Recession. A fall in quantity TFP, due for example to a decline in the rate of technical progress, represents a permanent loss of productive potential with substantial long-term implications for the economy. By contrast a demand downturn, due for example to a general climate of uncertainty, could have less permanent consequences. Second, they are informative about the policies that could more effectively address the weak growth of labour productivity and revenue TFP post-2008. In particular, our findings suggest that government policies should more prominently act towards boosting demand for firms rather than focusing only on productivity. In this respect, we believe this point might be particularly relevant in the current Covid-19 crisis.

Our paper is related to the literature devoted to the UK productivity puzzle. ${ }^{6}$ This literature has so far considered many complementary reasons for the poor post-2008 performance relative to the long-term trend. Among these are: measurement errors in output (Goodridge et al., 2016; Grice, 2012); productivity losses in specific sectors (Riley et al., 2018); labour hoarding (Martin and Rowthorn, 2012); capital shallowing (Pessoa and Van Reenen, 2014; Goodridge et al., 2016; Riley et al., 2018); the impact of badly-measured intangible capital (Goodridge et al., 2013); changes to firm entry and exit behaviour in the context of an impaired financial sector (Barnett et al., 2014; Riley et al., 2013, 2014); a lengthening of the left tail of poorly performing firms in the productivity distribution (Andrews et al., 2015); and a slowdown among high-performing firms in the right tail of the distribution (Schneider, 2018). However, while there are many proposed culprits and some fit better than others certain features of the puzzle, there is lack of consensus on some key elements of the productivity downturn, ${ }^{7}$ while we know little about to what extent the puzzle is demand- and/or supply-driven and what is the macro role played by markups (De Loecker et al., 2020).

Our paper is also related to the literature on heterogeneous markups and productivity inspired by Hall (1986) and Olley and Pakes (1996) and further developed in Ackerberg et al.

\footnotetext{
${ }^{6}$ See Bryson and Forth (2016) and McCann (2018) for a literature review.

${ }^{7}$ For example, in manufacturing there is not a consensus on whether the labour productivity puzzle is also a total factor productivity puzzle. More specifically, Goodridge et al. (2016) build upon an aggregate-level growth accounting approach and find that labour productivity in manufacturing has declined also because of a decline in total factor productivity. By contrast, Harris and Moffat (2017) build upon a firm-level approach and find that the labour productivity puzzle in manufacturing is mainly driven by a decline in intermediates intensity while TFP growth continued.
} 
(2015), De Loecker et al. (2016) and Forlani et al. (2016). More specifically, in our analysis we estimate a quantity-based production function for UK manufacturing using two estimation procedures, the one developed in De Loecker et al. (2016) (henceforth DGKP) and the one described in Forlani et al. (2016) (henceforth FMMM). These two methods are similar in their motivation to disentangle heterogeneity in revenue TFP into supply-side differences between firms, notably TFP-Q, from demand-side differences in prices which could be due to differences in input and/or output quality, demand and markups. As for services, we instead estimate revenue-based production functions by building on either the restricted version of the model introduced in FMMM or the more standard Wooldridge (2009) approach (henceforth WLD). Again, our results are largely unaffected by whether we use one or the other estimation method. For both manufacturing and services we use the TFP-R decomposition provided in FMMM to break down revenue productivity changes into underlying changes in TFP-Q and demand (a composite of TFP-Q and demand for services) as well as markups and production scale. We further develop a labour productivity decomposition generalizing the standard formula used in growth accounting exercises to the presence of heterogeneity in demand and markups. Finally, we show that our results are robust to whether we use a Cobb-Douglas or a Translog production function, to different weighting schemes (revenue, employment, unweighted) and samples (single-product vs. multi-product firms) as well as different estimation procedures.

The remainder of this paper is structured as follows. Section 2 presents key highlights of the FMMM model and related TFP-R and labour productivity decompositions. Section 3 describes the datasets used and provides some summary statistics and high-level patterns while Section 4 contains production function estimation results and develops a number of useful insights into how to interpret the results. Section 5 presents baseline results for both manufacturing and services while Section 6 contains a number of additional findings showing the robustness of our results. Finally, Section 7 concludes. Further details about the data and robustness findings are provided in the Appendix.

\section{The MULAMA model}

This Section follows FMMM and in particular we provide here the single-product firm version of the model. See FMMM for the multi-product firm extension of the model. The model is labelled MULAMA because of the names of the 3 heterogeneities it allows for: markups MU, demand LAMbda and quantity TFP A. FMMM also provide and estimation procedure to quantity markups, demand and quantity TFP that we employ in our analysis. At the same time, the estimation procedure developed in DGKP is also consistent with the MULAMA model and we employ such estimation procedure as well to corroborate the robustness of our 
findings. Furthermore, the MULAMA model allows for an exact decomposition of revenue TFP in terms of the underlying heterogeneities. In addition, we develop below a decomposition of labour productivity generalizing the standard formula used in growth accounting exercises to the presence of heterogeneity in demand and markups.

\subsection{Measuring demand}

In what follows we index firms by $i$ and time by $t$ and denote with lower case the $\log$ of a variable (for example $r_{i t}$ denotes the natural logarithm of revenue $R_{i t}$ ). Standard profit maximization (marginal revenue equal to marginal costs) implies that the elasticity of revenue $R_{i t}$ with respect to quantity $Q_{i t}$ is one over the profit maximizing markup:

$$
\frac{\partial r_{i t}}{\partial q_{i t}}=\underbrace{\frac{\partial R_{i t}}{\partial Q_{i t}}}_{\text {marginal revenue }} \quad \frac{Q_{i t}}{R_{i t}}=\underbrace{\frac{\partial C_{i t}}{\partial Q_{i t}}}_{\text {marginal cost }} \quad \frac{Q_{i t}}{P_{i t} Q_{i t}}=\frac{\frac{\partial C_{i t}}{\partial Q_{i t}}}{P_{i t}}=\frac{1}{\mu_{i t}}
$$

where $\mu_{i t}=\frac{P_{i t}}{\partial C_{i t}}$ is the profit maximizing markup. This result comes from static profit maximization and holds under different assumptions about demand (representative consumer and discrete choice models) and product market structure (monopolistic competition, monopoly and standard forms of oligopoly).

Despite the $\log$ revenue function, i.e., the function relating log revenue to log quantity, being both unknown and potentially different across firms, equation (1) provides us with the slope of the firm-specific log revenue function while data on the actual log revenue $r_{i t}$ and $\log$ quantity $q_{i t}$ referring to firm $i$ provide us with a point where such log revenue function cuts through the $(q, r)$ space. If we now linearize the log revenue function around the observed data point $\left(q_{i t}, r_{i t}\right)$ with a slope given by $\frac{1}{\mu_{i t}}$ we can uniquely pin down an intercept for this linearized log revenue function on the $r$ axis. We use such intercept $\tilde{\lambda}_{i t}$ as a measure of the firm-specific demand: ${ }^{8}$

$$
\tilde{\lambda}_{i t} \equiv r_{i t}-\frac{\partial r_{i t}}{\partial q_{i t}} q_{i t}=r_{i t}-\frac{q_{i t}}{\mu_{i t}}
$$

Given our definition of $\tilde{\lambda}_{i t}$ observed firm log revenue is simply

$$
r_{i t}=\tilde{\lambda}_{i t}+\frac{1}{\mu_{i t}} q_{i t},
$$

and so $\tilde{\lambda}_{i t}$ is a firm-specific log revenue shifter corresponding to the log price firm $i$ would face if selling one unit of its product. ${ }^{9}$

\footnotetext{
${ }^{8}$ To simplify notation we ignore components that are constant across firms in a given time period or within a product category. Those constants will be captured in our empirical analysis by a suitable set of dummies.

${ }^{9}$ At the intercept point $q_{i t}=0$ and so we have $Q_{i t}=1$ from which $R_{i t}=P_{i t}$ and $r_{i t}=p_{i t}=\tilde{\lambda}_{i t}$. Note this
} 
While being general and intuitive, this measure of firm-specific demand also maps to more formal and explicit differences in the underlying structure of preferences. In particular, FMMM show that $\tilde{\lambda}_{i t}=\frac{\lambda_{i t}}{\mu_{i t}}$ where $\lambda_{i t}$ is a parameter characterizing differences in utility derived from the consumption of products sold by different firms. More specifically, consider a representative consumer who maximises at each point in time $t$ a differentiable utility function $U($.$) subject to budget B_{t}$ :

$$
\max _{Q}\{U(\tilde{Q})\} \text { s.t. } \int_{i} P_{i t} Q_{i t} \mathrm{~d} i-B_{t}=0
$$

where $\tilde{Q}$ is a vector of elements $\Lambda_{i t} Q_{i t}$ and $\lambda_{i t}=\log \left(\Lambda_{i t}\right)$. Therefore, while the representative consumer chooses quantities $Q$, these quantities enter into the utility function as $\tilde{Q}$ and $\Lambda_{i t}$ can be interpreted as a measure of the perceived quality/appeal of a particular variety. In our analysis we employ $\lambda_{i t}$ as a complementary measure of the firm-specific demand and sometimes refer to $\tilde{\lambda}_{i t}$ as markup-adjusted demand. ${ }^{10}$

\subsection{Measuring Markups}

As far as markups are concerned FMMM build upon a result, first highlighted in Hall (1986) and implemented in De Loecker and Warzynski (2012) and DGKP among others, based on cost-minimization of a variable input free of adjustment costs (materials in our empirical implementation) and price-taking behaviour on the inputs side (the cost of materials $W_{\text {Mit }}$ is allowed to be firm-time specific but it is given to the firm). The proof goes as follows. Starting from the definition of marginal cost:

$$
\frac{\partial C_{i t}}{\partial Q_{i t}}=\frac{\partial C_{i t}}{\partial M_{i t}} \frac{\partial M_{i t}}{\partial Q_{i t}}=W_{M i t} \frac{\partial M_{i t}}{\partial Q_{i t}}
$$

Now define the markup as:

$$
\mu_{i t} \equiv \frac{P_{i t}}{\frac{\partial C_{i t}}{\partial Q_{i t}}} .
$$

has no implications whatsoever about the presence/absence of a choke price.

${ }^{10}$ The interpretation of $\Lambda_{i t}$ as a utility shifter and its relationship with the firm log revenue function are based on a first-order linear approximation around the profit maximizing solution, i.e., $r_{i t} \simeq \frac{1}{\mu_{i t}}\left(q_{i t}+\lambda_{i t}\right)$. In this respect, FMMM show that such linear approximation applies to any preferences structure that can be used to model monopolistic competition, and for which a well-behaved differentiable utility function exists, as well as to the oligopoly model developed in Atkeson and Burstein (2008) and further refined in Hottman et al. (2016). This includes standard CES preferences as well as generalized CES preferences (Spence, 1976), CARA preferences (Behrens et al., 2014), HARA preferences (Haltiwanger et al., 2018), Translog preferences (Feenstra, 2003) as well as the class of Variable Elasticity of Substitution (VES) preferences discussed in Zhelobodko et al. (2012) and Dhingra and Morrow (2019). Finally, FMMM provide examples suggesting that a log-linear approximation of the revenue function, which is behind both the construction of $\tilde{\lambda}_{i t}$ and its interpretation as a markup-adjusted measure of product appeal, works well for many utility specifications. 
We thus have:

$$
\frac{P_{i t}}{\mu_{i t}}=W_{M i t} \frac{\partial M_{i t}}{\partial Q_{i t}}
$$

Multiplying by $Q_{i t}$ and dividing by $M_{i t}$ on both sides we get:

$$
\frac{P_{i t} Q_{i t}}{M_{i t} \mu_{i t}}=\frac{R_{i t}}{M_{i t} \mu_{i t}}=W_{M i t} \frac{\partial M_{i t}}{\partial Q_{i t}} \frac{Q_{i t}}{M_{i t}}=W_{M i t} \frac{\partial m_{i t}}{\partial q_{i t}}
$$

Re-arranging we finally have:

$$
\mu_{i t}=\frac{\frac{\partial q_{i t}}{\partial m_{i t}}}{\frac{W_{M i t} M_{i t}}{R_{i t}}}=\frac{\frac{\partial q_{i t}}{\partial m_{i t}}}{s_{M i t}}
$$

The simple rule to pin-down markups is consistent with many hypotheses on product market structure (monopolistic competition, monopoly and standard forms of oligopoly) and consists in taking the ratio of the output elasticity of materials $\left(\frac{\partial q_{i t}}{\partial m_{i t}}\right)$ to the share of materials in revenue $\left(s_{M i t} \equiv \frac{W_{M i t} M_{i t}}{R_{i t}}\right)$. Measuring the output elasticity of materials requires estimation of the coefficients of the production function while the share of materials in revenue is directly observable in most datasets (including ours). For example, in the case of a Cobb-Douglas production function with 3 inputs (labour L, materials $\mathrm{M}$ and capital K) and with (log) quantity TFP being labeled as $a_{i t}$, log quantity is:

$$
q_{i t}=\alpha_{L} l_{i t}+\alpha_{M} m_{i t}+\alpha_{K} k_{i t}+a_{i t}
$$

and so the output elasticity of materials is constant and equal to $\alpha_{M}$ meaning that $\mu_{i t}=\frac{\alpha_{M}}{s_{M i t}}$. When instead considering a Translog production function log quantity is:

$$
q_{i t}=\sum_{x \in\{m, l, k\}}\left[\alpha_{X} x_{i t}+\frac{1}{2} \alpha_{X X}\left(x_{i t}\right)^{2}\right]+\alpha_{M K} m_{i t} k_{i t}+\alpha_{M L} m_{i t} l_{i t}+\alpha_{L K} l_{i t} k_{i t}+a_{i t}
$$

and so:

$$
\mu_{i t}=\frac{\alpha_{M}+\alpha_{M M} m_{i t}+\alpha_{M L} l_{i t}+\alpha_{M K} k_{i t}}{s_{M i t}} .
$$

Therefore, with estimates of the production function coefficients at hand, (4) can be used to recover firm-specific markups. At the same time, with markups as well as log quantity and log revenue, (2) can be used to get the demand measures $\tilde{\lambda}_{i t}$ and $\lambda_{i t}$.

\subsection{Quantity TFP}

The last step to close the model involves estimating the parameters of the production function and so recover quantity TFP $a_{i t}$ and subsequently markups and demand as explained above. There are many different hypotheses, and related estimation procedures, one can use in order 
to achieve this and in what follows we describe and employ two techniques.

One readily available approach to estimate the production function, that is consistent with the MULAMA model, is provided in DGKP. This methodology relies on the popular proxy variable approach pioneered by Olley and Pakes (1996) and in particular, starting from the conditional input demand for materials, adds to such function a number of observables (prices and market shares in particular) to proxy for unobservables (markups and demand heterogeneity in our framework) while further imposing invertibility of the conditional input demand for materials. More specifically, DGKP build on the GMM approach outlined in WLD and in particular consider the leading case of an $\mathrm{AR}(1)$ process for productivity:

$$
a_{i t}=\phi_{a} a_{i t-1}+\nu_{a i t}
$$

where $\nu_{\text {ait }}$ stands for productivity shocks that are iid and represent innovations with respect to the information set of the firm in $t-1$. Therefore, productivity shocks $\nu_{\text {ait }}$ are uncorrelated with past values of all firm-level variables (capital, revenue, quantity, etc.) including productivity. However, the productivity level $a_{i t}$ is allowed to be correlated with past and present firm-level variables and in particular is a variable considered by the firm when making choices in $t$.

Under the (usual) additional assumption that capital is predetermined in $t$, i.e., capital is chosen beforehand and cannot adjust immediately to shocks $\nu_{\text {ait }}$ occurring in $t{ }^{11}$ the firm will thus consider capital as given in $t$ and will choose the optimal amount of materials in order to minimize costs based on the given values of capital $k_{i t}$ and TFP $a_{i t}$ as well as the price of materials $W_{\text {Mit }}$. Such optimal amount will in general be a deterministic function $h($. of $k_{i t}, a_{i t}$ and $W_{\text {Mit }}$. Furthermore, with underlying differences in markups and demand, $h($. will also depend on markups $\mu_{i t}$ and demand $\lambda_{i t}$. Finally, if labour has also been chosen prior to $t$ (because it is like capital difficult to adjust in the wake of short-term shocks $\left.\nu_{a i t}\right),{ }^{12}$ then $h($.$) will also contain l_{i t}: m_{i t}=h\left(k_{i t}, l_{i t}, a_{i t}, W_{M i t}, \mu_{i t}, \lambda_{i t}\right)$. If $h($.$) is globally invertible with$ respect to $a_{i t}$, the inverse function $a_{i t}=g\left(k_{i t}, l_{i t}, m_{i t}, W_{M i t}, \mu_{i t}, \lambda_{i t}\right)$ exists and is well behaved and so one can use a semi-parametric polynomial approximation of $g($.$) in order to proxy for$ the unobservable (to the econometrician) quantity TFP $a_{i t}$. Furthermore, given also $W_{M i t}, \lambda_{i t}$ and $\mu_{i t}$ are unobservable (to the econometrician), DGKP suggest using the observable output price and market share of firm $i$ as proxies for $W_{M i t}, \lambda_{i t}$ and $\mu_{i t}$ in the semi-parametric

\footnotetext{
${ }^{11}$ Capital can nonetheless adjust to shocks $\nu_{\text {ait }}$ at time $\mathrm{t}+1$.

${ }^{12}$ Given the features of the UK labour market we do not assume, as DGKP do for India and Jacob and Mion (2020) do for France, that labour is, like capital, predetermined for the firm in $t$. More specifically we consider, in both the DGKP and FMMM estimation procedures, that labour is a semi-flexible input that is chosen at time $t-b(0<b<1)$, i.e., it can be adjusted in light of contemporaneous shocks in $t$ but not as fully as materials. In practice, this means we consider it as an endogenous variable, and use its lags as instruments in the estimation, but do not consider it flexible enough to use in the calculation of markups. See FMMM for more details on how to deal with semi-flexible inputs.
} 
approximation of $g(),.{ }^{13}$ that so becomes a function of observables only. Operationally, $g($. is thus approximated by a polynomial function in the 3 inputs plus the output price and the market share.

Two shortcomings of the DGKP approach are related to its implicit assumptions and the amount of identifying variation. More specifically, existence and invertibility of a suitable conditional input demand for materials implies making implicit assumptions about demand and market structure that are nor readily verifiable. Furthermore, in the estimation procedure described in DGKP firm market share (de facto firm revenue) and price in $t-1$ are, among other things, added as covariates in a regression where quantity at time $t$ in on the left-hand side. Therefore, there might be little variation left to precisely identify technology parameters.

In an attempt to address these two issues FMMM develop an alternative estimation methodology that does not rely on the proxy variable approach. More specifically, FMMM use both the first-order approximation of the log revenue function and the production function to recover technology parameters. Indeed, FMMM are sufficiently explicit about demand to be able to explicitly write the log revenue function in terms of observables and heterogeneities and use both this and the production function equation to estimate technology parameters. The key disadvantage of this methodology is that one has to be explicit about the process governing the evolution of demand $\lambda_{i t}$ and in particular FMMM assume it follows an AR(1) process. ${ }^{14}$ In our implementation of the FMMM procedure we use:

$$
\lambda_{i t}=\phi_{\lambda} \lambda_{i t-1}+\nu_{\lambda i t}
$$

where $\nu_{\lambda i t}$ stands for demand shocks that are iid and represent innovations with respect to the information set of the firm in $t-1$. However, FMMM do not impose any constraints on the correlation between demand shocks $\nu_{\lambda i t}$ and quantity TFP shocks $\nu_{a i t}$ and so ultimately do not impose a priori any constraints on the correlation between demand $\lambda_{i t}$ and quantity TFP $a_{i t}$. Indeed, our analyses confirm previous findings in FMMM of a negative correlation between $\lambda_{i t}$ and $a_{i t}$ irrespective of whether we use the FMMM or the DGKP procedure. This is suggestive of a trade-off between the appeal/quality of a firm's products and their production cost which in line with findings in the demand system literature (Ackerberg et al., 2007).

\footnotetext{
${ }^{13}$ DGKP cite Kugler and Verhoogen (2011) who document how producers of more expensive products also use more expensive inputs so suggesting that observable output prices could be reasonably used to proxy for unobservable input prices.

${ }^{14} \lambda_{i t}$ captures consumers' perception of a firm's products quality and appeal; something that arguably does not change much from one year to another. It takes years of effort and costly investments to firms to establish their brand and build their customers' base very much like it takes years of effort and costly investments to firms to put in place and develop an efficient production process for their products. FMMM thus argue that there are profound similarities between the processes of productivity (typically modelled as an autoregressive process) and product appeal.
} 


\subsection{TFP-R decomposed}

To appreciate how the MULAMA model is useful in linking revenue TFP and quantity TFP note that, with standard Hicks-neutral TFP, one can write the log of the production function as $q_{i t}=\bar{q}_{i t}+a_{i t}$ where $\bar{q}_{i t}$ is an index of inputs use that we label scale. ${ }^{15}$ Revenue TFP is simply $\log$ revenue minus scale $T F P_{i t}^{R} \equiv r_{i t}-\bar{q}_{i t}=a_{i t}+p_{i t}$, and it is also equal to quantity TFP plus log price. Using equation (3) to substitute for $r_{i t}$ along with $\tilde{\lambda}_{i t}=\frac{\lambda_{i t}}{\mu_{i t}}$ we get:

$$
T F P_{i t}^{R}=\frac{a_{i t}}{\mu_{i t}}+\frac{\lambda_{i t}}{\mu_{i t}}+\frac{1-\mu_{i t}}{\mu_{i t}} \bar{q}_{i t}
$$

meaning that $T F P_{i t}^{R}$ is a (non-linear) function of quantity-based TFP $a_{i t}$, demand $\lambda_{i t}$, the markup $\mu_{i t}$ and production scale $\bar{q}_{i t}$. (9) can also be made linear by considering markupadjusted quantity TFP and scale $\left(\tilde{a}_{i t}=\frac{a_{i t}}{\mu_{i t}}\right.$ and $\left.\tilde{\bar{q}}_{i t}=\frac{\left(1-\mu_{i t}\right) \bar{q}_{i t}}{\mu_{i t}}\right)$ :

$$
T F P_{i t}^{R}=\tilde{a}_{i t}+\tilde{\lambda}_{i t}+\tilde{\bar{q}}_{i t}
$$

so that $T F P_{i t}^{R}$ differences across firms and time can be decomposed as the sum of differences in $\tilde{a}_{i t}, \tilde{\lambda}_{i t}$ and $\tilde{\bar{q}}_{i t}$. In particular, using $\Delta$ to denote changes between $t-1$ and $t$ :

$$
\Delta T F P_{i t}^{R}=\Delta \tilde{a}_{i t}+\Delta \tilde{\lambda}_{i t}+\Delta \tilde{\bar{q}}_{i t}
$$

\subsection{Labour productivity decomposed}

TFP, whether of the quantity or revenue flavour, is not the only productivity measure of interest to economists and policymakers. Labour productivity measured as output per worker or per hour worked is widely used and is often more closely related to wages and living standards. In many empirical settings researchers use a simple growth accounting methodology to attribute $(\log )$ labour productivity changes to changes in the labour input, other inputs and TFP building on the Cobb-Douglas production function:

$$
r_{i t}=q_{i t}+p_{i t}=\alpha_{L} l_{i t}+\alpha_{M} m_{i t}+\alpha_{K} k_{i t}+\underbrace{a_{i t}+p_{i t}}_{T F P_{i t}^{R}},
$$

where $a_{i t}+p_{i t}$ is nothing else than revenue TFP. By subtracting $l_{i t}$ from both sides while rearranging and considering time changes $\Delta$, we have the following labour productivity $\left(L P_{i t}\right)$

\footnotetext{
${ }^{15}$ For example, with a Cobb-Douglas production technology $\bar{q}_{i t}=\alpha_{L} l_{i t}+\alpha_{M} m_{i t}+\alpha_{K} k_{i t}$.
} 
decomposition:

$$
\Delta L P_{i t}=\Delta\left(r_{i t}-l_{i t}\right)=\left(\alpha_{L}-1\right) \Delta l_{i t}+\alpha_{M} \Delta m_{i t}+\alpha_{K} \Delta k_{i t}+\Delta T F P_{i t}^{R}
$$

The equivalent factor proportions version used in Goodridge et al. (2016), Harris and Moffat (2017) and Pessoa and Van Reenen (2014) is:

$$
\Delta L P_{i t}=\gamma \Delta l_{i t}+\alpha_{M} \Delta\left(m_{i t}-l_{i t}\right)+\alpha_{K} \Delta\left(k_{i t}-l_{i t}\right)+\Delta T F P_{i t}^{R},
$$

where $\gamma=\alpha_{L}+\alpha_{M}+\alpha_{K}-1$ is a parameter measuring returns to scale.

Within the MULAMA model both decompositions can be further developed. More specifically, substituting (11) for $\triangle T F P_{i t}^{R}$ in (12) and simplifying leads to:

$$
\Delta L P_{i t}=\Delta\left[\left(\frac{\alpha_{L}}{\mu_{i t}}-1\right) l_{i t}\right]+\alpha_{M} \Delta\left(\frac{m_{i t}}{\mu_{i t}}\right)+\alpha_{K} \Delta\left(\frac{k_{i t}}{\mu_{i t}}\right)+\Delta\left(\frac{a_{i t}}{\mu_{i t}}\right)+\Delta\left(\frac{\lambda_{i t}}{\mu_{i t}}\right)
$$

while, in the factor proportions version, substituting (11) for $\Delta T F P_{i t}^{R}$ in (13) delivers:

$$
\Delta L P_{i t}=\Delta\left[\left(\frac{\gamma+1}{\mu_{i t}}-1\right) l_{i t}\right]+\alpha_{M} \Delta\left(\frac{m_{i t}-l_{i t}}{\mu_{i t}}\right)+\alpha_{K} \Delta\left(\frac{k_{i t}-l_{i t}}{\mu_{i t}}\right)+\Delta\left(\frac{a_{i t}}{\mu_{i t}}\right)+\Delta\left(\frac{\lambda_{i t}}{\mu_{i t}}\right) .
$$

From (14) and (15) it now appears clearly how changes in labour productivity materialize as a consequence of changes in quantity TFP, demand, markups and inputs use.

\subsection{The restricted model and services}

Quantity and price data are very often not available to researchers, almost universally for the service sectors where output measures can be particularly problematic (Office for National Statistics, 2007). In such cases, the only available option is to estimate the production function and related TFP using revenue, or value added, as a measure of output, i.e., measure revenue TFP. This raises the issue, discussed above, of the bias in the estimation of production function coefficients coming from any correlation between the underlying prices and inputs use. In this respect, FMMM provide an overall reassuring message.

More specifically, FMMM find that more standard revenue TFP measures obtained using revenue as a measure of output are reasonably well correlated with revenue TFP measures obtained using quantity as a measure of output; something we will show later on holds in our data too. In other words, the bias involving production function coefficients coming from the correlation between prices and inputs use is not a first-order issue. The key insights about this finding are as follows. In the data firms with higher TFP-Q are characterized by lower marginal costs and charge, as expected, lower prices while selling higher quantities, so using 
more inputs, everything else equal. Furthermore, firms with high demand $\lambda$ are characterized by higher marginal costs and charge, as expected, higher prices while selling higher quantities, so using more inputs, everything else equal. At the same time, the data suggest a trade-off between producing large quantities at low marginal costs and prices (high TFP-Q and low $\lambda$ firms) and producing large quantities at high marginal costs and prices (low TFP-Q and high $\lambda$ firms) which in line with findings in the demand system literature (Ackerberg et al., 2007). Therefore, there is no overall strong correlation between prices and inputs use and so the bias involving production function coefficients, when using revenue as a measure of output, is present but it is such that related TFP-R measures are still informative about the 'true' TFP-R.

FMMM further show that the key disadvantage of not having price and quantity data is the fact that one cannot any more disentangle quantity TFP $a$ from demand $\lambda$ but only retrieve a composite of the two: $\omega_{i t}=a_{i t}+\lambda_{i t}$. However, markups can still be computed from the estimated production function coefficients using (4) while the TFP-R and labour productivity decompositions provided above still hold by replacing the distinct $a$ and $\lambda$ terms with a unique $\omega$ term. For example, considering (9) we have:

$$
T F P_{i t}^{R}=\frac{\omega_{i t}}{\mu_{i t}}+\frac{1-\mu_{i t}}{\mu_{i t}} \bar{q}_{i t}
$$

which provides a formula to retrieve $\omega_{i t}$ from measures of revenue TFP, markups and scale; measures that only require estimates of the production function coefficients. At the same time, for example, (15) becomes:

$$
\Delta L P_{i t}=\Delta\left[\left(\frac{\gamma+1}{\mu_{i t}}-1\right) l_{i t}\right]+\alpha_{M} \Delta\left(\frac{m_{i t}-l_{i t}}{\mu_{i t}}\right)+\alpha_{K} \Delta\left(\frac{k_{i t}-l_{i t}}{\mu_{i t}}\right)+\Delta\left(\frac{\omega_{i t}}{\mu_{i t}}\right) .
$$

FMMM label this restricted version of the model MUOMEGA in reference to the two heterogeneities it allows for, markups (MU) and a composite of TFP-Q and $\lambda$ (OMEGA). FMMM also develop an estimation procedure for the restricted model.

In what follows we consider, in order to provide evidence of the robustness of our results, revenue-based production function estimations for UK service sectors obtained using either the estimation procedure provided in FMMM or the more standard WLD approach.

\subsection{Some additional remarks}

Manufacturing. As far as manufacturing is concerned, we consider as baseline the implementation of the MULAMA model and related decompositions based on the DGKP estimation method applied to the Cobb-Douglas production function (5) on single-product firms. How- 
ever, we also present results based on the FMMM estimation method, also in Cobb-Douglas form, as well as findings obtained from the Translog production function (6) and the sample of multi-product firms for robustness. Our key findings are little affected by whether we use the DGKP or the FMMM estimation procedure, by whether we use a Cobb-Douglas or a Translog production function and whether we use the single-product firms sample or the multi-product firms sample.

As customary in productivity analyses, we correct (in all estimations) for the presence of measurement error in output (quantity and revenue) and/or unanticipated (to the firm) shocks using the methodology described in DGKP and FMMM. We also consider a full battery of 8-digit product dummies, as well as year dummies in our production function estimations. Indeed, quantity in the data is measured in units (kilograms, litres, number of items, etc.) that are specific to each 8-digit product and so quantity TFP $a_{i t}$ can be reasonably compared across firms and time only within an 8-digit product category. For similar reasons, also $\lambda_{i t}$ can be reasonably compared across firms and time only within an 8-digit product category.

In terms of number of production function estimations we are forced, by sample constraints, to run a single estimation across the whole manufacturing firms sample instead of by two-digit industry groupings. As explained more in detail below, we indeed need firms to be in both the Prodcom and ARDx datasets, which are describe below, while also requiring information on one and two period lags for all variables. In this respect, results obtained using the more flexible Translog production function should reassure about the issue of heterogeneity in output elasticities across firms and industries in manufacturing. At the same time, we show later on that patterns of various TFP-R measures, as well as of value added per worker and output per worker, are very similar when comparing our estimation sample to the full set of manufacturing firms available in the ARDx dataset.

Services. As far as service industries are concerned, we consider as baseline the revenue TFP estimations, and related MUOMEGA model decompositions, based on the WLD approach applied to the Cobb-Douglas production function (5). We also present very similar results based on the FMMM estimation method for the MUOMEGA model, also in Cobb-Douglas form.

Again, as customary in productivity analyses, we correct (in all estimations) for the presence of measurement error in revenue and/or unanticipated (to the firm) shocks using the methodology described in DGKP and FMMM. Production function estimation are run separately for each NACE Section (11 in total) and include a full battery of 2-digit industry dummies as well as year dummies. 
Composition effects and weighting. There are reasonable concerns about composition effects as the ARDx firm sample changes over time, and particularly so from 2007-8 when the ONS switched from producing the Annual Respondents Database to the Annual Business Survey. Therefore we present, as baseline, results for what we label the 'within sample' which compares the mean of within-firm changes between $t-1$ and $t$. The within sample is thus comprised of firms present in the data in both $t-1$ and $t$, and if manufacturing firms also producing the same product in both years, and it allows minimising the impact of sample composition effects, including those related to different units of measurement for the products of manufacturing firms. We show below that the within sample accounts for the lion share of overall firm revenue in both $t-1$ and $t$.

Finally, we choose to present our baseline results using revenue weights, given that our research question is more closely aligned to understanding aggregate changes in productivity rather than for the average firm. We also present below robustness results based on employment weights as well as on equal weights, i.e., un-weighted.

Operationally, we calculate an index for each variable of interest after averaging withinfirm changes between $t-1$ and $t$ :

$$
\Delta \bar{y}_{t}=\frac{1}{N_{t}} \sum_{i=1}^{N_{t}}\left(y_{i t}-y_{i t-1}\right) w_{i t}
$$

where $y_{i t}$ is a variable of interest (TFP-Q, TFP-R, $\lambda$, $\mu$, etc.), $\Delta \bar{y}_{t}$ is the weighted average of within firm changes in $y_{i t}, w_{i t}=\frac{1}{2}\left(R_{i t}+R_{i t-1}\right)$ are the weights computed using the average firm revenue between $t-1$ and $t,{ }^{16}$ and $N_{t}$ is the number of firms present in the data in both $t-1$ and $t$. We use this formula to construct the index of changes, setting the base year to 2008 for manufacturing and 2007 for services.

\section{$3 \quad$ Data and Descriptives}

\subsection{Data}

The core data required to estimate firm-level revenue TFP using standard methodologies comprise revenue, employment costs, intermediate inputs and capital stock. For these variables we turn to the Office for National Statistics (ONS) Annual Respondents Database $\mathrm{X}^{17}$ $(A R D x)$. The ARDx is a recently-created dataset for researchers using ONS secure access via

\footnotetext{
${ }^{16}$ In terms of weighting we thus choose a compromise between Laspeyres and Paasche weights. In unreported results we also experimented with Laspeyres and Paasche weights obtaining very similar results.

${ }^{17}$ Office for National Statistics. Virtual Microdata Laboratory, University of the West of England, Bristol (2017)
} 
the Virtual Microdata Library and the Secure Data Service. It combines and standardizes data and variables across the period 1998-2017 from two surveys, the Annual Business Survey (ABS) which has been carried out since 2009, and its predecessor, the Annual Business Inquiry (ABI), which was carried out 1998-2008 and used to create the Annual Respondents Database. These are the largest business surveys in the UK and have been used by many UK productivity researchers including Barnett et al. (2014), Harris and Moffat (2017) and Riley et al. (2013). The ABI and ABS are similar in sampling method, structure and questions, and the ARDx was created to provide researchers with a consistent dataset across time.

The ARDx covers around two-thirds of UK economic activity, comprising most SIC 2007 sections, except parts of sections A (agriculture) and K (finance), and all of $\mathrm{O}$ (public administration and defence), $\mathrm{T}$ (activities of households) and $\mathrm{U}$ (extraterritorial organisations). The sample frame of the ABS is the Inter-Departmental Business Register (IDBR), a register of firms from HM Revenue and Customs data on VAT and PAYE details. The sample is stratified by SIC 2007 activities (at the 4-digit level), employment size and country (England \& Wales, and Scotland). A sample of 62,000 of the $2.1 \mathrm{~m}$ firms on the IDBR is drawn annually. All firms in the largest employment categories in each cell are selected. Firms in each of the cells including smaller businesses are drawn for two consecutive years only, and then not re-selected for at least two years afterwards. For the smallest (0-9) employment category, firms are only selected in a single year, and then not again for at least three years afterwards in respect of the Osmotherly rules to ensure that the compliance burden on firms is proportionate. Because we require lagged values of variables in our estimations, we drop these firms and focus on firms with at least 10 employees.

Estimation of quantity TFP and demand for the manufacturing sector requires data on quantities sold and prices, information that is available in the Products of the European Community (Prodcom) dataset. ${ }^{18}$ Prodcom is a standardized survey of production across the European Union, collected by national statistical agencies using a 3,500 product list in an 8-digit nomenclature established by Eurostat. The first four digits correspond to the Nomenclature Statistique des Activits Economiques dans la Communaut Europenne (NACE) using revision 1.1 up to 2007 and revision 2 from 2008, and the first six digits to the Classification of Products by Activity (CPA) with the last 2 digits adding further detail. It covers SIC 2007 sections B (mining) and C (manufacturing) sectors. We exclude section B to focus on manufacturing. The survey captures at least $90 \%$ of production in all the four digit industries covered by the survey.

Illustrating the advantages of highly disaggregated data, Table 1 shows an extract from the 2009 Prodcom list for the six-digit codes 13.10.61: 'Cotton yarn (other than sewing thread)' and 26.20.16: 'Input or output units, whether or not containing storage units in

\footnotetext{
${ }^{18}$ Office for National Statistics (2018c)
} 
Table 1: Examples of 8 digit PRODCOM products within 6 digit CPA categories

\begin{tabular}{|c|c|}
\hline PRODCOM & Description \\
\hline & COTTON YARN (OTHER THAN SEWING THREAD) \\
\hline 13.10.61.32 & $\begin{array}{l}\text { Yarn of uncombed cotton, not per retail sale, for woven } \\
\text { fabrics (excluding for carpets and floor coverings) }\end{array}$ \\
\hline 13.10.61.33 & $\begin{array}{l}\text { Yarn of uncombed cotton, not per retail sale, for knitted } \\
\text { fabrics and hosiery }\end{array}$ \\
\hline 13.10.61.35 & $\begin{array}{l}\text { Yarn of uncombed cotton, not per retail sale, for other uses } \\
\text { (including carpets and floor coverings) }\end{array}$ \\
\hline 13.10.61.52 & $\begin{array}{l}\text { Yarn of combed cotton, not per retail sale, for woven fabrics } \\
\text { (excluding for carpets and floor coverings) }\end{array}$ \\
\hline 13.10.61.53 & $\begin{array}{l}\text { Yarn of combed cotton, not per retail sale, for knitted fab- } \\
\text { rics and hosiery }\end{array}$ \\
\hline \multirow[t]{2}{*}{ 13.10.61.55 } & $\begin{array}{l}\text { Yarn of combed cotton, not per retail sale, for other uses } \\
\text { (including carpets and floor coverings) }\end{array}$ \\
\hline & $\begin{array}{l}\text { INPUT OR OUTPUT UNITS, WHETHER OR NOT CONTAINING } \\
\text { STORAGE UNITS IN THE SAME HOUSING }\end{array}$ \\
\hline 26.20.16.40 & $\begin{array}{l}\text { Printers, copying machines and facsimile machines, capable } \\
\text { of connecting to an automatic data processing machine or } \\
\text { to a network (excluding printing machinery used for print- } \\
\text { ing by means of plates, cylinders and other components, } \\
\text { and machines performing two or more of the functions of } \\
\text { printing, copying or facsimile transmission) }\end{array}$ \\
\hline 26.20.16.50 & Keyboards \\
\hline 26.20.16.40 & $\begin{array}{l}\text { Other input or output units, whether or not containing stor- } \\
\text { age units in the same housing }\end{array}$ \\
\hline
\end{tabular}

Source: EC RAMON Database (2009 Prodcom List)

the same housing'. The latter example highlights how it can often be necessary to work with 8-digit data rather than the already quite detailed 6-digit level, in order to be confident to compare reasonably similar items. The former example, highlights instead how a 8-digit product breakdown can be very precise in terms of narrowing down products and so working at this level of disaggregation allows us to take into account rich differences in technology, demand and degree of competition across finely defined products.

Around 20,000 firms a year, representing at least $90 \%$ of the value of production in each 4-digit industry, are surveyed to construct the Prodcom dataset using the IDBR as the sample frame. The sample is stratified by employment size and SIC 2007 4-digit industry. There are 3 employment band thresholds above which all firms are surveyed (20, 50 and 100), where the cut-off varies between industries. Below that firms are rotated through the sample.

The quantity and value of sales are recorded for each 8-digit product produced by a firm 
annually. ${ }^{19}$ We measure firm-product-year specific prices as the ratio of the value of sales to the quantity and apply a small trimming on the distribution of prices by 8-digit product to get rid of outliers. Prodcom product codes change occasionally over time and we employ the methodology described in Van Beveren et al. (2012) to obtain a time-consistent product classification. Appendix A provides more details on the product concordance procedure. We also ensure that the units of measure used to record quantities are consistent over time. Metadata provided by the ONS for Prodcom links each product-year with a unit of measure and where these units change over time within a product we define a new product, leaving us a total of 5,028 product-units. Some products are reported within Prodcom without quantity data and we drop these products, leaving 3,239 consistent product-units with non-missing quantity data. Our unit of observation is strictly firm-product-unit-year but for ease of exposition we refer to firm-product-year throughout the analysis.

Both datasets cover Great Britain while data for Northern Ireland are held separately and are excluded from our analysis. Our analysis focuses on the period 2003-2013 in order to both gain insights into the pre- and post-crisis productivity performance and provide evidence comparable to previous studies. We deflate, as standard, both output and inputs values from the ARDx using information provided by the ONS. Appendix A provides more details on the datasets, the construction of capital stocks and the deflators used in the analysis while Table 2 describes the main variables used in our estimations.

\subsection{Descriptives}

We merge the ARDx, capital stock and Prodcom data using a unique identifier for what the ONS refers to as a 'reporting unit'20 and we refer to as a firm, our unit of analysis. ${ }^{21}$

\subsubsection{Manufacturing}

Although the ARDx is a representative sample of private-sector firms and Prodcom is designed to cover $90 \%$ of manufacturing output, there is not perfect overlap between the two datasets, a

\footnotetext{
${ }^{19}$ This introduces a discrepancy with the ARDx. In Prodcom, firms report calendar-year product sales and quantities, while in the ARDx firms can report either calendar year or financial year revenue figures. We deal with this by dropping firms that report values for ARDx sales that are outside a range of $+/-30 \%$ of total Prodcom sales. This also has the effect of removing manufacturing firms with a high proportion of services in revenues.

${ }^{20}$ Large businesses (enterprises to the ONS, and the legal entity of the business) may be split into a number of reporting units, while reporting units can comprise a number of local units which are separated geographically. Data in the ARDx are collected at the reporting unit level

${ }^{21}$ Some authors, e.g. Harris and Moffat (2017), argue that the local unit (plant) is the preferred unit of analysis because provides cleaner estimates of capital stock due to plant entry and exit within a firm, but this requires apportioning firm-level inputs and outputs to plants, while information on production from Prodcom is only available at the firm level.
} 
Table 2: Description of main variables

\begin{tabular}{|c|c|}
\hline Variable & Description \\
\hline Output $£ 000$ s & $\begin{array}{l}\text { Approximate output at basic prices, calculated (following Ayoubkhani } \\
(2014) \text { ) as 'total turnover excluding VAT' less 'goods bought for resale' } \\
\text { plus 'changes in stocks and work-in-progress' less 'changes in stocks of } \\
\text { materials, storage and fuels' plus 'work of a capital nature' less 'total net } \\
\text { taxes' plus 'business rates' plus 'net taxes on production'. }\end{array}$ \\
\hline Intermediates $£ 000$ s & $\begin{array}{l}\text { Approximate intermediate consumption at purchaser's prices, calculated } \\
\text { as 'total purchases of goods and services' less 'value of insurance claims } \\
\text { received' less 'goods and services bought for resale' less 'changes in stocks } \\
\text { of materials, storage and fuels'. }\end{array}$ \\
\hline Value added $£ 000$ s & $\begin{array}{l}\text { Approximate GVA at basic prices, calculated as output less intermedi- } \\
\text { ates. }\end{array}$ \\
\hline Capital stock $£ 000$ s & $\begin{array}{l}\text { Plant and machinery capital stock, see Appendix A for details of calcu- } \\
\text { lation }\end{array}$ \\
\hline Employment & $\begin{array}{l}\text { From Inter-departmental Business Register at time of sample selection, } \\
\text { reported in ARDx }\end{array}$ \\
\hline Wage bill £000s & Total employment costs from ARDx \\
\hline Quantity & $\begin{array}{l}\text { Volume of production sold from Prodcom, measured in product-specific } \\
\text { units }\end{array}$ \\
\hline Sales & Value of production sold from Prodcom \\
\hline
\end{tabular}

problem compounded by the requirements of the DGKP and FMMM estimation procedures. More specifically, to estimate the production function for manufacturing firms while using quantity as a measure of output we require/impose:

- non-missing, positive values for employment, total turnover ex. VAT, purchases of goods and materials, capital stock, total wages and salaries from the ARDx

- the firm is in the Prodcom survey

- that Prodcom records a non-zero value for quantity of this product

- the firm produces only 1 product in any given year

- and that firm revenues reported in Prodcom are within $30 \%$ of the output calculated using ARDx data

These demands sharply reduce the available sample size and in Appendix A we provide more details on the merging process and the various constraints. ${ }^{22}$ We label 'final sample' the combined ARDx and Prodcom sample satisfying all our requirements.

\footnotetext{
${ }^{22}$ In our estimations we also apply some small trimming (top/bottom percentile) of unit prices by product, the capital-to-labour ratio and labour-output ratio by 2-digit industry, and drop firm-year observations where the share of materials in output is less than 0.1 or greater than 0.95 .
} 
Figure 1: Revenue TFP and labour productivity measures by sample, Manufacturing, 20032013

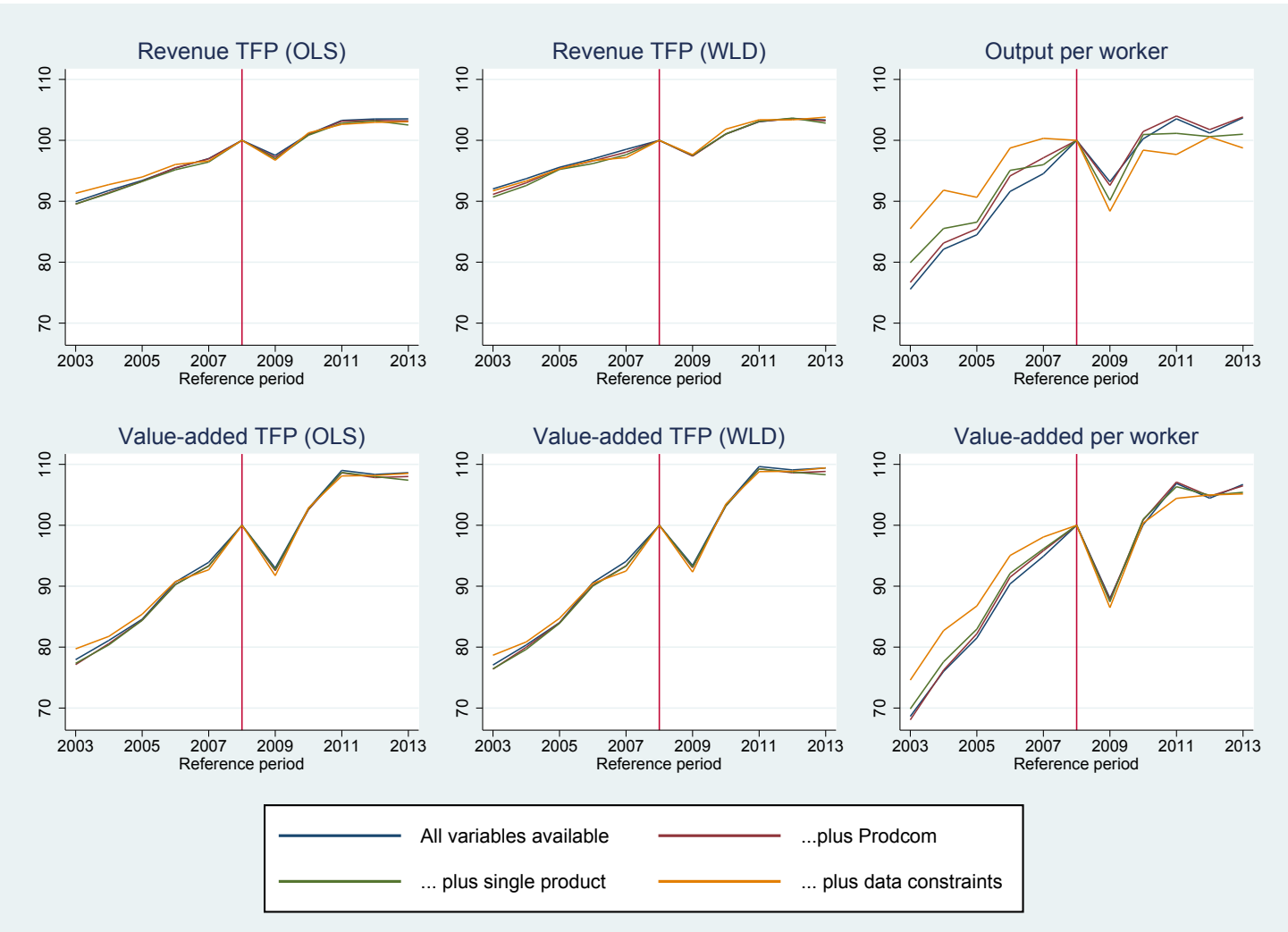

All revenue TFP and labour productivity measures are indexed: 2008=100. 'All variables available' refer to manufacturing firms in the ARDx that have a) at least 10 employees and b) have the following variables available: employment, total turnover ex. VAT, purchases of goods and materials, capital stock, total wages and salaries. '...plus Prodcom' adds the requirement that the firm-year observation is also in the Prodcom dataset. '...plus single product' adds the requirement that at least $90 \%$ of a firm's output at basic prices is accounted for by sales of a single product . '...plus data constraints' adds the requirement that Prodcom measures a non-zero quantity of production, and that firm revenues reported by Prodcom are within $30 \%$ of the output calculated from the ARDx. Revenue TFP estimated using ordinary least squares (OLS) or the Wooldridge procedure (WLD) in revenue and value-added forms.

We do not think of the final sample as being representative of the broader populations of manufacturing firms and/or single-product firms as selection into the estimation sample is unlikely to be random, particularly reflecting industry characteristics (for the availability of physical quantity data in Prodcom) and firm size (for selection separately into the Prodcom and ARDx surveys with differing stratification bands). Rather, we seek to show that time trends in productivity measures within the group of firms for which we are able to estimate the full MULAMA model (final sample) are similar to those in broader samples. Our first step to do this is to estimate standard two-factor (value-added based) and three-factor (revenue-based) production functions, using both the method of ordinary least squares and 
the WLD approach, on the whole sample of manufacturing firms in the ARDx for which revenue productivity can be estimated ('all variables available'). We report production function coefficients in Table B-1 in Appendix B, and use these to calculate mean revenue-based and value-added-based TFP over time for different samples going from the largest ('all variables available') to the final sample we use in our estimations ('...plus data constraints'). We graph the results, along with output per worker and value-added per worker, in Figure 1. All the productivity measures we consider indeed display a very similar behavior across time for the four samples. This builds confidence that the trends in quantity TFP, demand and markups for the wider sample of firms in the ARDx are similar to those we uncover in the final sample.

Table 3: Comparison of the final sample and the within sample: manufacturing firms.

\begin{tabular}{cccc}
\hline Year & $\begin{array}{c}\text { Final sample } \\
\mathrm{N}\end{array}$ & $\begin{array}{c}\text { Within sample } \\
\mathrm{N}\end{array}$ & $\begin{array}{c}\text { Within sample } \\
\text { revenue share }\end{array}$ \\
\hline 2003 & 1,193 & 641 & - \\
2004 & 1,134 & 641 & 0.6838 \\
2005 & 1,274 & 564 & 0.5686 \\
2006 & 1,148 & 617 & 0.6742 \\
2007 & 1,213 & 594 & 0.6556 \\
2008 & 1,048 & 401 & 0.4981 \\
2009 & 1,047 & 443 & 0.6315 \\
2010 & 1,056 & 496 & 0.6991 \\
2011 & 1,014 & 450 & 0.6870 \\
2012 & 1,016 & 478 & 0.6711 \\
2013 & 968 & 477 & 0.7401 \\
\hline
\end{tabular}

The last column reports the share of revenue (combined revenue in $t-1$ and $t$ ) accounted for by firms in the within sample.

One final issue we address is related to the ARDx sampling frame changing over time notably in 2008/9 when SIC 2008 replaced SIC 2004 - leading to concern that comparing firm averages over time, whether weighted on un-weighted, will be biased by changes in the sample composition. Because of this in our results we focus, as already discussed above, on withinfirm changes over time using an unbalanced panel of firms for which we have observations in both year $t$ and year $t-1$ : the within sample.

Table 3 shows the number of observations by year corresponding to the final sample and the within sample for manufacturing along with the share of revenue (combined revenue in $t-1$ and $t$ ) accounted for by firms in the within sample. While within sample observations account for fewer than half the available firm-year observations, they account for roughly two-thirds of full-sample revenues. Summary statistics for key variables and MULAMA model estimates (obtained with the DGKP estimation procedure) referring to both samples are provided in Table 4. 
Table 4: Summary statistics for the final sample and the within sample: manufacturing firms.

\begin{tabular}{lcccc}
\hline & \multicolumn{2}{c}{ Final sample } & \multicolumn{2}{c}{ Within sample } \\
& mean & sd. & mean & sd. \\
\hline log output & 9.351 & 1.438 & 9.815 & 1.352 \\
log wage bill & 7.928 & 1.295 & 8.346 & 1.214 \\
log intermediates & 8.798 & 1.596 & 9.322 & 1.468 \\
log capital stock & 7.605 & 1.772 & 8.160 & 1.622 \\
log price & -2.380 & 3.368 & -2.309 & 3.381 \\
TFP-R (DGKP) & 0.859 & 0.174 & 0.832 & 0.136 \\
TFP-R (OLS) & 1.050 & 0.134 & 1.048 & 0.129 \\
TFP-R (WLD) & 0.722 & 0.131 & 0.697 & 0.106 \\
log value-add/worker & 3.668 & 0.520 & 3.683 & 0.493 \\
log revenue/worker & 4.717 & 0.648 & 4.794 & 0.629 \\
a & 3.238 & 3.377 & 3.141 & 3.387 \\
$\lambda$ & -0.932 & 5.859 & -1.674 & 4.692 \\
$\omega$ & 2.307 & 4.875 & 1.467 & 3.276 \\
$\mu$ & 1.183 & 0.561 & 1.081 & 0.348 \\
scale & 8.492 & 1.463 & 8.983 & 1.353 \\
adjusted a & 3.060 & 3.461 & 3.120 & 3.564 \\
adjusted $\lambda$ & -1.935 & 4.488 & -2.332 & 4.433 \\
adjusted $\omega$ & 1.124 & 2.165 & 0.788 & 2.013 \\
adjusted scale & -0.265 & 2.080 & 0.045 & 1.969 \\
$N$ & 12,111 & & 5,802 & \\
\hline
\end{tabular}

\subsubsection{Services}

For services firms we merge the ARDx and capital stock data, using the unique identifier reporting unit, and impose non-missing, positive values for employment, total turnover ex. VAT, purchases of goods and materials, capital stock and total wages and salaries. This delivers the final sample for services firms. ${ }^{23}$ Again, because of concerns about sampling frame changes, we focus on within-firm changes over time using an unbalanced panel of firms for which we have observations in both year $t$ and year $t-1$ : the within sample for services. We also provide (very similar) results using both un-weighted and weighted results.

Table 5 shows the number of observations by year corresponding to the final sample and the within sample for services along with the share of revenue (combined revenue in $t-1$ and $t$ ) accounted for by firms in the within sample. Again, while within sample observations account for fewer than half the available firm-year observations, they account for more than two-thirds of full-sample revenues. Summary statistics for key variables and MUOMEGA

\footnotetext{
${ }^{23} \mathrm{We}$ also apply, in line with the manufacturing analysis, a small trimming based on the top/bottom percentiles of the capital-to-labour ratio and labour-output ratio by 2-digit industry while dropping firm-year observations where the share of materials in output is less than 0.1 or greater than 0.95 .
} 
Table 5: Comparison of the final sample and the within sample: services firms.

\begin{tabular}{cccc}
\hline Year & $\begin{array}{c}\text { Final sample } \\
\mathrm{N}\end{array}$ & $\begin{array}{c}\text { Within sample } \\
\mathrm{N}\end{array}$ & $\begin{array}{c}\text { Within sample } \\
\text { revenue share }\end{array}$ \\
\hline 2003 & 18,941 & 8,387 & - \\
2004 & 18,063 & 8,387 & 0.71 \\
2005 & 17,174 & 7,813 & 0.73 \\
2006 & 14,024 & 6,438 & 0.73 \\
2007 & 15,206 & 6,266 & 0.70 \\
2008 & 12,945 & 5,674 & 0.68 \\
2009 & 12,795 & 6,493 & 0.80 \\
2010 & 12,086 & 6,079 & 0.82 \\
2011 & 12,829 & 5,966 & 0.83 \\
2012 & 12,983 & 6,404 & 0.82 \\
2013 & 12,802 & 6,626 & 0.82 \\
\hline
\end{tabular}

The last column reports the share of revenue (combined revenue in $t-1$ and $t$ ) accounted for by firms in the within sample.

Table 6: Summary statistics for the final sample and the within sample: services firms.

\begin{tabular}{lcccc}
\hline & \multicolumn{2}{c}{ Final sample } & \multicolumn{2}{c}{ Within sample } \\
& mean & sd. & mean & sd. \\
\hline log ouput & 8.396 & 1.775 & 9.028 & 1.810 \\
log wage bill & 7.432 & 1.743 & 8.072 & 1.776 \\
log intermediates & 7.360 & 1.960 & 8.026 & 1.979 \\
log capital stock & 5.461 & 2.426 & 6.280 & 2.369 \\
TFP-R (OLS) & 1.165 & 0.164 & 1.166 & 0.169 \\
TFP-R (WLD) & 0.629 & 0.588 & 0.597 & 0.633 \\
$\mu$ & 1.720 & 0.878 & 1.631 & 0.748 \\
$\omega$ & 6.361 & 7.158 & 6.014 & 6.591 \\
scale & 7.767 & 2.017 & 8.431 & 2.063 \\
adjusted $\omega$ & 2.737 & 2.420 & 2.766 & 2.508 \\
adjusted scale & -2.108 & 2.417 & -2.168 & 2.508 \\
$N$ & 159,848 & & 74,533 & \\
\hline
\end{tabular}

model estimates (obtained with the WLD estimation procedure) referring to both samples are provided in Table 6 . 


\section{Estimates and insights}

\subsection{Manufacturing}

Estimates of the Cobb-Douglas production function coefficients for manufacturing firms belonging to the final sample using the DGKP procedure are shown in Table 7 while descriptive statistics on the various MULAMA model components are displayed in Table 4 in Section 3. The coefficients are in line with those reported in DGKP for India, FMMM for Belgium and Jacob and Mion (2020) for France using quantity as a measure of output and follow the expected pattern; materials coefficient larger than that of labour, which is larger than that of capital and evidence of roughly constant returns to scale. The coefficients - representing estimates of quantity elasticities rather than revenue elasticities - are reasonably close to those obtained in the revenue production function estimations reported in Table B-1 in Appendix $\mathrm{B}$, particularly the WLD method.

Table 7: Manufacturing. Production function coefficients from the DGKP estimation procedure using quantity as a measure of output

\begin{tabular}{lc}
\hline & $\log$ quantity \\
\hline log wage bill & 0.342 \\
& $(0.015)^{* * *}$ \\
log intermediates & 0.636 \\
& $(0.036)^{* * *}$ \\
log capital stock & 0.025 \\
& $(0.012)^{* *}$ \\
Obs & 3,002 \\
\hline
\end{tabular}

Cobb-Douglas production function coefficients estimated using the DGKP method on the final sample of manufacturing firms. The regression includes 8-digit product dummies and year dummies. The number of observations refers to firms with at least 2-period lags for all variables required in the estimation procedure. See FMMM for more details. Robust standard errors clustered by firm. ${ }^{*} p<0.1{ }^{* *} p<0.05 ;{ }^{* * *} p<0.01$.

Production function estimation allows us to calculate quantity TFP $a_{i t}$ along with markups $\mu_{i t}$ and demand $\lambda_{i t}$, as well as revenue total factor productivity $T F P_{i t}^{R}$, from the corresponding equations in Section 2. With reference to revenue TFP, and in line with evidence provided in FMMM discussed above, Table 8 shows that this measure - TFP-R (DGKP) - is reasonably well correlated with alternative measures of revenue productivity. More specifically, the correlation is stronger the more sophisticated the alternative measure: low with output per worker, then increasing through value-added per worker, OLS revenue TFP and most strongly 
with WLD revenue TFP. In a similar spirit we show, building on the linear revenue TFP decomposition provided by (10), that markup-adjusted TFP-Q $\tilde{a}_{i t}$, markup-adjusted demand $\tilde{\lambda}_{i t}$ and markup-adjusted scale $\tilde{\bar{q}}_{i t}$ explain a large share of the variation in OLS and WLD revenue TFP in both levels and changes. This is reported in Table 9 along with coefficients (equal to one) and $\mathrm{R}^{2}$ (equal to one) related to the DGKP revenue TFP. Coefficients for OLS and WLD revenue TFP indicate that an increase in markup-adjusted TFP-Q and/or demand and/or scale are associated to an increase in firm revenue TFP. As discussed above, the evidence provided in Tables 8 and 9 suggests that the bias involving production function coefficients in revenue TFP estimations coming from the correlation between prices and inputs use is not a first-order issue. In this respect, the real advantage of having price and quantity data is the capacity to disentangle quantity TFP from demand.

Table 8: Pairwise correlation coefficients between revenue productivity measures.

\begin{tabular}{lccccc}
\hline & $\begin{array}{c}\text { TFP-R } \\
\text { (OLS) }\end{array}$ & $\begin{array}{c}\text { TFP-R } \\
\text { (WLD) }\end{array}$ & $\begin{array}{c}\text { TFP-R } \\
\text { (DGKP) }\end{array}$ & $\begin{array}{c}\text { log value-add } \\
\text { per worker }\end{array}$ & $\begin{array}{c}\text { log revenue } \\
\text { per worker }\end{array}$ \\
\hline TFP-R (OLS) & 1 & & & & \\
TFP-R (WLD) & 0.791 & 1 & & & \\
TFP-R (DGKP) & 0.638 & 0.783 & 1 & & 1 \\
log value-add per worker & 0.425 & 0.262 & 0.506 & 1 & \\
log revenue per worker & 0.542 & 0.0468 & 0.167 & 0.724 & \\
\hline Obs & 12,111 & & & \\
\hline
\end{tabular}

Correlations are across observations in the final sample for manufacturing firms.

In order to provide useful insights for our analysis, while confirming previous findings in FMMM and Jacob and Mion (2020), Table 10 reports results of some simple regressions looking at the relationship of prices and markups with the underlying driving variables of the MULAMA model; namely quantity TFP, demand and the capital stock. ${ }^{24}$ More specifically, we regress $\log$ price $p_{i t}$ and $\log$ markup $\log \left(\mu_{i t}\right)$ on quantity TFP $a_{i t}$, demand $\lambda_{i t}$ and $\log$ capital stock $k_{i t}$. We estimate those regressions both in levels and in first-differences (finding very similar coefficients), and include a full set of year dummies and 8-digit product dummies while clustering standard errors at the firm-level.

Estimations referring to log prices (log markups) in columns 1 and 2 (3 and 4) of Table 10 indicate, in line with expectations and previous results in FMMM and Jacob and Mion (2020), that more productive firms and/or an increase in productivity for a firm (higher $a_{i t}$ ) are associated to both lower prices and higher markups, i.e., an incomplete pass-through. At the same time firms facing a stronger demand and/or an increase in demand for a firm (higher

\footnotetext{
${ }^{24}$ In the MULAMA model the capital stock is predetermined for the firm in $t$ and so, along with quantity TFP and demand, determines inputs choices and pricing.
} 
Table 9: Regressions of TFP-R measures on $\tilde{a}, \tilde{\lambda}$ and $\tilde{\bar{q}}$

\begin{tabular}{lcccccc}
\hline & OLS & $\begin{array}{c}\text { Levels } \\
\text { WLD }\end{array}$ & $\begin{array}{c}\text { DGKP } \\
(1)\end{array}$ & $\begin{array}{c}\text { OLS } \\
(4)\end{array}$ & $\begin{array}{c}\text { Changes } \\
\text { WLD }\end{array}$ & $\begin{array}{c}\text { DGKP } \\
(5)\end{array}$ \\
& $(1)$ & $(2)$ & $(3)$ & $0)$ \\
\hline adjusted $a$ & 0.713 & 0.698 & 1.000 & 0.699 & 0.660 & 1.000 \\
& $(0.013)^{* * *}$ & $(0.013)^{* * *}$ & $(0.000)^{* * *}$ & $(0.018)^{* * *}$ & $(0.019)^{* * *}$ & $(0.000)^{* * *}$ \\
adjusted $\lambda$ & 0.710 & 0.696 & 1.000 & 0.697 & 0.659 & 1.000 \\
& $(0.013)^{* * *}$ & $(0.013)^{* * *}$ & $(0.000)^{* * *}$ & $(0.017)^{* * *}$ & $(0.018)^{* * *}$ & $(0.000)^{* * *}$ \\
adjusted scale & 0.744 & 0.698 & 1.000 & 0.732 & 0.667 & 1.000 \\
& $(0.013)^{* * *}$ & $(0.014)^{* * *}$ & $(0.000)^{* * *}$ & $(0.018)^{* * *}$ & $(0.019)^{* * *}$ & $(0.000)^{* * *}$ \\
$R^{2}$ & 0.88 & 0.86 & 1.00 & 0.79 & 0.80 & 1.00 \\
$N$ & 12,111 & 12,111 & 12,111 & 5,161 & 5,161 & 5,161 \\
\hline
\end{tabular}

Regressions in columns 1 to 3 use the manufacturing firms final sample and the levels of all variables, while columns 4 to 6 use the manufacturing firms within sample and firm-level changes between $t-1$ and $t$. All regressions include a set of year dummies and 8-digit product dummies. Robust standard errors clustered by firm. ${ }^{*} p<0.1 ;{ }^{* *} p<0.05 ;{ }^{* * *} p<0.01$.

$\left.\lambda_{i t}\right)$ are associated to both higher prices and higher markups, so confirming the relevance of $\lambda_{i t}$ as a measure of firm-specific demand. Finally, larger firms and/or an increase in size for a firm (higher $k_{i t}$ ) is associated to both lower prices and lower markups, which is in line with the elasticity of demand decreasing along the demand curve.

Table 10: Regressions of log prices and log markups on $a, \lambda$ and $\log$ capital

\begin{tabular}{lcccc}
\hline & \multicolumn{2}{c}{ log price } & \multicolumn{2}{c}{ log markup } \\
& $\begin{array}{c}\text { Levels } \\
(1)\end{array}$ & $\begin{array}{c}\text { Changes } \\
\text { Levels }\end{array}$ & $\begin{array}{c}\text { Changes } \\
(3)\end{array}$ & $(4)$ \\
\hline a & -0.968 & -0.944 & 0.118 & 0.109 \\
& $(0.001)^{* * *}$ & $(0.005)^{* * *}$ & $(0.002)^{* * *}$ & $(0.003)^{* * *}$ \\
$\lambda$ & 0.026 & 0.027 & 0.115 & 0.107 \\
& $(0.000)^{* * *}$ & $(0.001)^{* * *}$ & $(0.001)^{* * *}$ & $(0.001)^{* * *}$ \\
log capital & -0.010 & -0.013 & -0.013 & -0.005 \\
& $(0.001)^{* * *}$ & $(0.006)^{* *}$ & $(0.001)^{* * *}$ & $(0.002)^{* *}$ \\
$R^{2}$ & 1.00 & 0.96 & 0.98 & 0.98 \\
$N$ & 12,111 & 5,161 & 12,111 & 5,161 \\
\hline
\end{tabular}

Regressions in columns 1 and 3 use the manufacturing firms final sample and the levels of all variables, while columns 2 and 4 use the manufacturing firms within sample and firm-level changes between $t-1$ and $t$. All regressions include a set of year dummies and 8-digit product dummies. Robust standard errors clustered by firm. ${ }^{*} p<0.1 ;{ }^{* *} p<0.05 ;{ }^{* * *} p<0.01$. 


\subsection{Services}

We estimate revenue-based production functions using the WLD approach by SIC section and use the estimated coefficients to measure revenue TFP - TFP-R (WLD) - and further employ the corresponding equations of the MUOMEGA model from Section 2 to quantify markups, the composite of quantity TFP and demand $(\omega)$, and production scale.

Table 11: Service industries: Production function coefficients from the WLD estimation procedure using revenue as a measure of output.

\begin{tabular}{lccccc}
\hline SIC Section & log wage bill & log intermediates & log capital & Ret. to scale & $\mathrm{N}$ \\
\hline $\mathrm{F}$ & 0.329 & 0.862 & -0.013 & 1.178 & 16,340 \\
$\mathrm{G}$ & $(0.019)^{* * *}$ & $(0.138)^{* * *}$ & $(0.017)$ & & \\
$\mathrm{H}$ & 0.499 & 0.485 & 0.025 & 1.009 & 50,758 \\
$\mathrm{H}$ & $(0.006)^{* * *}$ & $(0.016)^{* * *}$ & $(0.008)^{* * *}$ & & \\
$\mathrm{I}$ & 0.369 & 0.748 & 0.028 & 1.145 & 10,089 \\
& $(0.011)^{* * *}$ & $(0.077)^{* * *}$ & $(0.016)^{*}$ & & \\
$\mathrm{~J}$ & 0.529 & 0.503 & 0.037 & 1.069 & 11,948 \\
& $(0.019)^{* * *}$ & $(0.054)^{* * *}$ & $(0.012)^{* * *}$ & & \\
$\mathrm{~L}$ & 0.463 & 0.596 & 0.033 & 1.093 & 9,043 \\
& $(0.013)^{* * *}$ & $(0.048)^{* * *}$ & $(0.020)^{*}$ & & \\
$\mathrm{M}$ & 0.430 & 0.533 & 0.032 & 0.995 & 4,064 \\
& $(0.012)^{* * *}$ & $(0.045)^{* * *}$ & $(0.010)^{* * *}$ & & \\
$N$ & 0.506 & 0.546 & 0.015 & 1.068 & 18,336 \\
& $(0.015)^{* * *}$ & $(0.057)^{* * *}$ & $(0.012)$ & & \\
$\mathrm{P}$ & 0.474 & 0.553 & 0.002 & 1.029 & 13,169 \\
& $(0.011)^{* * *}$ & $(0.085)^{* * *}$ & $(0.015)$ & & \\
$\mathrm{Q}$ & 0.387 & 0.508 & 0.006 & 0.901 & 7,326 \\
$\mathrm{RSTU}$ & $(0.030)^{* * *}$ & $(0.060)^{* * *}$ & $(0.018)$ & & \\
& 0.690 & 0.292 & 0.046 & 1.028 & 8,539 \\
& $(0.009)^{* * *}$ & $(0.024)^{* * *}$ & $(0.010)^{* * *}$ & & \\
& 0.369 & 0.660 & -0.001 & 1.028 & 10,236 \\
& $(0.016)^{* * *}$ & $(0.055)^{* * *}$ & $(0.018)$ & & \\
\hline
\end{tabular}

Estimations of Cobb-Douglas revenue production functions by SIC 2007 sector using the WLD method applied to the final sample of services firms. Regressions include 2-digit industry and year dummies. The number of observations refers to firms with at least 2-period lags for all variables required in the estimation procedure. See FMMM for more details. Robust standard errors clustered by firm. ${ }^{*} p<0.1{ }^{* *} p<0.05 ;{ }^{* * *} p<0.01$.

Production function estimates are reported in Table 11 while descriptive statistics on the various MUOMEGA model components are displayed in Table 6 in Section 3. Coefficients are, as expected, on average higher for the labour input in services as compared to manufacturing (a weighted average of 0.446 in services compared to the 0.342 for manufacturing). The labour input coefficients is particularly high in sections one might expect, for instance, 'Q: Human health and social work', and to a lesser extent in 'I: Accommodation and food service', and low in 'F: Construction' and 'H: Transport and storage'. The opposite is true for the intermediates coefficient (a weighted average of 0.603 in services compared to 0.636 in manufacturing). Sections like construction and transport are both at or above 0.8 but most others are well 
below 0.6. Capital stock coefficients are small, as typically found in 3-factors production function estimations, and somewhat noisy, which is likely related to the well-known issue of measurement error particularly plaguing the capital stock (Griliches and Mairesse, 1995). Finally, there is evidence of roughly constant or slightly increasing returns to scale.

\section{Results}

\subsection{Manufacturing}

We next turn to our main results and start by focusing two features that our quantity and price data allow to analyze for manufacturing firms. For manufacturing, we find more relevant to use the year 2008 to define the pre- and post-crisis periods.

The first feature is about prices, and in particular about the difference between actual price changes and price index changes and how this impacts the measurement of productivity. Producer price indices, and in particular the output price index we have used to deflate sales in our data, should measure average changes in prices for the same product over time. Actual price changes, that are typically not observable to researchers but are observable in our data, instead reflect any changes in prices operated by an individual firm and so include, for example, quality improvements to products or changes to the specification of a product. The procedure followed by statistical offices to translate actual price changes into average price changes for the same product, and so deliver official prices indices, is complex and beyond the scope of this paper. ${ }^{25}$ However, all we want to highlight here is that actual price changes and price index changes are two different things and, in principle, the difference between the former and the latter, that we label 'real prices changes', should essentially reflect product quality improvements. At the same time, real prices changes are actually included in standard micro and macro productivity analyses because nominal values are deflated using prices indices and so what is left does contain real prices changes. This is the reason why we label as revenue TFP those productivity measures obtained deflating nominal values with a price index. By contrast, quantity TFP levels and changes are in our framework derived from actual quantity data expressed in physical units that are specific to each product (number of items, kilograms, liters, etc.) and, by construction, the revenue TFP of a firm is the sum of the quantity TFP and the log real price.

Table 12, and the companion Figure B-1 in Appendix B, provide information on changes in actual prices, the official price index and real prices for the manufacturing firm within sample. More specifically, we start from the firm-product-specific actual prices changes, and the industry/product-specific output price index changes, between $t-1$ to $t$ and aggregate

\footnotetext{
${ }^{25}$ See, for example, Office for National Statistics (2014).
} 
both changes across firms using revenue weights. At the same time, we also construct real price changes starting from the differences between actual prices changes and output price index changes and aggregating them up using again revenue weights. Table 12 indicates that, on average, the official price index rose by $2.8 \%$ per year for manufacturing products over the period 2003-2008 and by 2.3\% per year over the period 2008-2013. Meanwhile, actual prices increased more than the official price index and particularly so in the post-2008 period. Indeed, real price changes averaged $0.7 \%$ per year over 2003-2008 and a considerably higher $1.5 \%$ per year over 2008-2013. Therefore, irrespective of whether real price changes only reflect product quality improvements or also other elements, and in this respect the $2.2 \%$ real prices drop in 2008 does suggest that real prices measure more than just quality improvements, these changes actually helped mitigate the measured productivity slowdown. Indeed, everything else equal, revenue TFP growth over 2008-2013 would have been 0.8=1.5-0.7 per cent lower had real prices increased at the same rate as in the period 2003-2008. Tables B-2 and B-3 in Appendix B further show that this result is robust to considering simple un-weighted changes as well as to using the multi-products firms sample.

Table 12: Real, actual and official price index changes

\begin{tabular}{lcccc}
\hline & $\begin{array}{c}\Delta \text { real } \\
\text { prices }\end{array}$ & $\begin{array}{c}\Delta \text { actual } \\
\text { prices }\end{array}$ & $\begin{array}{c}\Delta \text { official } \\
\text { price index }\end{array}$ & Obs \\
\hline 2004 & 0.014 & 0.022 & 0.008 & 641 \\
2005 & 0.010 & 0.026 & 0.015 & 564 \\
2006 & 0.010 & 0.034 & 0.024 & 617 \\
2007 & 0.018 & 0.044 & 0.027 & 594 \\
2008 & -0.022 & 0.046 & 0.068 & 401 \\
2009 & 0.042 & 0.069 & 0.028 & 443 \\
2010 & 0.017 & 0.036 & 0.019 & 496 \\
2011 & 0.001 & 0.041 & 0.040 & 450 \\
2012 & -0.001 & 0.011 & 0.011 & 478 \\
2013 & 0.016 & 0.031 & 0.016 & 477 \\
\hline & & & & \\
$2003-2008$ & 0.007 & 0.034 & 0.028 & 2,817 \\
$2008-2013$ & 0.015 & 0.037 & 0.023 & 2,344 \\
\hline
\end{tabular}

The Table shows mean revenue-weighted changes from $t-1$ to $t$, for the manufacturing firms within sample, of real and actual prices as well as of the official price index. The final two rows show the mean of changes over the two periods using all the annual observations.

The second feature we want to highlight here is that, the availability of both price and quantity data, allows us to measure demand and in particular demand changes over time. The demand measures $\tilde{\lambda}_{i t}$ and $\lambda_{i t}$ obtained from the MULAMA model, that we use below 
to analyze the evolution of demand over the time frame 2003-2013, are quite general in that they allow for Variable Elasticity of Substitution (VES) preferences and for markups to be different both across firms and across time. In terms of findings, both of our demand measures $\tilde{\lambda}_{i t}$ and $\lambda_{i t}$ indicate a significant slowdown of demand post-2008. In this respect, Figure 2 provides complementary evidence of such a slowdown building on a more restrictive, albeit more widely used, framework to measure demand and demand changes over time. More specifically, building on CES preferences and monopolistic competition, and so constant markups across firms and time, we computed, for a given value of the elasticity of substitution $\sigma$, a firm-product-time-specific demand measure $d_{i t}^{C E S}$ matching actual (log) quantity and (log) real price data: $q_{i t}=d_{i t}^{C E S}-\sigma p_{i t} \cdot{ }^{26}$ We then computed within-firm (and product) time changes in $d_{i t}^{C E S}$ and aggregate them up using revenue weights to construct a demand measure index based on the year $2008(2008=100)$. Figure 2 also provides, for each panel, two regression lines obtained by fitting index yearly changes between 2003 and 2008 (left regression line) and changes between 2009 and 2013 (right regression line). Figure 2 shows two CES demand indices, one constructed using $\sigma=5$ (left panel) and one constructed using $\sigma=10$ (right panel), ${ }^{27}$ both pointing towards a significant slowdown of demand particularly from 2011 onwards. Figures B-2 and B-3 in Appendix B further show that this result is robust to considering simple un-weighted changes as well as to using the multi-products firms sample. Regarding the nature of the slowdown of demand, that we systematically find in our analyses, our results are consistent with several sources including uncertainty and the related postponement of purchases, the well-documented fall in the UK labour share of GDP and its consequences for consumption and savings, as well as the spending cuts operated by the UK government.

We now move to the results obtained from the MULAMA model and report in Table 13 mean revenue-weighted changes from $t-1$ to $t$, referring to the manufacturing firms within sample, in DGKP revenue TFP and its components building on the non-linear decomposition of equation (9). We also report (column 1) mean revenue-weighted changes in WLD revenue TFP as well as the mean revenue-weighted changes in real prices (column 4). First, we see a similar trend for the DGKP revenue TFP, reported in column 2, to that illustrated across larger samples in Figure 1. The DGKP measure rises at a rate of 1.6 percentage points a year from 2003 to 2008, then falls by 2.2 points in 2008/9, averaging across the 2008 to 2013 post-crisis period at a rate of $0.6 \mathrm{pp}$ per year, and leaving it 5 points below the pre-crisis trend by 2013. The WLD measure displays a similar pattern: growth of 1.5pp a year through 2008, a drop of 2.3pp in 2008/9 and growing over the 2008 to 2013 post-crisis period at a rate of 0.8

\footnotetext{
${ }^{26}$ This measure of demand $d_{i t}^{C E S}=q_{i t}+\sigma p_{i t}$ is, for example, used by Khandelwal et al. (2013) and Stiebale and Vencappa (2018).

${ }^{27} \mathrm{~A}$ value of $\sigma$ between 5 and 10 is what the literature would typically suggest (Anderson and Van Wincoop, 2004).
} 
Figure 2: Manufacturing. CES demand measure for different values of $\sigma$

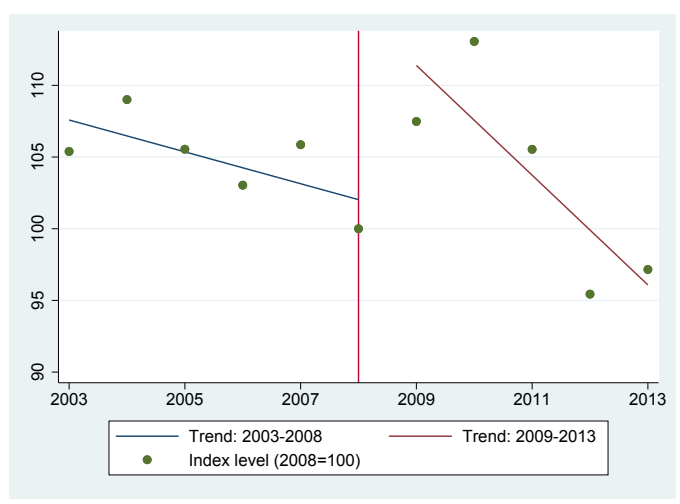

(a) CES demand measure $\sigma=5$

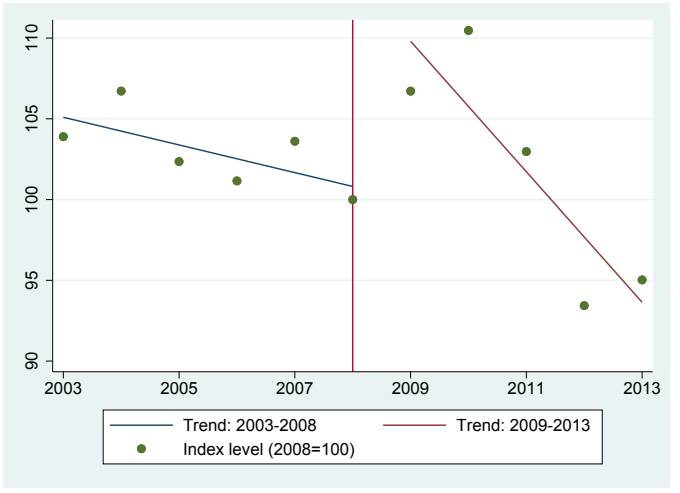

(b) CES demand measure $\sigma=10$

Indices of changes in CES demand measures $(2008=100)$. Indices are computed for the manufacturing firms within sample using revenue-weighted changes from $t-1$ to $t$ and two alternative values for the elasticity of substitution: $\sigma=5$ and $\sigma=10$.

points per year. These results are in line with the evidence that UK's manufacturing dismal post-crisis productivity performance contains a strong productivity, and in particular revenue TFP, component. However, this paper's contribution is to disentangle the underlying causes of this revenue TFP drop and in particular assess whether and how changes in quantity TFP, demand and markups have generated the fall.

In this respect, columns 3 and 4 of Table 13 provide evidence that quantity TFP $a$ actually slowed more than revenue TFP in the post-crisis period. The average pre-crisis TFP-Q growth rate of $0.9 \%$ turned into a $-0.9 \%$ growth rate post-crisis leading to a whopping 9 points gap with respect to the pre-crisis trend by 2013. At the same time, and as already discussed above, real prices increased substantially more post-2008 switching from a $0.7 \%$ growth rate pre-crisis to a $1.5 \%$ growth rate post-crisis. Revenue TFP changes (column 2), are the sum of quantity TFP changes (column 3) and real price changes (column 4), and so the stronger real prices increase post-2008 helped to contain the fall in revenue TFP to a 5 points gap with respect to the pre-crisis trend.

Without information on demand and markups, one would be left wondering what caused the increase in real prices and how quantity TFP and real price changes translate into firms' profit margins and scale of operations. In this respect, column 5 indicates that demand (as measured by changes in $\lambda$ ) also plunged in 2008-9 and overall slowed down with respect to the pre-crisis growth trend. Therefore, the increasing real prices post-2008 are likely related to firms passing to consumers the increasing production costs driven by the declining quantity TFP. Though, the pass-through is incomplete as shown by both the difference between the TFP-Q drop and the real prices increase with respect to the trend (1.8\% drop in TFP-Q and 
$0.8 \%$ increase in real prices) and by the decline in markups in column 7 . Indeed, markups sharply declined in 2008-9 and slowed down their growth ever since. One important element to stress at this point is that the decline in demand, as measured by $\lambda$, is on top of the negative effect on sales produced by increasing real prices post-2008. Indeed, changes in $\lambda$ measure changes in demand for the same price (and markup), i.e., changes in the underlying demand curve.

Therefore the depth of the crisis, and in particular its overall impact on sales, production and inputs use, has been particularly severe due to both a supply (TFP-Q a) and a demand $(\lambda)$ downturn. This is, for example, reflected in the use of inputs by firms in column 8 (scale). More specifically, the growth rate of the average inputs bundle turned from a $1.6 \%$ pre-crisis growth rate to a $0.7 \%$ post-crisis growth rate, leading to a $4.5 \%$ negative gap with respect to the pre-crisis trend. This is reflected also in the combined TFP-Q and demand MULAMA component $\omega=a+\lambda$ (column 6) summarizing the negative supply and demand shocks. In terms of broader implications, the fact that in 2013 scale was up by $3.1 \%$ and quantity TFP was down by $4.4 \%$ with respect to their 2008 levels implies, given that (log) quantity is equal to TFP-Q plus scale at the firm-level as well as in our aggregation, that quantities sold in 2013 were still $1.3 \%$ below their levels back in 2008 .

Table 13: Manufacturing. Changes of revenue TFP and its components over the period 2003-2013.

\begin{tabular}{lc|ccc|ccccc}
\hline & $\begin{array}{c}\Delta \text { TFP-R } \\
(\text { WLD })\end{array}$ & $\begin{array}{c}\Delta \text { TFP-R } \\
\text { (DGKP) }\end{array}$ & $\Delta a$ & $\Delta p$ & $\Delta \lambda$ & $\Delta \omega$ & $\Delta \mu$ & $\Delta$ scale & Obs \\
& 0.007 & 0.021 & 0.008 & 0.013 & 0.232 & 0.240 & 0.020 & 0.040 & 641 \\
2004 & 0.011 & -0.004 & -0.014 & 0.010 & 0.029 & 0.014 & 0.002 & 0.021 & 564 \\
2005 & 0.020 & 0.016 & 0.006 & 0.010 & 0.094 & 0.100 & 0.007 & 0.021 & 617 \\
2006 & 0.012 & 0.020 & 0.003 & 0.017 & 0.087 & 0.090 & 0.006 & 0.029 & 594 \\
2007 & 0.028 & 0.022 & 0.044 & -0.022 & 0.280 & 0.324 & 0.028 & -0.037 & 401 \\
2008 & -0.023 & -0.022 & -0.064 & 0.042 & -0.221 & -0.284 & -0.023 & -0.071 & 443 \\
2009 & 0.033 & 0.028 & 0.012 & 0.016 & -0.009 & 0.003 & -0.000 & 0.042 & 496 \\
2010 & 0.026 & 0.024 & 0.023 & 0.001 & 0.305 & 0.328 & 0.027 & 0.019 & 450 \\
2011 & -0.008 & -0.015 & -0.014 & -0.001 & -0.043 & -0.057 & -0.003 & 0.017 & 478 \\
2012 & 0.011 & 0.015 & -0.001 & 0.016 & 0.187 & 0.186 & 0.015 & 0.024 & 477 \\
2013 & 0.015 & 0.016 & 0.009 & 0.007 & 0.143 & 0.152 & 0.013 & 0.016 & 2,817 \\
$2003-2008$ & 0.008 & 0.006 & -0.009 & 0.015 & 0.045 & 0.036 & 0.003 & 0.007 & 2,344 \\
$2008-2013$ & 0.034 \\
\hline
\end{tabular}

The Table shows mean revenue-weighted changes from $t-1$ to $t$, for the manufacturing firms within sample, of WLD and DGKP revenue TFP, of real prices $p$ as well as of the various components of the revenue TFP non-linear decomposition following from equation (9) applied to the DGKP revenue TFP. The final two rows show the mean of changes over the two periods using all the annual observations shown above. 
Figure 3: Manufacturing. Evolution of revenue TFP and its components over the period 2003-2013.

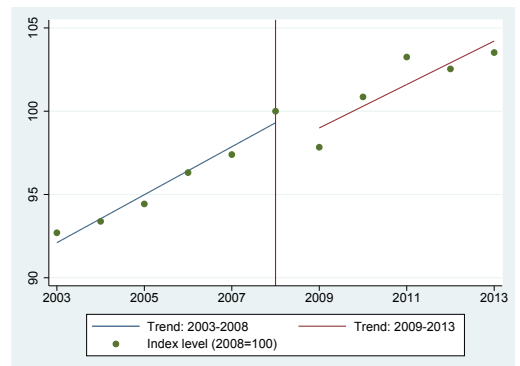

(a) WLD rev TFP

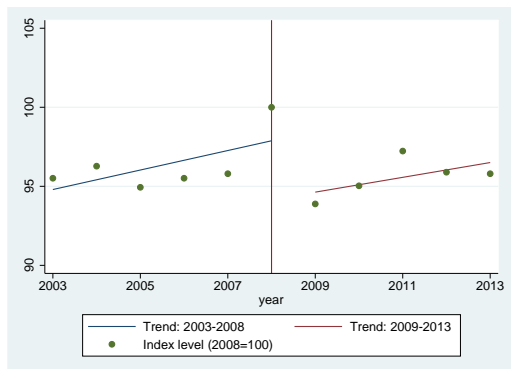

(c) TFPQ a

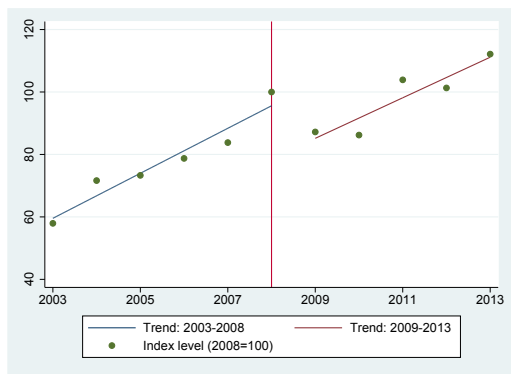

(e) Demand $\lambda$

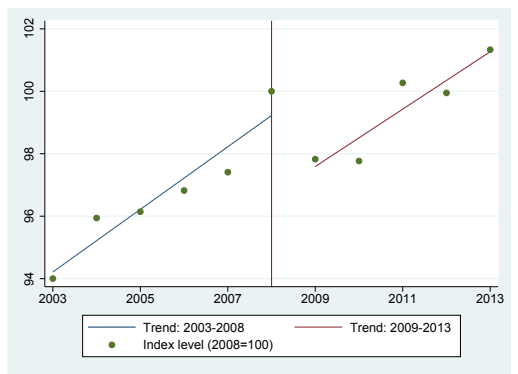

(g) Markups $\mu$

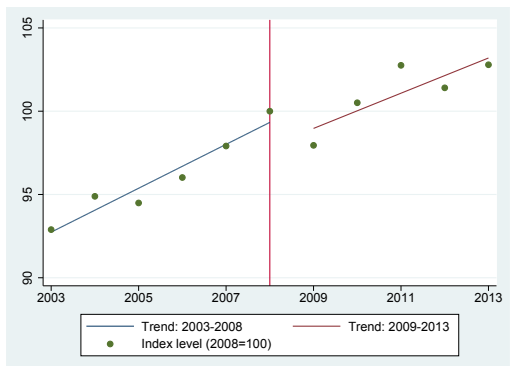

(b) DGKP rev TFP

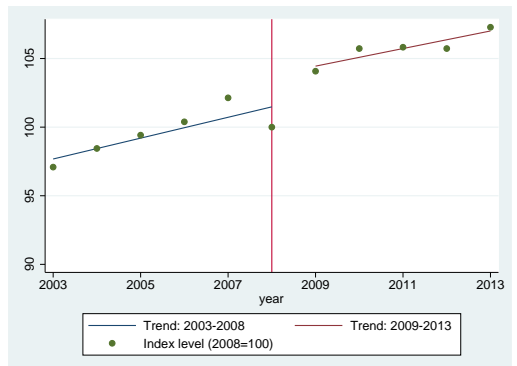

(d) Real price $p$

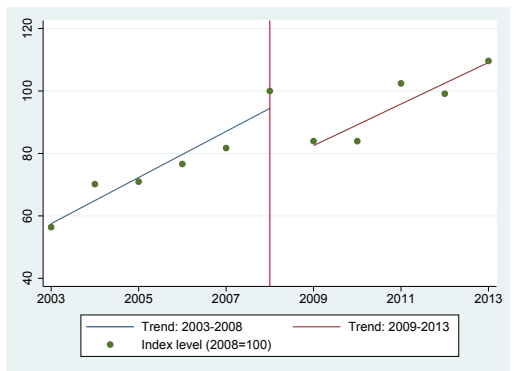

(f) Composite $\omega$

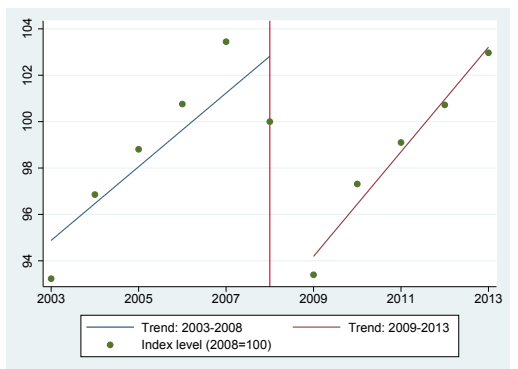

(h) Production scale

Indices $(2008=100)$ calculated using revenue-weighted changes between $t-1$ and $t$ for the within sample of manufacturing firms. Panels (a) and (b) refer to revenue TFP computed using the WLD method and DGKP method, respectively. Panels (c)-(h) show real prices and components of the DGKP revenue TFP following from equation (9). 
Figure 3 presents the results graphically. We construct an index for each variable, setting 2008 as the reference year with a value of 100 so that the graph shows the percentage deviation in the index. Figure 3 also provides two regression lines obtained by fitting index yearly changes between 2003 and 2008 (left regression line) and changes between 2009 and 2013 (right regression line). Panels (a) and (b) show quite neatly the break in WLD and DGKP revenue productivity growth before and after 2008 while panels (c) and (d) highlight the more severe downturn in quantity TFP and the mitigating effect of real prices. At the same time, panels (e) and (f) show the downturn in demand and the overall combined change in the pattern of $\omega$. Furthermore, panels (f) and (g) display the post-2008 decline in the evolution of markups and production scale. Finally, Table B-4 in Appendix B shows formal Chow test results regarding the presence of a structural break for some key variables. As can be appreciated from Table B-4, there is indeed strong support for the presence of a structural break in 2008.

A common approach in the literature on the UK productivity puzzle is to decompose the shortfall in labour productivity into contributions of changes in factor inputs and TFP or, to be more precise, factor inputs and revenue TFP as highlighted by equation (13) in Section 2. Growth accounting exercises using sectoral national accounts data find that the labour productivity puzzle turns out to be a revenue TFP puzzle (Goodridge et al., 2013). That is, after accounting for changes to capital and labour inputs, the bulk of the 'lost' growth over 2008-2013 was due to a slower rate of revenue TFP growth. More similar to our paper, is a bottom-up econometric approach that estimates revenue-based production functions to obtain inputs parameters and firm-level TFP in Harris and Moffat (2017). ${ }^{28}$ Harris and Moffat (2017) find that while in services the decline in labour productivity growth is mostly the result of a decline in revenue TFP growth, in manufacturing there is no revenue TFP puzzle: weighted plant-level revenue TFP barely changed or grew in the 2008-12 period. Instead, a measured 19\% decline over 2007-12 in labour productivity is entirely due to changes in the intensity of inputs and in particular the log intermediates per labour ratio $\Delta\left(m_{i t}-l_{i t}\right)$ in (13).

Table 14 shows this standard labour productivity decomposition over the period 20032013 for our revenue-weighted manufacturing firms within sample. ${ }^{29}$ Results indicate that manufacturing labour productivity growth in the period 2003-2008 was around 2.7pp a year

\footnotetext{
${ }^{28}$ It builds on previous work that estimates plant-level TFP (Harris and Drinkwater, 2000)

${ }^{29}$ In our analysis we use the firm wage bill, not the number of workers, as a measure of the labour input because we do not want potential changes in worker quality to affect the results. However, to show how changes in demand, TFP-Q and markups are important for labour productivity, it makes little sense to consider the (log of the) ratio between revenue and the wage bill on the left hand side of the decomposition. Instead we use, in our labour productivity decompositions, the (log) number of full-time-equivalent employees as a measure of the labour input and, in order to make sure that the decomposition goes through, we borrow our estimate of the output elasticity of labour, $\hat{\alpha}_{L}$, and recompute TFP-Q, TFP-R and scale accordingly. As can be appreciated from Table 14, this makes little difference in terms of the patterns of TFP-Q, TFP-R and scale so far discussed.
} 
Table 14: Manufacturing. Standard labour productivity decomposition (factor proportions version) over the period 2003-2013.

\begin{tabular}{lc|ccccc}
\hline & $\Delta(r-l)$ & $\begin{array}{c}\Delta \text { TFP-R } \\
(\text { DGKP })\end{array}$ & $\gamma \Delta l$ & $\left(\alpha_{M}\right) \Delta(m-l)$ & $\left(\alpha_{K}\right) \Delta(k-l)$ & Obs \\
\hline 2004 & 0.062 & 0.035 & -0.000 & 0.026 & 0.001 & 641 \\
2005 & 0.012 & 0.004 & 0.000 & 0.007 & 0.001 & 564 \\
2006 & 0.044 & 0.023 & -0.000 & 0.024 & -0.002 & 617 \\
2007 & 0.040 & 0.019 & 0.000 & 0.021 & 0.000 & 594 \\
2008 & -0.035 & 0.006 & 0.000 & -0.038 & -0.002 & 401 \\
2009 & -0.092 & -0.046 & -0.000 & -0.042 & -0.004 & 443 \\
2010 & 0.118 & 0.042 & -0.000 & 0.074 & 0.002 & 496 \\
2011 & 0.038 & 0.030 & 0.000 & 0.009 & -0.001 & 450 \\
2012 & -0.012 & -0.008 & 0.000 & -0.004 & 0.000 & 478 \\
2013 & 0.007 & 0.011 & 0.000 & -0.005 & 0.000 & 477 \\
\hline $2003-2008$ & 0.027 & 0.018 & 0.000 & 0.009 & -0.001 & 2,817 \\
$2008-2013$ & 0.012 & 0.006 & 0.000 & 0.006 & -0.000 & 2,344 \\
\hline
\end{tabular}

See equation (13) in Section 2 for the derivation of this standard labour productivity decomposition. Final two rows show the mean of changes over the two periods using all the annual observations shown above. Computations refer to revenue-weighted changes for the within sample of manufacturing firms.

and, while experiencing significant drops in 2008 and 2009, increased on average by only $1.2 \mathrm{pp}$ a year in the period 2008-2013 ending up almost 8pp below its per-crisis trend (more if considering 2003-2007 as the baseline period). Column 2 of Table 14 indicates that the main culprit of this under-performance is the drop in revenue TFP growth who changed from about 1.8 pp a year in the period 2003-2008 to 0.6pp per year post-2008, i.e., [(1.8 $0.6) /(2.7-1.2)]=80 \%$ of the labour productivity growth slowdown. ${ }^{30}$ The remaining $20 \%$ is almost entirely accounted for by a reduction of the log intermediates to labour ratio, i.e., the term $\Delta(m-l)$.

Table 15, based on the more involved decomposition provided by equation (15) in Section 2 , provides deeper insights on the decline in labour productivity by highlighting the role of demand, quantity TFP and markups. Markup-adjusted TFP-Q barely changed its growth rate in the two periods 2003-2008 and 2008-2013 while the largest growth rate drop in the whole Table is related to markup-adjusted demand $\tilde{\lambda}$ experiencing a decline from the $16.9 \mathrm{pp}$ per year average over 2003-2008 to only 5.9pp post-2008. At the same time, the related slowdown of markups seen in Table 13 helped to contain the fall in labour productivity

\footnotetext{
${ }^{30}$ Numbers for DGKP revenue TFP in column 2 of Tables 13 and 14 are slightly different because in the latter case we use, as indicated in a previous footnote, the number of employees rather than the wage bill as a measure of the labour input.
} 
Table 15: Manufacturing. More detailed labour productivity decomposition (factor proportions version) over the period 2003-2013.

\begin{tabular}{lc|cccccc}
\hline & $\Delta(r-l)$ & $\Delta(a / \mu)$ & $\Delta(\lambda / \mu)$ & $\Delta\left[\left(\frac{\gamma+1}{\mu}-1\right) l\right]$ & $\alpha_{M} \Delta\left(\frac{m-l}{\mu}\right)$ & $\alpha_{K} \Delta\left(\frac{k-l}{\mu}\right)$ & Obs \\
\hline 2004 & 0.062 & -0.056 & 0.300 & -0.139 & -0.042 & -0.001 & 641 \\
2005 & 0.012 & -0.012 & 0.004 & 0.007 & 0.012 & 0.001 & 564 \\
2006 & 0.044 & 0.044 & 0.050 & -0.053 & 0.005 & -0.002 & 617 \\
2007 & 0.040 & -0.060 & 0.138 & -0.035 & -0.003 & -0.001 & 594 \\
2008 & -0.035 & -0.124 & 0.357 & -0.151 & -0.112 & -0.005 & 401 \\
2009 & -0.092 & 0.011 & -0.312 & 0.171 & 0.040 & -0.002 & 443 \\
2010 & 0.118 & -0.020 & 0.082 & -0.012 & 0.066 & 0.002 & 496 \\
2011 & 0.038 & -0.103 & 0.354 & -0.150 & -0.061 & -0.003 & 450 \\
2012 & -0.012 & 0.002 & -0.071 & 0.039 & 0.017 & 0.001 & 478 \\
2013 & 0.007 & -0.082 & 0.234 & -0.091 & -0.054 & -0.001 & 477 \\
\hline $2003-2008$ & 0.027 & -0.040 & 0.169 & -0.074 & -0.027 & -0.002 & 2,817 \\
$2008-2013$ & 0.012 & -0.038 & 0.059 & -0.009 & 0.001 & -0.001 & 2,344 \\
\hline
\end{tabular}

See equation (15) in Section 2 for the derivation of this more detailed labour productivity decomposition. Final two rows show the mean of changes over the two periods using all the annual observations shown above. Computations refer to revenue-weighted changes for the within sample of manufacturing firms.

through an increase in the average yearly growth rate of the markup-adjusted labour term $\left(\Delta\left[\left(\frac{\gamma+1}{\mu}-1\right) l\right]\right)$ and intermediates over labour term $\left(\alpha_{M} \Delta\left(\frac{m-l}{\mu}\right)\right) .{ }^{31}$ Markup-adjusted capital over labour changes only weakly contributed throughout. To sum up, the decline in demand appears to be the single most important determinant of the fall in UK labour productivity.

\subsection{Services}

Using the within sample for services, and weighting observations by revenues, we report in Table 16 mean changes from $t-1$ to $t$ in WLD revenue TFP and its components building on the decomposition of equation (16). For services, we find more relevant to use the year 2007 to define the pre- and post-crisis periods.

First, revenue TFP growth in services was rather weak already prior to the crisis with an average of $0.2 \mathrm{pp}$ per year in the period 2003-2007. This further weakened after the crisis falling to a $0.1 \mathrm{pp}$ per year over 2007-2013. In this respect, column 2 of Table 16 suggests (like for manufacturing) that a decline in the combined quantity TFP and demand component $\omega$

\footnotetext{
${ }^{31}$ From the expressions of these two terms it appears clearly how a reduction in markups $\mu$ increases both. Markups are endogenous in the MULAMA/MUOMEGA models and their equilibrium level (determined by profit maximization) increases with both TFP-Q and demand. A fall in demand and/or TFP-Q thus pushes markups to decrease and this decrease in markups helps firms to contain the fall in both profits and revenue TFP.
} 
has been driving the weakening of TFP-R growth in services. At the same time, columns 3 and 4 indicate that this process has been accompanied by a decline in markups and production scale growth, which is again in line with the evidence provided above for manufacturing. Overall, this turned into a weakening of markup-adjusted $\omega$ (column 5) while the reduction in markups helped, like in manufacturing, containing the fall in revenue TFP through the increase in markup-adjusted scale (column 6), with the two adjusted components adding up to the overall change in revenue TFP as from equation (16).

Table 16: Services. Changes of revenue TFP and its components over the period 2003-2013.

\begin{tabular}{lccccccc}
\hline & $\begin{array}{c}\Delta \text { TFP-R } \\
\text { (WLD) }\end{array}$ & $\Delta \omega$ & $\Delta \mu$ & $\Delta$ scale & $\Delta$ adjusted $\omega$ & $\begin{array}{c}\Delta \text { adjusted } \\
\text { scale }\end{array}$ & Obs \\
\hline 2004 & 0.004 & 0.154 & 0.011 & 0.044 & 0.070 & -0.066 & 8,387 \\
2005 & -0.006 & 0.028 & 0.001 & 0.044 & 0.002 & -0.007 & 7,813 \\
2006 & -0.001 & -0.032 & -0.005 & 0.044 & 0.038 & -0.039 & 6,438 \\
2007 & 0.008 & 0.258 & 0.019 & 0.042 & 0.101 & -0.092 & 6,266 \\
2008 & -0.020 & -0.185 & -0.015 & 0.016 & -0.090 & 0.070 & 5,674 \\
2009 & -0.002 & 0.042 & 0.005 & -0.041 & -0.011 & 0.010 & 6,493 \\
2010 & 0.011 & 0.124 & 0.009 & 0.014 & 0.068 & -0.057 & 6,079 \\
2011 & -0.000 & -0.203 & -0.018 & 0.017 & -0.088 & 0.088 & 5,966 \\
2012 & 0.017 & 0.141 & 0.009 & 0.022 & 0.073 & -0.056 & 6,404 \\
2013 & -0.002 & -0.066 & -0.006 & 0.031 & 0.006 & -0.008 & 6,626 \\
$2003-2007$ & 0.002 & 0.104 & 0.007 & 0.043 & 0.053 & -0.052 & 28,904 \\
$2007-2013$ & 0.001 & -0.021 & -0.002 & 0.010 & -0.005 & 0.006 & 37,242 \\
\hline
\end{tabular}

The Table shows mean revenue-weighted changes from $t-1$ to $t$, for the services firms within sample, of WLD revenue TFP as well as of the various MUOMEGA model components following from the linear revenue-TFP decomposition provided by equation (16) and applied to WLD revenue TFP. The final two rows show the mean of changes over the two periods using all the annual observations shown above.

Figure 4 presents the results graphically and it is constructed in the same way as Figure 3 for manufacturing except that we now set 2007 as the reference year. Panels (a) and (b) show quite neatly the break in revenue TFP and $\omega$ before and after 2007 while panels (c) and (d) highlight the decline in the evolution of markups and production scale. Panels (e) and (f) visualize the downturn in adjusted $\omega$ and the counter-increase in adjusted scale helping to contain the overall fall in TFP-R. Finally, Table B-5 in Appendix B shows formal Chow test results confirming the presence of a structural break around 2007.

Table 17 shows the standard labour productivity decomposition over the period 2003-2013 for our revenue-weighted services firms within sample. ${ }^{32}$ Results indicate that services labour

\footnotetext{
${ }^{32} \mathrm{As}$ in the case of manufacturing we use, in our labour productivity decompositions, the (log) number of full-time-equivalent employees as a measure of the labour input and, in order to make sure that the
} 
Figure 4: Services. Evolution of revenue TFP and its components over the period 2003-2013.

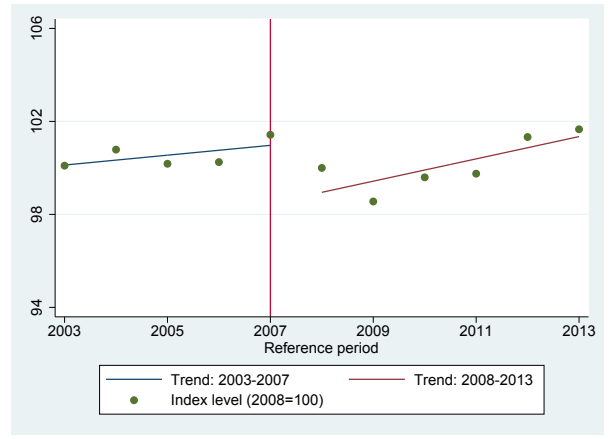

(a) WLD rev TFP

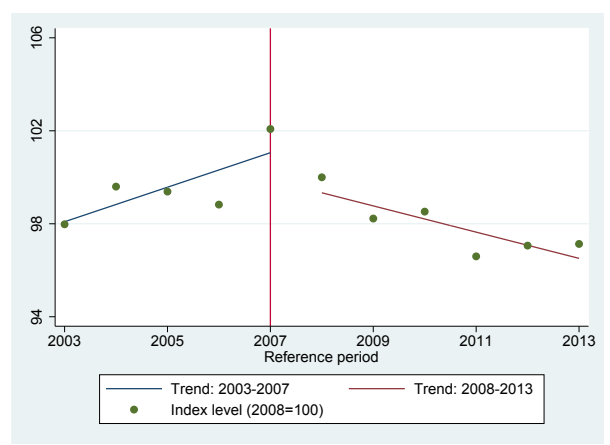

(c) $\mu$

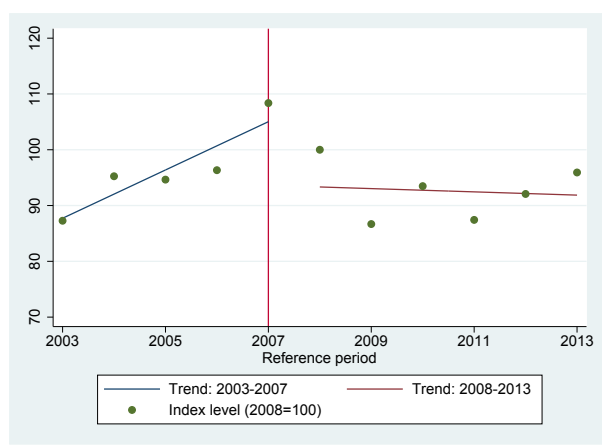

(e) adjusted $\omega$

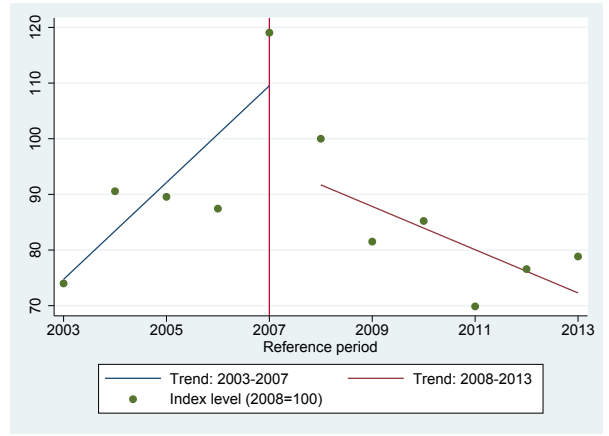

(b) $\omega$

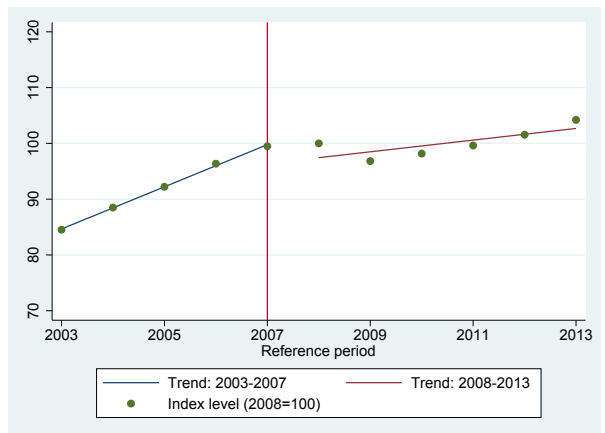

(d) scale

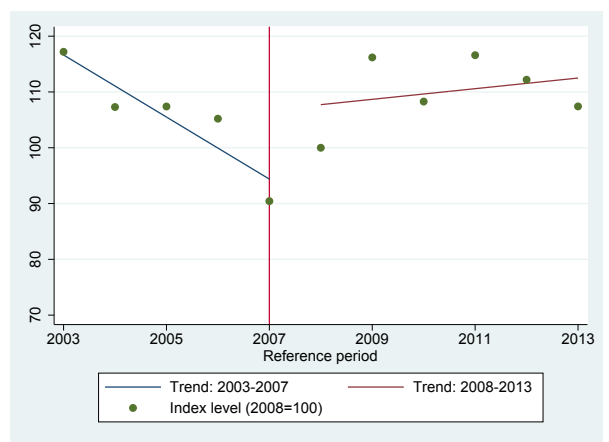

(f) adjusted scale

Index of revenue TFP $(2007=100)$ calculated using revenue-weighted changes in mean annual value and measured using the WLD method (a) for the within sample of services firms. Panels (b)-(f) show indices of components of the WLD revenue TFP following from the decomposition (16).

productivity growth in the period 2003-2007 was about $0.8 \mathrm{pp}$ a year and, while experiencing large drops in 2008 and 2009, decreased on average by 1.1pp a year in the period 2007-2013 ending up around 11.4pp below its per-crisis trend. Column 2 of Table 17 indicates that a key culprit of this under-performance is the drop in revenue TFP growth who changed from a positive $0.3 p p$ a year in the period 2003-2007 to a negative -0.6pp per year post-2007, i.e., decomposition goes through, we borrow our estimate of the output elasticity of labour, $\hat{\alpha}_{L}$, and recompute $\omega$, TFP-R and scale accordingly. As can be appreciated from Table 17, this makes little difference in terms of the overall patterns of $\omega$, TFP-R and scale so far discussed. 
Table 17: Services. Standard labour productivity decomposition (factor proportions version) over the period 2003-2013.

\begin{tabular}{lc|ccccc}
\hline & $\Delta(r-l)$ & $\begin{array}{c}\Delta \text { TFP-R } \\
\text { (WLD) }\end{array}$ & $\gamma \Delta l$ & $\left(\alpha_{M}\right) \Delta(m-l)$ & $\left(\alpha_{K}\right) \Delta(k-l)$ & Obs \\
\hline 2004 & 0.011 & 0.006 & 0.002 & 0.001 & 0.001 & 8,387 \\
2005 & 0.004 & -0.004 & 0.003 & 0.004 & 0.001 & 7,813 \\
2006 & 0.007 & -0.002 & 0.003 & 0.006 & -0.001 & 6,438 \\
2007 & 0.009 & 0.011 & 0.002 & -0.005 & 0.001 & 6,266 \\
2008 & -0.049 & -0.036 & 0.008 & -0.021 & -0.000 & 5,674 \\
2009 & -0.069 & -0.024 & -0.001 & -0.043 & -0.002 & 6,493 \\
2010 & 0.039 & 0.017 & -0.001 & 0.022 & 0.001 & 6,079 \\
2011 & -0.003 & -0.009 & -0.000 & 0.007 & 0.000 & 5,966 \\
2012 & 0.011 & 0.013 & -0.002 & -0.000 & 0.000 & 6,404 \\
2013 & -0.002 & -0.004 & 0.003 & -0.001 & 0.000 & 6,626 \\
\hline $2003-2007$ & 0.008 & 0.003 & 0.003 & 0.002 & 0.001 & 28,904 \\
$2007-2013$ & -0.011 & -0.006 & 0.001 & -0.006 & -0.000 & 37,242 \\
\hline
\end{tabular}

See equation (13) in Section 2 for the derivation of this standard labour productivity decomposition. Final two rows show the mean of changes over the two periods using all the annual observations shown above. Computations refer to revenue-weighted changes for the within sample of services firms.

Table 18: Services. More detailed labour productivity decomposition (factor proportions version) over the period 2003-2013.

\begin{tabular}{lc|ccccc}
\hline & $\Delta(r-l)$ & $\Delta(\omega / \mu)$ & $\Delta\left[\left(\frac{\gamma+1}{\mu}-1\right) l\right]$ & $\alpha_{M} \Delta\left(\frac{m-l}{\mu}\right)$ & $\alpha_{K} \Delta\left(\frac{k-l}{\mu}\right)$ & Obs \\
\hline 2004 & 0.011 & 0.062 & -0.041 & -0.011 & 0.000 & 8,387 \\
2005 & 0.004 & 0.002 & 0.006 & -0.004 & 0.001 & 7,813 \\
2006 & 0.007 & 0.033 & -0.020 & -0.005 & -0.001 & 6,438 \\
2007 & 0.009 & 0.091 & -0.059 & -0.024 & 0.001 & 6,266 \\
2008 & -0.049 & -0.092 & 0.051 & -0.009 & 0.001 & 5,674 \\
2009 & -0.069 & -0.031 & 0.006 & -0.043 & -0.002 & 6,493 \\
2010 & 0.039 & 0.062 & -0.033 & 0.009 & 0.001 & 6,079 \\
2011 & -0.003 & -0.084 & 0.055 & 0.025 & 0.000 & 5,966 \\
2012 & 0.011 & 0.065 & -0.038 & -0.016 & 0.000 & 6,404 \\
2013 & -0.002 & 0.001 & -0.002 & -0.001 & 0.000 & 6,626 \\
\hline $2003-2007$ & 0.008 & 0.047 & -0.029 & -0.011 & 0.000 & 28,904 \\
$2007-2013$ & -0.011 & -0.011 & 0.005 & -0.006 & 0.000 & 37,242 \\
\hline
\end{tabular}

See equation (17) in Section 2 for the derivation of this more detailed labour productivity decomposition. Final two rows show the mean of changes over the two periods using all the annual observations shown above. Computations refer to revenue-weighted changes for the within sample of services firms.

$[(0.3+0.6) /(0.8+1.1)]=47.4 \%$ of the labour productivity growth slowdown. ${ }^{33}$ The remaining

\footnotetext{
${ }^{33}$ Numbers for WLD revenue TFP in column 1 of Table 16 and column 2 of Table 17 are different because
} 
share is almost entirely accounted for by a reduction of the log intermediates to labour ratio, i.e., the term $\Delta(m-l)$.

Table 18 provides further insights on the decline in labour productivity by highlighting the combined role of demand and TFP-Q as well as of markups. Markup-adjusted $\omega$ experienced a strong growth decline from the 6.5pp per year average over 2003-2007 to only 0.1pp post-2007. At the same time, the related slowdown of markups helped to contain the fall in labour productivity through a substantial improvement in the average yearly growth rate of the markup-adjusted labour term $\left(\Delta\left[\left(\frac{\gamma+1}{\mu}-1\right) l\right]\right)$ and intermediates over labour term $\left(\alpha_{M} \Delta\left(\frac{m-l}{\mu}\right)\right) .{ }^{34}$ Finally, markup-adjusted capital over labour changes only weakly contributed throughout.

\subsection{Comparing services with manufacturing}

The evidence provided so far for manufacturing and services points to very similar patterns, although with somewhat different magnitudes, in terms of the common measures. More specifically, our results indicate that the labour productivity puzzle is to a large extent also a revenue TFP puzzle while the downturn in revenue TFP has been largely driven by a decline in the combined TFP-Q and demand component $\omega$, to which firms have reacted by decreasing both markups and production scale. In turn, this decrease of markups and production scale has helped containing the negative impact of the less favourable post-crisis environment on TFP-R and so also on labour productivity.

In the case of manufacturing, our data allows us to go one step further and in particular assess whether the reduction in $\omega$ has been TFP-Q and/or demand driven. The answer to such question is that both a supply and a demand shock have negatively affected manufacturing revenue TFP. Our data does not allow to directly answer the above question for services. However we might conjecture, based on one key element, that supply (and possibly also demand) contributed to the overall downturn of services TFP-R. More specifically, we believe that the capital stock available to firms, which is generated by yearly investments, is the production input most closely related to the level of technology, i.e., quantity TFP used in the production process. In this respect, Figure 5 shows the mean, across firms and revenue-weighted, annual level of real investments in the capital stock in manufacturing (left panel) and services (right panel) over 2004-2013. The timing and depth of the decrease in investments and subsequent recovery are somewhat different between manufacturing and services but the overall picture is rather similar: a deep slump around the financial crisis and a

in the latter case we use, as indicated in a previous footnote, the number of employees rather than the wage bill as a measure of the labour input.

${ }^{34}$ As already highlighted above, markups are endogenous in the MULAMA/MUOMEGA models and their equilibrium level (determined by profit maximization) increases with $\omega$. A fall in $\omega$ thus pushes markups to decrease and this decrease in markups helps firms to contain the fall in both profits and revenue TFP. 
Figure 5: Investment patterns in manufacturing and services over the period 2004-2013.

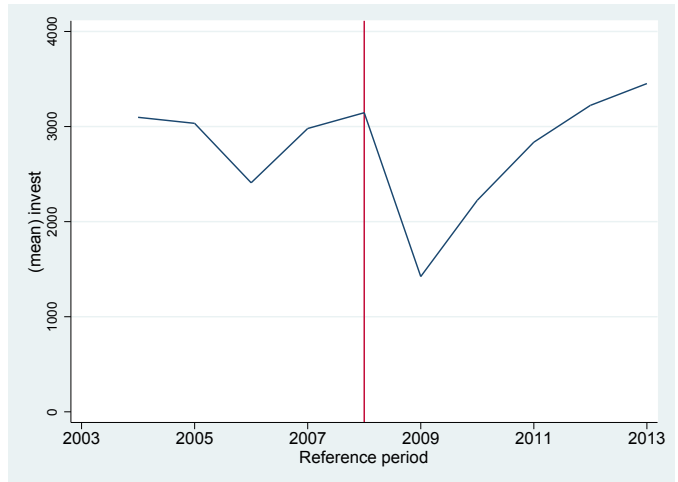

(a) Manufacturing

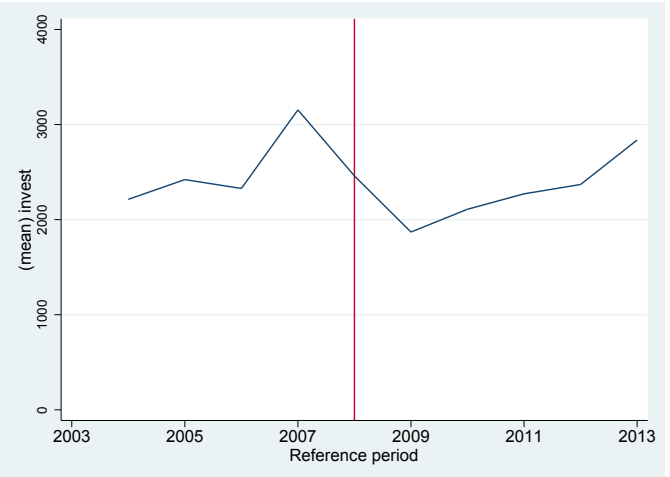

(b) Services

Mean firm annual real investments in the capital stock in manufacturing and services. Computations refer to the manufacturing and services within samples and are revenue-weighted.

sizeable (especially in manufacturing) recovery thereafter. Given that the fall in investments in manufacturing has turned into a sizeable post-crisis drop in TFP-Q, we can conjecture that a sizeable post-crisis drop in TFP-Q for services is also likely.

\section{Robustness}

In what follows we provide evidence supporting the robustness of our results by using different samples, different weighting schemes, different estimation techniques as well as a Translog production function.

Using the multi-product firms sample for manufacturing. In our main analysis for manufacturing we focus on single-product firms because dealing with multi-product firms requires a number of additional assumptions. However, multi-product firms account for a large share of production and revenue in manufacturing. In order to analyse multi-product firms we proceed as in FMMM and DGKP, i.e., we break them down into several single-product firms by using a procedure allowing to assign firm-level inputs to the different products produced by a multi-product firm (inputs assignment problem). In doing so, we then consider again within firm and product changes between $t-1$ and $t$ and weigh observations based on the corresponding firm-product-specific revenue. Results displayed in Table B-6 and Figure B-4 indicate that our key insights apply to the sample of multi-product manufacturing firms too.

Using un-weighted or employment-weighted values. So far we have always considered firm revenue in order to weigh observations because we want our results to be representative 
of aggregate rather than average-firm outcomes. However, in Tables B-7 and B-8, and corresponding Figures B-5 and B-6, we provide results obtained using un-weighted changes. As can be appreciated from the two Tables and Figures, our baseline results are virtually unaffected. At the same time, Tables B-9 and B-10, and corresponding Figures B-7 and B-8, show results obtained using firm employment to weigh observation and still confirm the robustness of our findings.

Using alternative estimation procedures. In our baseline results, we use the DGKP estimation procedure to estimate the production function and recover the different components of the MULAMA model for manufacturing, while for services we use the WLD estimation procedure to estimate the production function and recover the different components of the restricted MUOMEGA model. In order to assess the robustness of our results to the specific estimation technique employed we provide in Tables B-11 and B-12, as well as in Figures B-9 and B-10, results obtained using the FMMM estimation procedures for the MULAMA model (manufacturing) and MUOMEGA model (services). This new set of results is again in line with our baseline findings.

Using the Translog production function for manufacturing. The limited overlap between the Prodcom and ARDx datasets force us to estimate a unique production function for manufacturing firms rather than estimate different production functions for different 2-digit industries. In this respect, results provided in Table B-13 and Figure B-11, and obtained using the more flexible Translog production function, allay concerns about the issue of heterogeneity in output elasticities across firms and industries in manufacturing.

\section{Conclusions}

In this paper we provide novel evidence that the poor UK firms' productivity performance post-2008 is due to a negative downturn in both quantity TFP and demand pushing down sales, markups and revenue TFP, as well as labour productivity. More specifically, in the first part of our analysis we focus on manufacturing firms and use information on firm-level prices and quantities to measure firm-level quantity TFP by building upon the frameworks developed in De Loecker et al. (2016) and Forlani et al. (2016). This allows us to further quantify firmlevel demand and markups and, while aggregating-up the information at the manufacturing industry-level, compare the evolution of TFP-Q, markups and demand before and after 2008. Finally, we exploit two exact decompositions for TFP-R and labour productivity to show how changes in TFP-Q, markups and demand have affected the two productivity measures. Our results suggest that both a slowing down of demand and a decline in quantity TFP, and 
the related markups fall, are behind the decline in revenue TFP and labour productivity in manufacturing.

In the second part of our analysis, we instead consider service industries and estimate a restricted version of the model due to the absence of reliable and meaningful information on prices. In doing so we find, for those measures that are common to both the full and restricted versions of the model, very similar patterns to those obtained for manufacturing. These findings, along with the absence of noticeable differences in capital investments patterns between manufacturing and services industries, lead us to conjecture that both supply and demand also contributed to the poor revenue TFP and labour productivity performance of UK service industries.

We believe that our results are important for at least two reasons. First, they are informative about the long-term impacts of the Great Recession. A fall in quantity TFP, due for example to a decline in the rate of technical progress, represents a permanent loss of productive potential with substantial long-term implications for the economy. By contrast a demand downturn, due for example to a general climate of uncertainty, could have less permanent consequences. Second, they are informative about the policies that could more effectively address the weak growth of labour productivity and revenue TFP post-crisis. In particular, our findings suggest that government policies should more prominently act towards boosting demand for firms rather than focusing only on productivity. In this respect, we believe this point might be particularly relevant in the current Covid-19 crisis.

In terms of avenues for future research, we believe our analysis could be fruitfully extended to other countries to identify both common features and country specificities. In this respect, the detailed price and quantity data used in our paper is available for quite a few countries including EU member states, the US and Brazil. At the same time, we believe the analysis could be usefully extended to a more recent time frame, possibly including the ongoing Covid19 crisis, to provide evidence into the current patterns of, for example, TFP-Q, demand and markups.

\section{References}

Ackerberg, D., Benkard, C. L., Berry, S., and Pakes, A. (2007). Econometric tools for analyzing market outcomes. Handbook of econometrics, 6:4171-4276.

Ackerberg, D. A., Caves, K., and Frazer, G. (2015). Identification properties of recent production function estimators. Econometrica, 83(6):2411-2451.

Anderson, J. E. and Van Wincoop, E. (2004). Trade costs. Journal of Economic literature, 42(3):691-751.

Andrews, D., Criscuolo, C., and Gal, P. N. (2015). Frontier Firms, Technology Diffusion 
and Public Policy: Micro Evidence from OECD Countries. OECD Productivity Working Papers, 2.

Atkeson, A. and Burstein, A. (2008). Pricing-to-market, trade costs, and international relative prices. The American Economic Review, 98(5):1998-2031.

Ayoubkhani, D. (2014). A Comparison between Annual Business Survey and National Accounts Measures of Value Added. Technical report. Office for National Statistics.

Barnett, A., Chiu, A., Franklin, J., and Sebastiá-Barriel, M. (2014). The productivity puzzle: a firm-level investigation into employment behaviour and resource allocation over the crisis. Bank of England Staff Working Papers, 495.

Behrens, K., Mion, G., Murata, Y., and Südekum, J. (2014). Trade, wages, and productivity. International Economic Review, 55(4):1305-1348.

Bryson, A. and Forth, J. (2016). The UK 's Productivity Puzzle. In Askenazy, P., Bellman, L., Bryson, A., and Moreno Galbis, E., editors, Productivity Puzzles Across Europe, chapter 5, pages 129-173. Oxford University Press.

Cette, G., Fernald, J., and Mojon, B. (2016). The pre-Great Recession slowdown in productivity. European Economic Review, 88:3-20.

De Loecker, J., Eeckhout, J., and Unger, G. (2020). The Rise of Market Power and the Macroeconomic Implications. The Quarterly Journal of Economics, Forthcoming.

De Loecker, J., Goldberg, P. K., Khandelwal, A. K., and Pavcnik, N. (2016). Prices, Markups, and Trade Reform. Econometrica, 84(2):445-510.

De Loecker, J. and Warzynski, F. (2012). Markups and Firm-Level Export Status. American Economic Review, 102(6):2437-2471.

Dhingra, S. and Morrow, J. (2019). Monopolistic competition and optimum product diversity under firm heterogeneity. Journal of Political Economy, 127(1):196-232.

Feenstra, R. C. (2003). A homothetic utility function for monopolistic competition models, without constant price elasticity. Economics Letters, 78(1):79-86.

Forlani, E., Martin, R., Mion, G., and Muûls, M. (2016). Unraveling firms: Demand, productivity and markups heterogeneity. CEPR Discussion Paper 11058.

Goodridge, P., Haskel, J., and Wallis, G. (2013). Can Intangible Investment Explain the UK Productivity Puzzle? National Institute Economic Review, 224(1):48-58.

Goodridge, P., Haskel, J., and Wallis, G. (2016). Accounting for the UK Productivity Puzzle: A Decomposition and Predictions. Economica, 85:581-605.

Grice, J. (2012). The Productivity Conundrum, Interpreting the Recent Behaviour of the Economy. Technical report. Office for National Statistics.

Griliches, Z. and Mairesse, J. (1995). Production Functions: The Search for Identification. NBER Working Paper Series, (5067).

Hall, R. E. (1986). Market Structure and Macroeconomic Fluctuations. Brookings Papers on 
Economic Activity, 2.

Haltiwanger, J., Kulick, R., and Syverson, C. (2018). Misallocation measures: The distortion that ate the residual. NBER Working Papers 24199, National Bureau of Economic Research, Inc.

Harris, R. and Moffat, J. (2017). The UK productivity puzzle, 2008 to 2012: evidence using plant-level estimates of total factor productivity. Oxford Economic Papers, 69(3):529-549.

Harris, R. I. D. and Drinkwater, S. (2000). UK Plant and Machinery Capital Stocks and Plant Closures. Oxford Bulletin of Economics and Statistics, 62(2):243-265.

Hottman, C. J., Redding, S. J., and Weinstein, D. E. (2016). Quantifying the sources of firm heterogeneity. The Quarterly Journal of Economics, 131(3):1291-1364.

Jacob, N. and Mion, G. (2020). On the productivity advantage of cities. Mimeo.

Khandelwal, A. K., Schott, P. K., and Wei, S.-J. (2013). Trade liberalization and embedded institutional reform: Evidence from chinese exporters. American Economic Review, 103(6):2169-95.

Kugler, M. and Verhoogen, E. (2011). Prices, plant size, and product quality. The Review of Economic Studies, 79(1):307-339.

Martin, B. and Rowthorn, R. (2012). Is the British economy supply constrained II? A renewed critique of productivity pessimism. Centre for Business Research, University of Cambridge.

McCann, P. (2018). Productivity Perspectives Synthesis. PIN Evidence Review 07, ESRC Productivity Insights Network.

OECD (2018). OECD Compendium of Productivity Indicators 2018. OECD Publishing, Paris. Office for National Statistics (2007). The ONS Productivity Handbook. Palgrave-Macmillan.

Office for National Statistics (2014). Producer Price Indices: Methods and Guidance. Technical report.

Office for National Statistics (2018a). International comparisons of productivity. Technical report.

Office for National Statistics (2018b). Labour productivity, UK: October to December 2017. Statistical bulletin.

Office for National Statistics (2018c). Products of the European Community, 1997-2016: Secure Access. (8th Edition). [data collection].

Office for National Statistics. Virtual Microdata Laboratory, University of the West of England, Bristol (2017). Annual Respondents Database X, 1998-2014: Secure Access (4th Edition). [data collection].

Olley, G. S. and Pakes, A. (1996). The dynamics of productivity in the telecommunications equipment industry. Econometrica, 64(6):1263-1297.

Pessoa, J. P. and Van Reenen, J. (2014). The UK productivity and jobs puzzle: Does the answer lie in wage flexibility? Economic Journal, 124(576):433-452. 
Riley, R., Bondibene, C. R., and Young, G. (2013). Productivity Dynamics in the Great Stagnation: Evidence from British businesses. CFM Discussion Papers 1407, Centre for Macroeconomics.

Riley, R., Rincon-Aznar, A., and Samek, L. (2018). Below the Aggregate: A Sectoral Account of the UK Productivity Puzzle. ESCoE Discussion Papers 2018-06, Economic Statistics Centre of Excellence.

Riley, R., Rosazza-Bondibene, C., and Young, G. (2014). The Financial Crisis, Bank Lending and UK Productivity: Sectoral and Firm-Level Evidence. National Institute Economic Review, 228(1):17-34.

Schneider, P. (2018). Decomposing differences in productivity distributions. Bank of England working papers 740, Bank of England.

Spence, M. (1976). Product selection, fixed costs, and monopolistic competition. The Review of Economic Studies, 43(2):217-235.

Stiebale, J. and Vencappa, D. (2018). Acquisitions, markups, efficiency, and product quality: Evidence from india. Journal of International Economics, 112:70-87.

Van Beveren, I., Bernard, A. B., and Vandenbussche, H. (2012). Concording EU Trade and Production Data over Time. NBER Working Papers 18604, National Bureau of Economic Research, Inc.

Wooldridge, J. M. (2009). On estimating firm-level production functions using proxy variables to control for unobservables. Economics Letters, 104(3):112-114.

Zhelobodko, E., Kokovin, S., Parenti, M., and Thisse, J.-F. (2012). Monopolistic competition: Beyond the constant elasticity of substitution. Econometrica, 80(6):2765-2784. 


\section{Appendix}

\section{A Data appendix}

\section{A.1 The ARDx}

The ARDx covers around two-thirds of UK economic activity, comprising most SIC 2007 sections, except parts of sections A (agriculture) and K (finance), and all of O (public administration and defence), $\mathrm{T}$ (activities of households) and $\mathrm{U}$ (extraterritorial organisations). We split the data in order to run the full model on manufacturing and the restricted model on services as described in section 2.6 above. Tables A-1 and A-2 show the ARDx coverage for these sectors for firms with 10 or more employees, weighting the survey data using sampling weights based on the stratification of country, 4-digit SIC 2007 headings and employment band. Monetary values in the data are deflated using appropriate series published by the ONS (see below for details) and are reported in $2010 £ s$.

Table A-1: Manufacturing aggregates by year (using deflated prices)

\begin{tabular}{cccccccc}
\hline & Observations & Firms & $\begin{array}{c}\text { Output } \\
£ b n\end{array}$ & $\begin{array}{c}\text { GVA } \\
£ b n\end{array}$ & $\begin{array}{c}\text { Intermediates } \\
£ b n\end{array}$ & $\begin{array}{c}\text { Capital } \\
£ b n\end{array}$ & $\begin{array}{c}\text { Employment } \\
\text { m }\end{array}$ \\
\hline 2003 & 9,277 & 37,048 & 390.47 & 110.33 & 280.14 & 111.45 & 2.75 \\
2004 & 8,910 & 35,337 & 396.73 & 115.79 & 280.94 & 108.66 & 2.60 \\
2005 & 8,406 & 34,279 & 389.92 & 117.58 & 272.35 & 106.38 & 2.47 \\
2006 & 7,718 & 37,732 & 384.96 & 123.77 & 261.19 & 93.40 & 2.36 \\
2007 & 8,360 & 36,271 & 421.76 & 136.63 & 285.13 & 91.70 & 2.31 \\
2008 & 5,223 & 34,771 & 427.56 & 142.44 & 285.11 & 95.14 & 2.35 \\
2009 & 4,813 & 30,349 & 372.08 & 118.64 & 253.44 & 72.74 & 2.25 \\
2010 & 4,901 & 28,994 & 393.36 & 131.94 & 261.42 & 72.14 & 2.09 \\
2011 & 4,554 & 28,485 & 401.68 & 137.72 & 263.96 & 71.35 & 2.05 \\
2012 & 4,694 & 29,378 & 397.11 & 135.78 & 261.33 & 70.78 & 2.06 \\
2013 & 4,543 & 29,034 & 394.84 & 136.57 & 258.27 & 70.87 & 2.07 \\
\hline
\end{tabular}

GVA, output and intermediates all calculated at basic prices from ARDx dataset for firms with 10 or more employees. Manufacturing firms SIC 2007 industries 10-33. Capital stock estimated using ARDx and perpetual inventory method code supplied by ONS to SecureLab users. Employment at time of ARDx sample selection. First column shows un-weighted cell count, all other columns weighted using ARDx sample weights with appropriate auxiliary variable.

The recession of 2008-9 is clearly visible for both manufacturing and services, with output and gross value-added dropping substantially for both. The picture for inputs is mixed, however, with manufacturing employment shrinking substantially over the entire 2003-13 period, while real capital stock and real intermediates consumption also declined. The services 
Table A-2: Services aggregates by year (using deflated prices)

\begin{tabular}{cccccccc}
\hline Year & Observations & Firms & $\begin{array}{c}\text { Output } \\
£ b n\end{array}$ & $\begin{array}{c}\text { GVA } \\
£ b n\end{array}$ & $\begin{array}{c}\text { Intermediates } \\
£ b n\end{array}$ & $\begin{array}{c}\text { Capital } \\
£ b n\end{array}$ & $\begin{array}{c}\text { Employment } \\
\text { m }\end{array}$ \\
\hline 2003 & 24,059 & 162,782 & 888.43 & 437.05 & 451.38 & 151.25 & 11.42 \\
2004 & 23,353 & 162,321 & 944.75 & 470.77 & 473.98 & 166.74 & 11.84 \\
2005 & 22,810 & 166,425 & 963.46 & 475.33 & 488.13 & 179.60 & 12.03 \\
2006 & 19,643 & 247,799 & 983.87 & 487.82 & 496.05 & 159.89 & 11.67 \\
2007 & 21,766 & 270,784 & $1,089.66$ & 536.77 & 552.89 & 179.76 & 12.38 \\
2008 & 19,369 & 282,954 & $1,167.54$ & 560.97 & 606.58 & 197.72 & 13.65 \\
2009 & 17,627 & 179,346 & $1,074.91$ & 514.30 & 560.62 & 170.20 & 13.93 \\
2010 & 16,381 & 177,204 & $1,088.87$ & 521.79 & 567.08 & 166.36 & 13.40 \\
2011 & 17,532 & 181,681 & $1,096.46$ & 522.17 & 574.30 & 168.53 & 13.60 \\
2012 & 18,100 & 194,493 & $1,117.38$ & 529.87 & 587.50 & 171.48 & 14.26 \\
2013 & 17,949 & 201,314 & $1,179.53$ & 557.94 & 621.59 & 177.70 & 14.58 \\
\hline
\end{tabular}

GVA, output and intermediates all calculated at basic prices from ARDx dataset for firms with 10 or more employees.Services firms SIC 2007 sectors F-U, excluding K. Capital stock estimated using ARDx and perpetual inventory method code supplied by ONS to SecureLab users. Employment at time of ARDx sample selection. First column shows un-weighted cell count, all other columns weighted using ARDx sample weights with appropriate auxiliary variable.

sectors saw a substantial post-recession rebound in employment, capital stock, and intermediates consumption. We also note a pronounced fall in the number of firms sampled from the manufacturing industries from 2007 to 2008 when the survey changed from the ABI to the ABS, leading us to prefer our within-firm analysis that is likely to be less heavily biased by selection effects (see main text).

\section{A.2 Revenue, value added and labour measures}

As a measure of firms' revenues from production we calculate what the ONS labels 'output at basic prices' by adjusting reported firm turnover for value-added tax, goods bought and sold for resale (i.e. where no production has taken place), changes in stocks and work-in-progress, and changes in stocks of materials, storage and fuels, see Ayoubkhani (2014). We similarly calculate gross value added, measuring intermediates as consumption at purchaser prices, less goods and services bought for resale and changes in stocks of materials, storage and fuels.

We use the firm wage bill as our preferred measure of labour input, instead of the number of employees, as it controls for ability differences across workers over time. In our setting in particular, if firms responded to the recession by substituting workers of different skill levels - with a corresponding difference in wages - we would if using the headcount measure mistakenly pick this up in our estimates of revenue TFP and TFP. 


\section{A.3 Capital stock}

The ARD/ABS does not report a capital stock variable but it does have investment data allowing capital stock to be estimated using the perpetual inventory method. The ONS made available supplementary data files and its Stata code that allow researchers to construct firm capital stocks over any time period and with suitable parameters. We construct the variable for the years 2003-2013 using data for the period 1998-2013.

The perpetual inventory method requires a value for the capital stock on the first observation of a firm in the data. The ONS solution is to compare the amount of investment in the survey data with the amount of investment known to occur from National Accounts data, in order to establish the proportion of observed investment to total investment at a (letter code) industry level. This proportion is assumed to also apply to capital stocks. We then obtain

a measure of industry level capital stocks (again using the National Accounts estimates of capital services) in the observed data. All that remains is to share this among firms within each industry, which we do based on the IDBR turnover variable.

The procedure also needs to deal with the unbalanced nature of the panel giving rise to many missing observations for investment for all but the largest firms. These missing values are imputed using the average of investment per employee for observed years. We keep observations when capex is negative, even if total capex for a firm over time is negative, dealing with negative capital stocks instead at the end of the process. This procedure first attempts to correct negative capital stocks by rebasing the initial estimate and then recalculating subsequent observations, iterating five times or until the process leads to a positive capital stock. Those that remain negative are removed from our final dataset.

Standard ONS industry and national accounts data contains 10 types of capital, while the ABS/ABI has investment data for only three types: buildings, vehicles and plant and machinery, the latter being a residual other category. Our preferred capital stock is to use plant and machinery, following Harris and Drinkwater (2000); Harris and Moffat (2017). In doing so we do not require detailed user costs in order to aggregate different types of capital stock. We use an annual depreciation rate of $10 \%$ for plant and machinery.

Firms are also asked about capital hires in the ABS/ABI surveys but, since in our model capital must be pre-decided in each period, we do not add this to the capital stock as it is presumably more flexible than the fixed stock. Instead, it will be included in firms intermediates expenditures.

\section{A.4 Product concordance}

The core Prodcom list is published annually by Eurostat, however until 2005 it contained some aggregate codes and some national-level codes. These national level codes are dropped from 
the analysis. The Prodcom list typically has minor changes from year to year as new codes are added, obsolete products removed, and other codes either merged or split. However, the 2007/8 revision of NACE, and corresponding move from UK Standard Industry Classification (SIC) 2003 to SIC 2007, involved wholesale changes to Prodcom when 4,396 Prodcom codes were made obsolete and replaced with 3,864 new codes. Since we need to track a firms production and sales of a product over time, we need a concordance procedure to give us a consistent set of products. For this we borrow use the procedure and Stata code due to Van Beveren et al. (2012). The concordance works by grouping together new codes that map from obsolete codes into a synthetic code, and then keeps track of these family trees. Each tree becomes a new product, and we are left with 3,795 consistent products. We drop firmproduct-year observations that we are not able to match using the concordance procedure.

\section{A.5 Deflators}

We deflate all monetary variables to constant 2010 prices. For output price deflators we use a series provided by the ONS, 'Experimental Industry Level Deflators'I.

These are a mixture of 2-, 3- and 4-digit deflators produced by aggregating industry product deflators based on their use of products in line with the National Accounts suppleuse framework. Finance (SIC section $\mathrm{K}$ ) is excluded, and we drop the section from the services analysis. For most service sectors, the deepest level of detail available is at the SIC division (2-digit) level.

Detailed input price deflators are available for manufacturing but not services. For manufacturing we turn to the ONS Producer Price Index (PPI) time series ${ }^{\mathrm{II}}$ which provides Gross Sector Input (GSI) deflators at the one to four digit SIC 2007 level, depending on GSI subsection. Each GSI sub-section can span several SIC divisions (the 2 digit level), while data for some levels of aggregation are not available. We group the data in such a way as to produce deflators at the SIC division level. Most ${ }^{\mathrm{III}}$ SIC divisions map 1:1 to the GSI deflators we have available $^{\mathrm{IV}}$.

For services inputs we deflate using the same output price series described above. Our estimates of the plant and machinery capital stock are deflated by the ONS deflator series ${ }^{\mathrm{V}}$

\footnotetext{
${ }^{\mathrm{I} D o w n l o a d e d}$ from https://www.ons.gov.uk/economy/inflationandpriceindices/adhocs/ 006718industryleveldeflatorsexperimentaluk1997to2015

${ }^{\mathrm{II} D o w n l o a d e d ~ f r o m ~ h t t p s: / / w w w . o n s . g o v . u k / e c o n o m y / i n f l a t i o n a n d p r i c e i n d i c e s / d a t a s e t s / ~}$ producerpriceindex

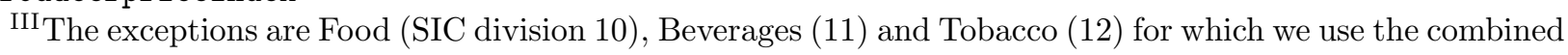
GSI sub-section Food, Beverages and Tobacco.

${ }^{\text {IV }}$ We map SIC division 22 ('Rubber and Plastic Products') to GSI sub-section 'Other manufactured goods n.e.c.'; division 23 ('Other non-metallic mineral products') to 'Cement, Lime \& Plaster'; division 27 ('Electrical equipment') to 'Computer, Elect \& Optical Products'; division 30 ('Other transport equipment') to 'Motor Vehicles'; and division 33 ('Repair and Installation') to 'Other manufactured goods n.e.c.'

VDownloaded from: https://www.ons.gov.uk/economy/economicoutputandproductivity/output/
} 
for other machinery \& equipment by SIC section.

We use the output price deflators to convert wage costs into real terms. Calculations of value added for manufacturing are made using double deflation, deflating output and inputs separately before calculating value added.

\section{A.6 Merging the ARDx and Prodcom}

The merging process, and the impact it has on the mean values of key variables, is shown in Table A-3. Firms in Prodcom and the ARDx (column 2) are on average larger by every metric than those only in the ARDx (column 1) while single product firms are smaller (column 3). Firms in the final single product estimation sample (column 4) have slightly higher output, intermediates and capital stock than all the single product firms, and slightly lower value added, wage bills and employment.

Table A-3: Summary statistics and data constraints

\begin{tabular}{lcccc}
\hline & $\begin{array}{c}\text { All variables } \\
\text { available }\end{array}$ & $\begin{array}{c}\text {...plus } \\
\text { Prodcom }\end{array}$ & $\begin{array}{c}\text {... plus } \\
\text { single product }\end{array}$ & $\begin{array}{c}\text {... plus } \\
\text { data constraints }\end{array}$ \\
\hline Output £m & 45.86 & 50.65 & 35.80 & 37.08 \\
Value-added £m & 15.35 & 17.52 & 12.67 & 12.11 \\
Intermediates £m & 30.51 & 33.13 & 23.13 & 24.97 \\
Capital £m & 10.07 & 11.33 & 8.42 & 9.28 \\
Wage Bill £m & 8.49 & 9.72 & 7.35 & 6.89 \\
Employment & 239.40 & 279.48 & 217.79 & 217.07 \\
Average N per year & 5,731 & 4,268 & 2,266 & 1,140 \\
\hline
\end{tabular}

Means of variables by sample. 'All variables available' is the number of manufacturing sector firms in the ARDx that have a) at least 10 employees and b) have the following variables available: employment, total turnover ex. VAT, purchases of goods and materials, capital stock, total wages and salaries. '...plus Prodcom' adds the requirement that the firm-year observation is also in the Prodcom dataset. '...plus single product' adds the requirement that at least $90 \%$ of a firm's output at basic prices is accounted for by sales of a single product. '...plus data constaints' adds the requirement that Prodcom measures a non-zero quantity of production, and that firm revenues reported by Prodcom are within $30 \%$ of the output calculated from the ARDx.

datasets/capitalservicesestimates 


\section{B Additional results}

Table B-1: Revenue production function estimates for the whole sample of manufacturing firms in the ARDx.

\begin{tabular}{|c|c|c|c|c|}
\hline & \multicolumn{2}{|c|}{ log output } & \multicolumn{2}{|c|}{ log value-added } \\
\hline & (1) $\overline{\mathrm{OLS}}$ & (2) WLD & $(\overline{3) \mathrm{OLS}}$ & (4) WLD \\
\hline \multirow[t]{2}{*}{ log wage bill } & 0.421 & 0.358 & 0.946 & 0.914 \\
\hline & $(0.003)^{* * *}$ & $(0.006)^{* * *}$ & $(0.002)^{* * *}$ & $(0.006)^{* * *}$ \\
\hline \multirow[t]{2}{*}{ log intermediates } & 0.549 & 0.646 & & \\
\hline & $(0.002)^{* * *}$ & $(0.016)^{* * *}$ & & \\
\hline \multirow[t]{2}{*}{ log capital stock } & 0.016 & 0.013 & 0.030 & 0.064 \\
\hline & $(0.001)^{* * *}$ & $(0.007)^{*}$ & $(0.001)^{* * *}$ & $(0.008)^{* * *}$ \\
\hline$R^{2}$ & 0.99 & & 0.99 & \\
\hline Obs & 63,043 & 16,050 & 63,043 & 16,050 \\
\hline
\end{tabular}

All regressions include 2-digit industry and year dummies. Standard errors clustered by firm. ${ }^{*} p<0.1$; ${ }^{* *}$ $p<0.05 ;{ }^{* * *} p<0.01$. 
Figure B-1: Real, actual and official price index changes: manufacturing, revenue-weighted, within sample

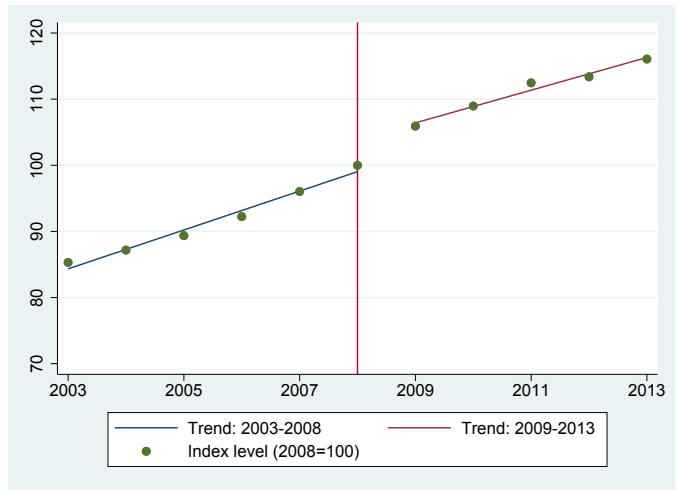

(a) Actual prices

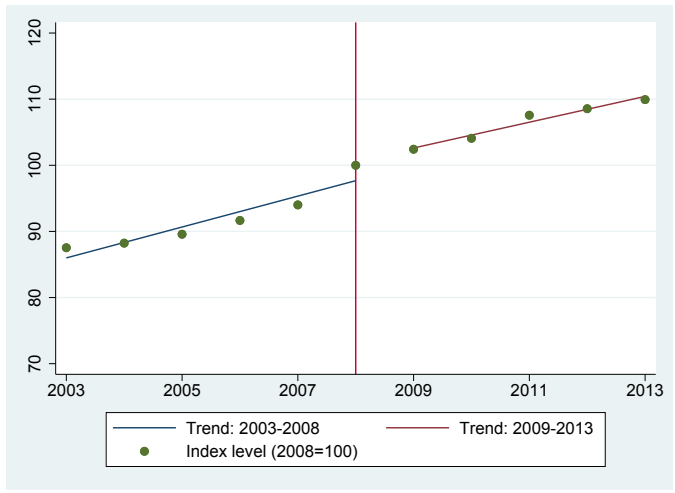

(b) Official price index

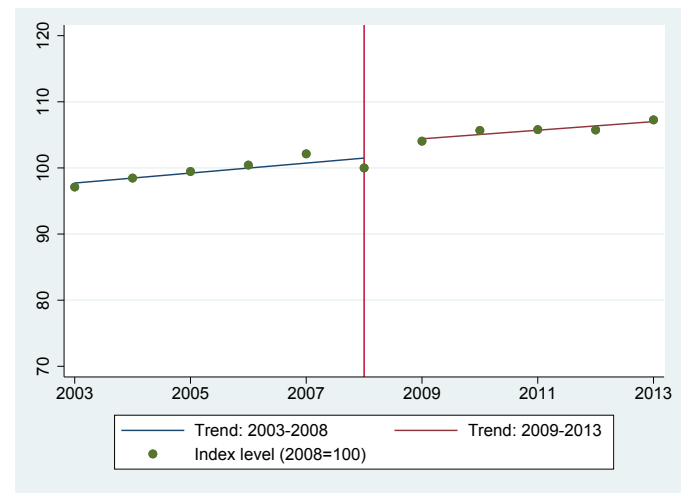

(c) Real prices

Indices of prices $(2008=100)$ calculated using revenue-weighted changes from $t-1$ to $t$ for the manufacturing firms within sample. 
Table B-2: Real, actual and official price index changes: manufacturing, un-weighted, within sample

\begin{tabular}{lcccc}
\hline & $\begin{array}{c}\Delta \text { real } \\
\text { prices }\end{array}$ & $\begin{array}{c}\Delta \text { actual } \\
\text { prices }\end{array}$ & $\begin{array}{c}\Delta \text { official } \\
\text { price index }\end{array}$ & Obs \\
\hline 2004 & 0.009 & 0.018 & 0.009 & 641 \\
2005 & 0.009 & 0.027 & 0.018 & 564 \\
2006 & 0.002 & 0.025 & 0.023 & 617 \\
2007 & 0.014 & 0.042 & 0.028 & 594 \\
2008 & -0.001 & 0.069 & 0.069 & 401 \\
2009 & 0.024 & 0.047 & 0.024 & 443 \\
2010 & 0.015 & 0.036 & 0.021 & 496 \\
2011 & -0.001 & 0.039 & 0.040 & 450 \\
2012 & 0.003 & 0.012 & 0.009 & 478 \\
2013 & -0.001 & 0.012 & 0.012 & 477 \\
\hline & & & & \\
$2003-2008$ & 0.007 & 0.033 & 0.026 & 2,817 \\
$2008-2013$ & 0.008 & 0.029 & 0.021 & 2,344 \\
\hline
\end{tabular}

The Table shows mean un-weighted within-firm changes from $t-1$ to $t$ for the within sample. The final two rows show the mean of changes over the two periods using all the annual observations. 
Table B-3: Real, actual and official price index changes: manufacturing, multi-product firms, within changes, revenue-weighted

\begin{tabular}{lcccc}
\hline & $\begin{array}{c}\Delta \text { real } \\
\text { prices }\end{array}$ & $\begin{array}{c}\Delta \text { actual } \\
\text { prices }\end{array}$ & $\begin{array}{c}\Delta \text { official } \\
\text { price index }\end{array}$ & Obs \\
\hline 2004 & 0.002 & 0.011 & 0.008 & 2,189 \\
2005 & -0.007 & 0.008 & 0.015 & 1,891 \\
2006 & -0.005 & 0.017 & 0.023 & 2,376 \\
2007 & 0.007 & 0.034 & 0.027 & 2,368 \\
2008 & -0.012 & 0.075 & 0.087 & 1,657 \\
2009 & 0.010 & 0.040 & 0.030 & 2,079 \\
2010 & 0.005 & 0.023 & 0.017 & 2,267 \\
2011 & 0.008 & 0.056 & 0.048 & 2,277 \\
2012 & -0.012 & 0.002 & 0.014 & 2,243 \\
2013 & 0.007 & 0.024 & 0.017 & 2,210 \\
\hline \multirow{2}{*}{$2003-2008$} & -0.003 & 0.029 & 0.032 & 10,481 \\
$2008-2013$ & 0.003 & 0.029 & 0.026 & 11,076 \\
\hline
\end{tabular}

The Table shows mean revenue-weighted within-firm-product changes from $t-1$ to $t$ for the multi-product firms sample, where the weights used are average revenues in the two periods. The final two rows show the mean of changes over the two periods using all the annual observations.

Figure B-2: CES demand measure for different values of $\sigma$ : manufacturing, within sample, un-weighted

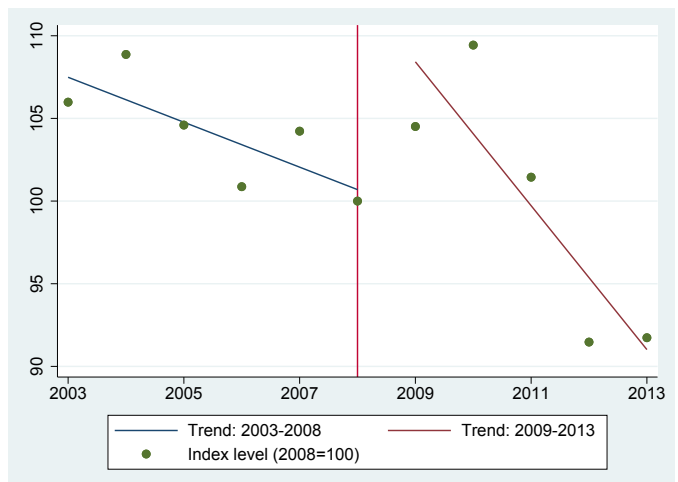

(a) CES demand measure $\sigma=5$, un-weighted

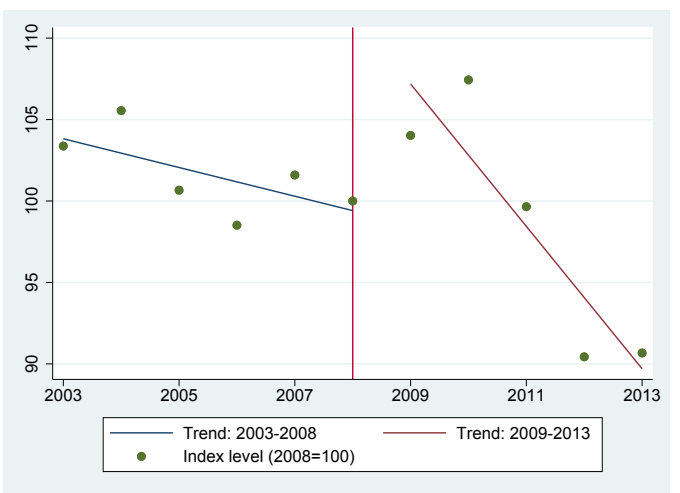

(b) CES demand measure $\sigma=10$, unweighted

Indices of changes in CES demand measures $(2008=100)$. Indices are computed for the manufacturing firms within sample using un-weighted within changes and two alternative values for the elasticity of substitution:

$$
\sigma=5 \text { and } \sigma=10 \text {. }
$$


Figure B-3: CES demand measures for different values of $\alpha$ : manufacturing, multi-product firms, within sample, revenue-weighted

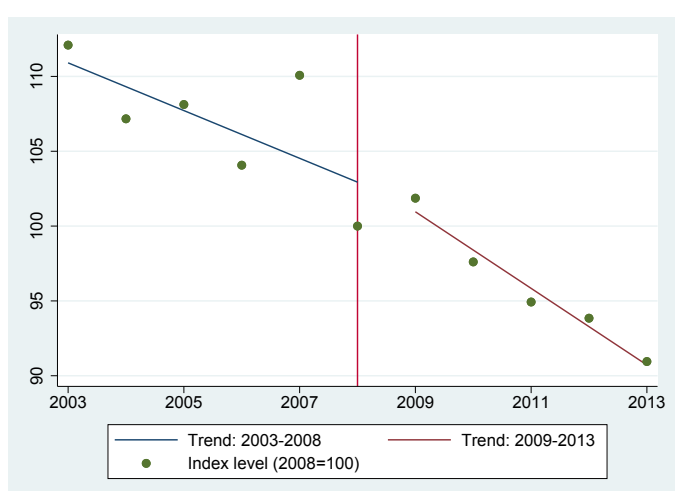

(a) CES demand measure $\alpha=5$, revenue (b) CES demand measure $\alpha=10$, revenue weighted

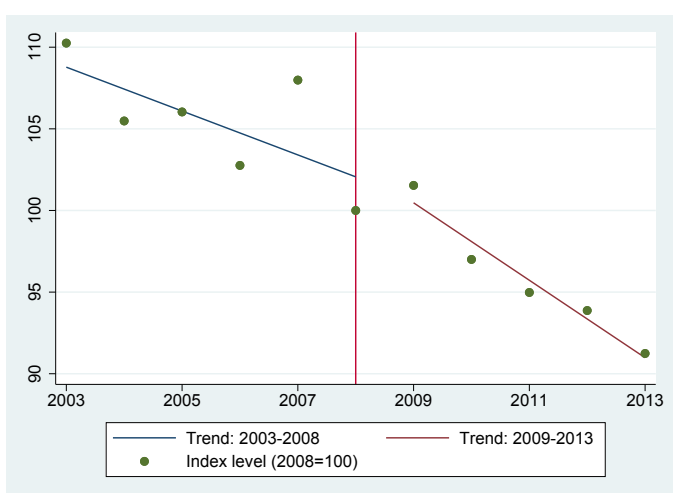

weighted

Indices of changes in CES demand measures $(2008=100)$. Indices are computed for multi-product firms within sample using revenue-weighted within changes and two alternative values for the elasticity of substitution, $\alpha=5$ and $\alpha=10$.

Table B-4: Chow tests on changes in revenue TFP and its components: manufacturing, within sample, revenue weighted.

\begin{tabular}{lccc}
\hline & $\mathrm{F}(\mathrm{k}, \mathrm{N}-2 \mathrm{k})$ & $\mathrm{p}$ & $\mathrm{N}$ \\
\hline$\Delta$ TFP-R (WLD) & 54.89 & 0.000 & 5,161 \\
$\Delta$ TFP-R (DGKP) & 28.54 & 0.000 & 5,161 \\
$\Delta a$ & 19.16 & 0.000 & 5,161 \\
$\Delta \lambda$ & 27.43 & 0.000 & 5,161 \\
$\Delta \omega$ & 35.93 & 0.000 & 5,161 \\
$\Delta \mu$ & 28.64 & 0.000 & 5,161 \\
$\Delta$ scale & 54.43 & 0.000 & 5,161 \\
\hline
\end{tabular}

The Table shows the F-stat and corresponding p-value from Chow tests of the null hypothesis of no structural break in each listed variable in 2008 , where $k=2$. 
Table B-5: Chow tests on changes in revenue TFP and its components: services, within sample, revenue weighted.

\begin{tabular}{lccc}
\hline & $\mathrm{F}(\mathrm{k}, \mathrm{N}-\mathrm{k})$ & $\mathrm{p}$ & $\mathrm{N}$ \\
\hline$\Delta$ TFP-R (WLD) & 36.12 & 0.000 & 66,146 \\
$\Delta \omega$ & 17.71 & 0.000 & 66,146 \\
$\Delta \mu$ & 9.39 & 0.000 & 66,146 \\
$\Delta$ scale & 156.43 & 0.000 & 66,146 \\
$\Delta$ adjusted $\omega$ & 34.71 & 0.000 & 66,146 \\
$\Delta$ adjusted scale & 26.20 & 0.000 & 66,146 \\
\hline
\end{tabular}

The Table shows the F-stat and corresponding p-value from Chow tests of the null hypothesis of no structural break in each listed variable in 2008 , where $k=2$.

Table B-6: Manufacturing. Changes of revenue TFP and its components over the period 2003-2013. Multi-product firms, within changes, revenue-weighted.

\begin{tabular}{lcccccccc}
\hline & $\begin{array}{c}\Delta \text { TFP-R } \\
(\text { WLD })\end{array}$ & $\begin{array}{c}\Delta \text { TFP-R } \\
(\text { DGKP })\end{array}$ & $\Delta a$ & $\Delta \lambda$ & $\Delta \omega$ & $\Delta \mu$ & $\Delta$ scale & Obs \\
\hline 2004 & 0.001 & 0.002 & 0.000 & -0.022 & -0.022 & -0.002 & 0.019 & 2,189 \\
2005 & -0.000 & -0.002 & 0.006 & 0.004 & 0.010 & 0.004 & -0.027 & 1,891 \\
2006 & 0.009 & 0.008 & 0.013 & 0.061 & 0.074 & 0.005 & -0.017 & 2,376 \\
2007 & 0.004 & 0.005 & -0.002 & 0.088 & 0.087 & 0.009 & 0.021 & 2,368 \\
2008 & 0.026 & 0.041 & 0.053 & -0.030 & 0.023 & -0.000 & -0.074 & 1,657 \\
2009 & -0.014 & -0.012 & -0.023 & -0.170 & -0.192 & -0.017 & -0.057 & 2,079 \\
2010 & 0.031 & 0.036 & 0.031 & 0.272 & 0.302 & 0.023 & 0.008 & 2,267 \\
2011 & 0.012 & 0.016 & 0.007 & 0.075 & 0.082 & 0.007 & 0.013 & 2,277 \\
2012 & 0.003 & -0.002 & 0.010 & 0.075 & 0.085 & 0.009 & -0.025 & 2,243 \\
2013 & 0.000 & 0.002 & -0.005 & 0.018 & 0.014 & 0.000 & 0.009 & 2,210 \\
$2003-2008$ & 0.008 & 0.011 & 0.014 & 0.023 & 0.036 & 0.003 & -0.014 & 10,481 \\
$2008-2013$ & 0.007 & 0.008 & 0.005 & 0.058 & 0.062 & 0.005 & -0.009 & 11,076 \\
\hline
\end{tabular}


Figure B-4: Manufacturing. Evolution of revenue TFP and its components over the period 2003-2013. Multi-product firms, within changes, revenue-weighted.

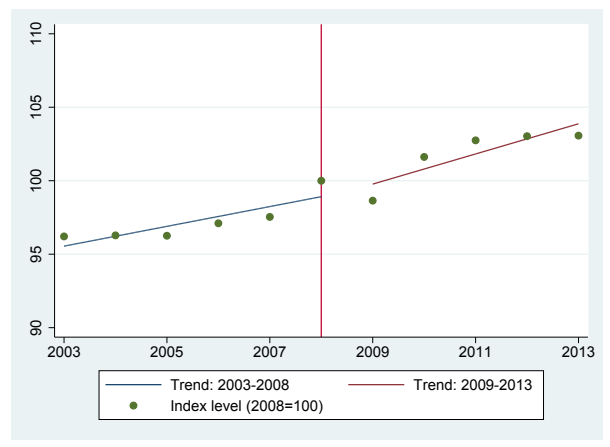

(a) WLD rev TFP

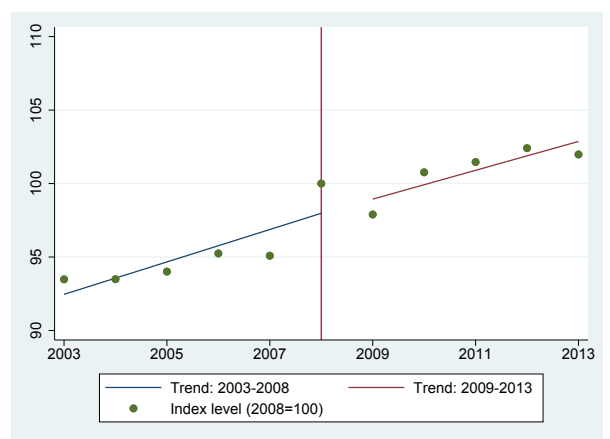

(c) a

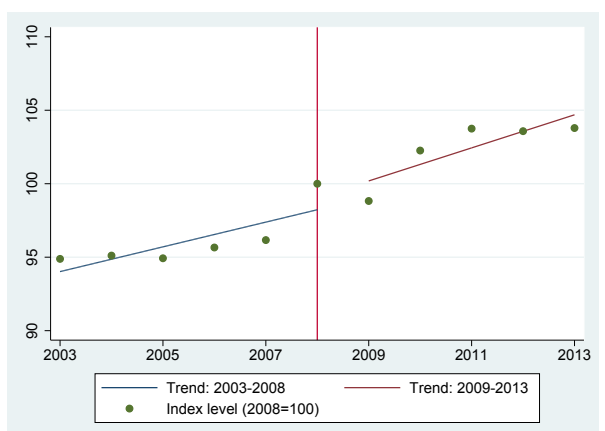

(b) DGKP rev TFP

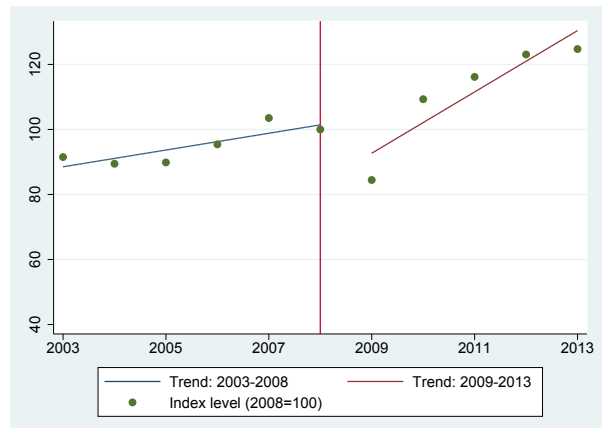

(d) $\lambda$

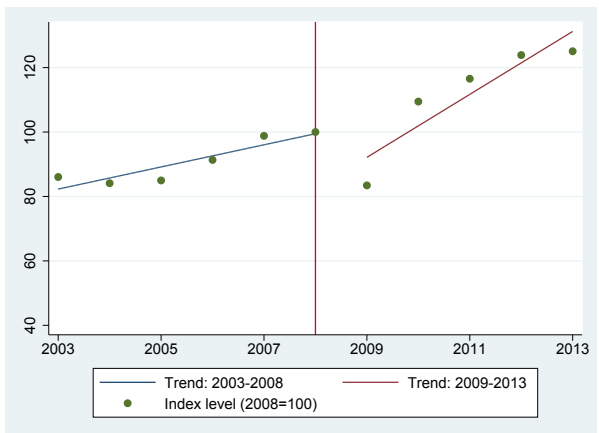

(e) $\omega$

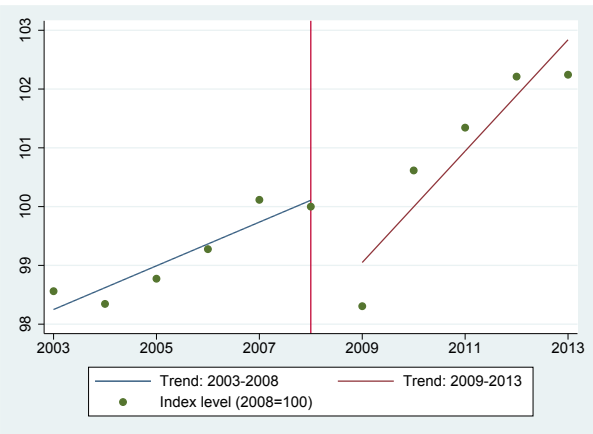

(f) $\mu$

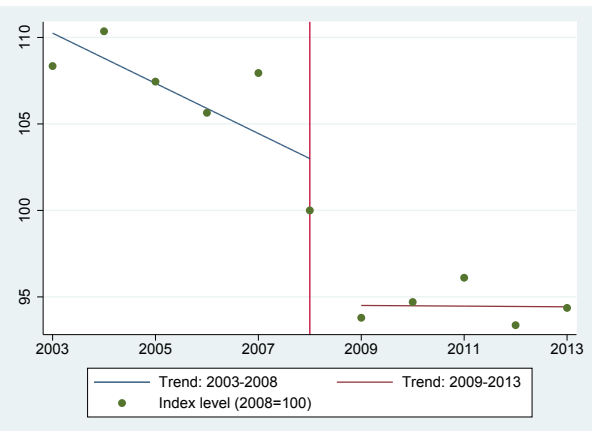

(g) scale 
Table B-7: Manufacturing. Changes of revenue TFP and its components over the period 2003-2013. Within sample, un-weighted

\begin{tabular}{lcccccccc}
\hline & $\begin{array}{c}\Delta \text { TFP-R } \\
(\text { WLD })\end{array}$ & $\begin{array}{c}\Delta \text { TFP-R } \\
(\text { DGKP })\end{array}$ & $\Delta a$ & $\Delta \lambda$ & $\Delta \omega$ & $\Delta \mu$ & $\Delta$ scale & Obs \\
& 0.008 & 0.018 & 0.010 & 0.162 & 0.171 & 0.016 & 0.036 & 641 \\
2004 & 0.016 & 0.002 & -0.007 & 0.078 & 0.071 & 0.008 & 0.001 & 564 \\
2005 & 0.014 & 0.015 & 0.013 & 0.023 & 0.036 & 0.002 & 0.008 & 617 \\
2006 & 0.010 & 0.014 & 0.001 & 0.150 & 0.150 & 0.016 & 0.015 & 594 \\
2007 & 0.028 & 0.026 & 0.027 & 0.321 & 0.348 & 0.032 & -0.054 & 401 \\
2008 & -0.025 & -0.026 & -0.050 & -0.260 & -0.310 & -0.027 & -0.084 & 443 \\
2009 & 0.037 & 0.030 & 0.016 & 0.179 & 0.194 & 0.019 & 0.026 & 496 \\
2010 & 0.022 & 0.022 & 0.023 & 0.195 & 0.218 & 0.019 & 0.015 & 450 \\
2011 & -0.001 & -0.005 & -0.009 & 0.050 & 0.042 & 0.007 & 0.001 & 478 \\
2012 & 0.009 & 0.011 & 0.012 & 0.132 & 0.144 & 0.013 & 0.019 & 477 \\
2013 & 0.014 & 0.015 & 0.008 & 0.135 & 0.142 & 0.014 & 0.005 & 2,817 \\
$2003-2008$ & 0.009 & 0.007 & -0.001 & 0.063 & 0.062 & 0.007 & -0.003 & 2,344 \\
$2008-2013$ & & & & & & & & \\
\hline
\end{tabular}

Table B-8: Services. Changes of revenue TFP and its components over the period 2003-2013. Within sample, un-weighted

\begin{tabular}{lccccccc}
\hline & $\begin{array}{c}\Delta \text { TFP-R } \\
\text { (WLD) }\end{array}$ & $\Delta \omega$ & $\Delta \mu$ & $\Delta$ scale & $\Delta$ adjusted $\omega$ & $\begin{array}{c}\Delta \text { adjusted } \\
\text { scale }\end{array}$ \\
\hline 2004 & 0.002 & 0.096 & 0.008 & 0.042 & 0.044 & -0.043 & 8,387 \\
2005 & -0.008 & 0.038 & 0.005 & 0.022 & 0.019 & -0.026 & 7,813 \\
2006 & 0.004 & -0.024 & -0.004 & 0.022 & 0.003 & 0.001 & 6,438 \\
2007 & 0.006 & 0.129 & 0.008 & 0.033 & 0.058 & -0.052 & 6,266 \\
2008 & -0.017 & -0.219 & -0.021 & -0.005 & -0.105 & 0.088 & 5,674 \\
2009 & -0.005 & 0.052 & 0.011 & -0.048 & -0.005 & -0.000 & 6,493 \\
2010 & 0.012 & 0.073 & 0.005 & 0.018 & 0.049 & -0.037 & 6,079 \\
2011 & -0.002 & -0.150 & -0.015 & 0.012 & -0.058 & 0.056 & 5,966 \\
2012 & 0.011 & 0.053 & 0.002 & 0.012 & 0.044 & -0.034 & 6,404 \\
2013 & 0.002 & -0.013 & -0.003 & 0.025 & 0.016 & -0.014 & 6,626 \\
$2003-2007$ & 0.001 & 0.061 & 0.004 & 0.030 & 0.031 & -0.030 & 28,904 \\
$2007-2013$ & 0.000 & -0.030 & -0.003 & 0.002 & -0.008 & 0.008 & 37,242 \\
\hline
\end{tabular}


Figure B-5: Manufacturing. Evolution of revenue TFP and its components over the period 2003-2013. Within sample, un-weighted

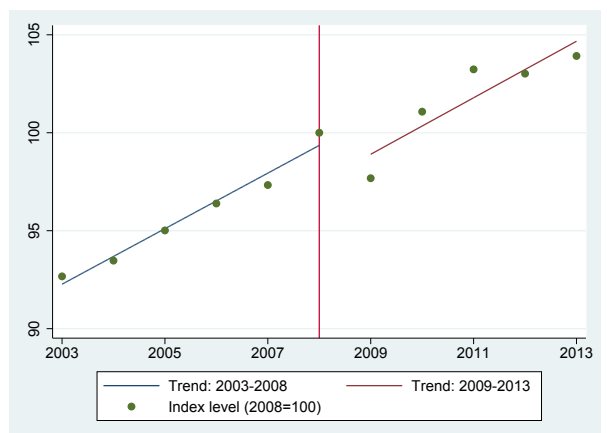

(a) WLD rev TFP

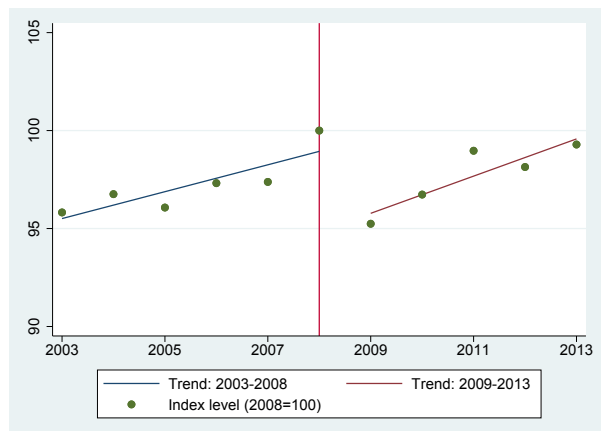

(c) a

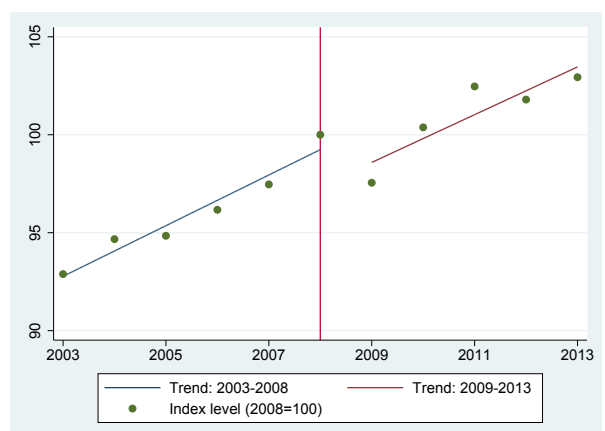

(b) DGKP rev TFP

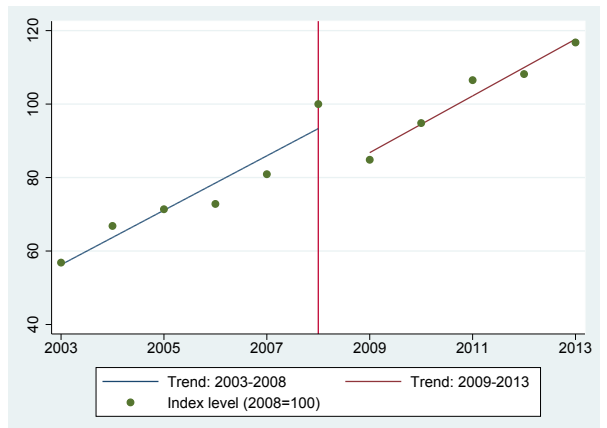

(d) $\lambda$

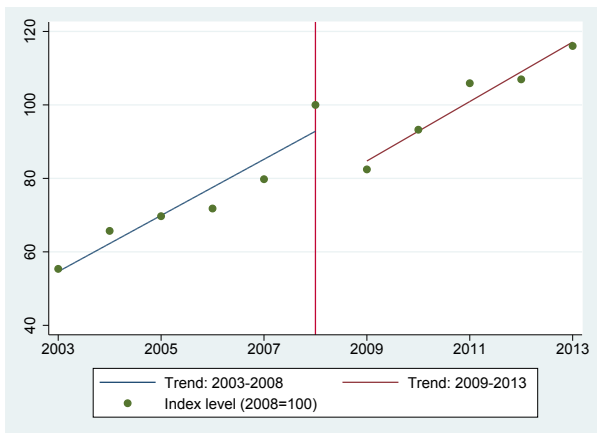

(e) $\omega$

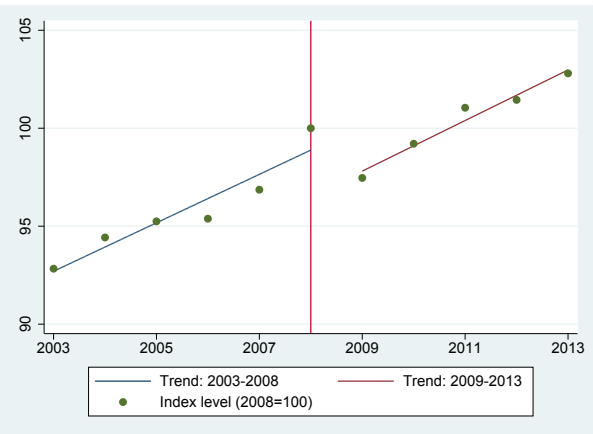

(f) $\mu$

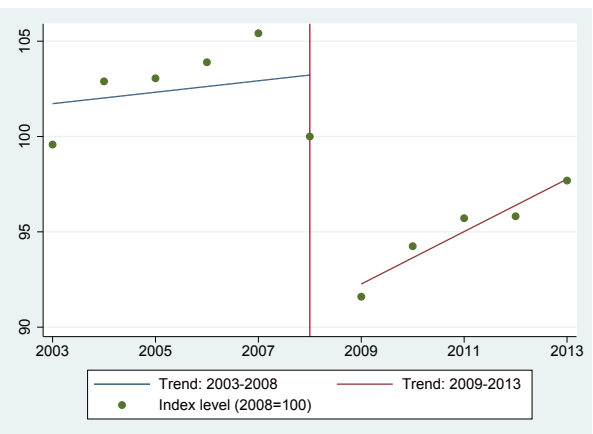

(g) scale 
Figure B-6: Services. Evolution of revenue TFP and its components over the period 20032013. Within sample, un-weighted

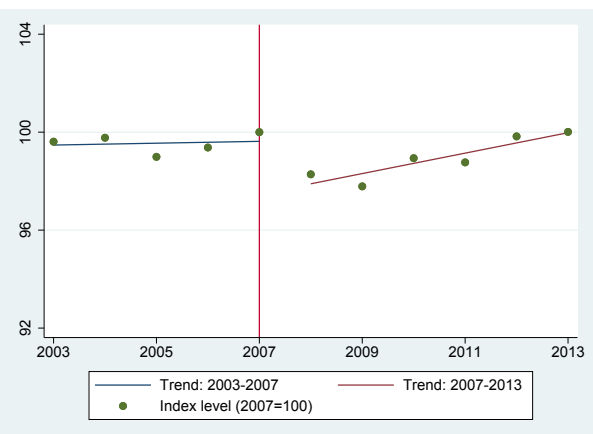

(a) WLD rev TFP

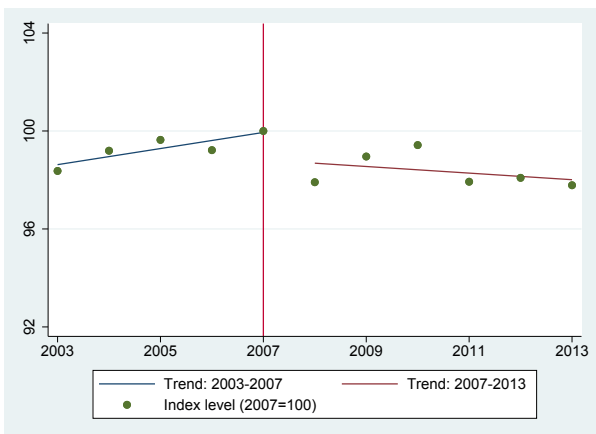

(c) $\mu$

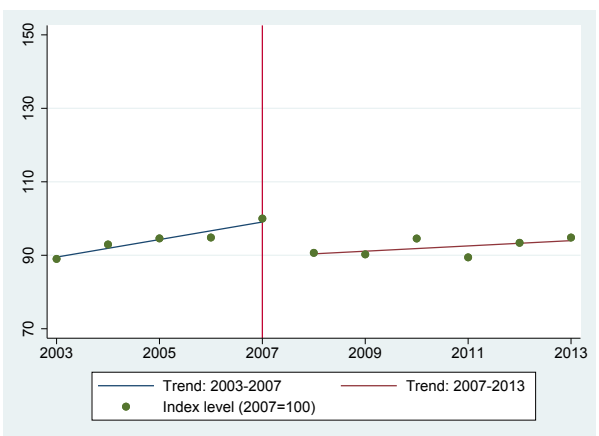

(e) adjusted $\omega$

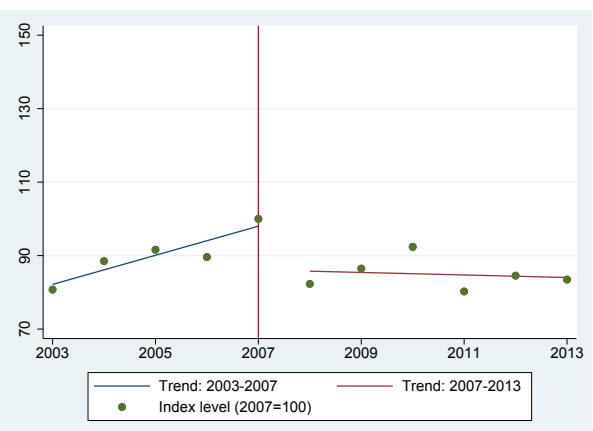

(b) $\omega$

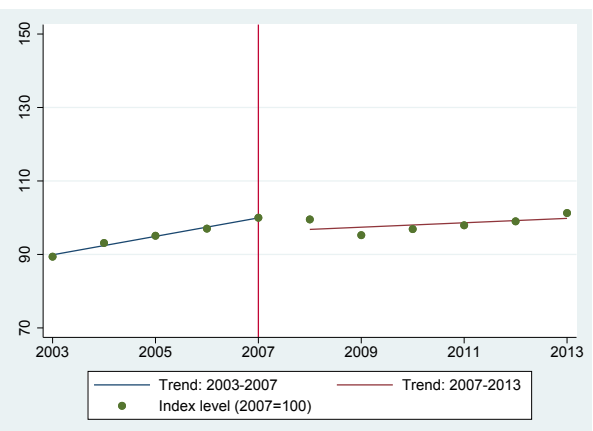

(d) scale

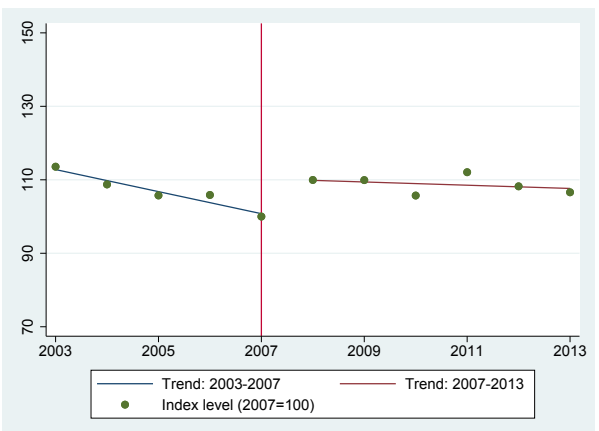

(f) adjusted scale 
Table B-9: Manufacturing. Changes of revenue TFP and its components over the period 2003-2013. Within sample, employment-weighted

\begin{tabular}{lcccccccc}
\hline & $\begin{array}{c}\Delta \text { TFP-R } \\
\text { (WLD) }\end{array}$ & $\begin{array}{c}\Delta \text { TFP-R } \\
\text { (DGKP) }\end{array}$ & $\Delta a$ & $\Delta \lambda$ & $\Delta \omega$ & $\Delta \mu$ & $\Delta$ scale & Obs \\
\hline 2004 & 0.006 & 0.019 & 0.015 & 0.214 & 0.229 & 0.019 & 0.030 & 641 \\
2005 & 0.013 & -0.002 & -0.017 & 0.065 & 0.049 & 0.006 & 0.007 & 564 \\
2006 & 0.017 & 0.019 & 0.019 & 0.111 & 0.129 & 0.010 & 0.009 & 617 \\
2007 & 0.011 & 0.017 & -0.007 & 0.155 & 0.148 & 0.011 & 0.024 & 594 \\
2008 & 0.025 & 0.022 & 0.030 & 0.352 & 0.382 & 0.033 & -0.052 & 401 \\
2009 & -0.022 & -0.019 & -0.056 & -0.306 & -0.362 & -0.031 & -0.080 & 443 \\
2010 & 0.028 & 0.022 & 0.009 & -0.013 & -0.004 & -0.000 & 0.035 & 496 \\
2011 & 0.022 & 0.022 & 0.017 & 0.295 & 0.312 & 0.026 & 0.011 & 450 \\
2012 & -0.003 & -0.008 & -0.000 & -0.027 & -0.027 & -0.001 & 0.009 & 478 \\
2013 & 0.011 & 0.014 & 0.001 & 0.177 & 0.178 & 0.014 & 0.021 & 477 \\
$2003-2008$ & 0.014 & 0.015 & 0.008 & 0.176 & 0.184 & 0.016 & 0.006 & 2,817 \\
$2008-2013$ & 0.007 & 0.006 & -0.006 & 0.024 & 0.018 & 0.002 & -0.001 & 2,344 \\
\hline
\end{tabular}

Table B-10: Services. Changes of revenue TFP and its components over the period 2003-2013. Within sample, employment-weighted

\begin{tabular}{lccccccc}
\hline & $\begin{array}{c}\Delta \text { TFP-R } \\
\text { (WLD) }\end{array}$ & $\Delta \omega$ & $\Delta \mu$ & $\Delta$ scale & $\Delta$ adjusted $\omega$ & $\begin{array}{c}\Delta \text { adjusted } \\
\text { scale }\end{array}$ & Obs \\
\hline 2004 & 0.005 & 0.051 & 0.002 & 0.042 & 0.044 & -0.039 & 8,387 \\
2005 & -0.008 & -0.013 & -0.002 & 0.047 & -0.030 & 0.022 & 7,813 \\
2006 & 0.002 & -0.036 & -0.004 & 0.024 & 0.019 & -0.017 & 6,438 \\
2007 & 0.006 & 0.174 & 0.013 & 0.031 & 0.061 & -0.055 & 6,266 \\
2008 & -0.021 & -0.238 & -0.019 & 0.013 & -0.118 & 0.098 & 5,674 \\
2009 & -0.006 & -0.033 & -0.001 & -0.029 & -0.090 & 0.084 & 6,493 \\
2010 & 0.009 & 0.131 & 0.010 & 0.021 & 0.081 & -0.071 & 6,079 \\
2011 & -0.002 & -0.298 & -0.026 & 0.012 & -0.068 & 0.066 & 5,966 \\
2012 & 0.011 & 0.062 & 0.001 & 0.029 & 0.058 & -0.047 & 6,404 \\
2013 & 0.001 & -0.064 & -0.006 & 0.040 & 0.025 & -0.024 & 6,626 \\
$2003-2007$ & 0.001 & 0.045 & 0.002 & 0.036 & 0.024 & -0.023 & 28,904 \\
$2007-2013$ & -0.001 & -0.070 & -0.007 & 0.015 & -0.016 & 0.015 & 37,242 \\
\hline
\end{tabular}


Figure B-7: Manufacturing. Evolution of revenue TFP and its components over the period 2003-2013. Within sample, employment-weighted

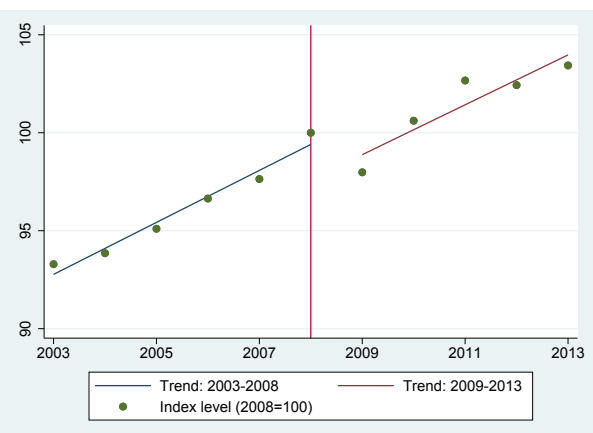

(a) WLD rev TFP

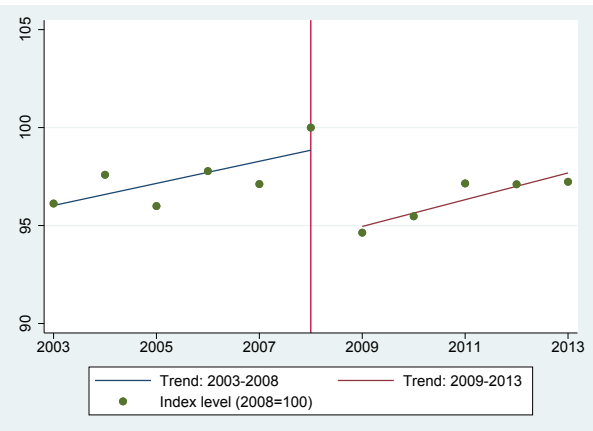

(c) a

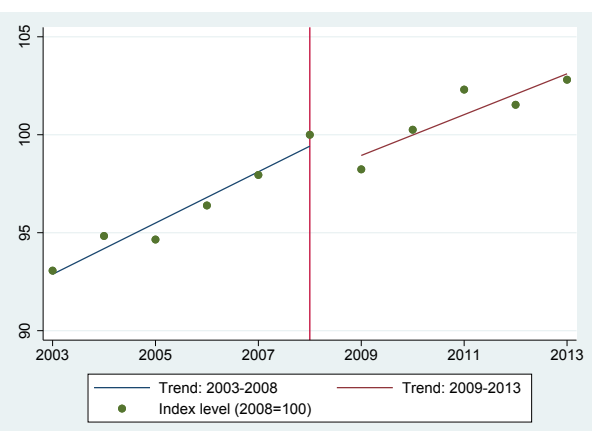

(b) DGKP rev TFP

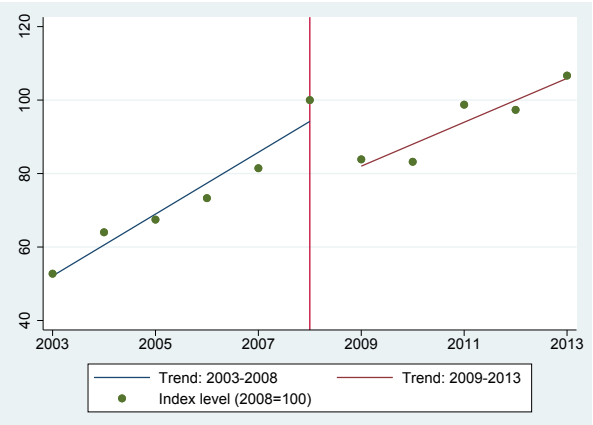

(d) $\lambda$

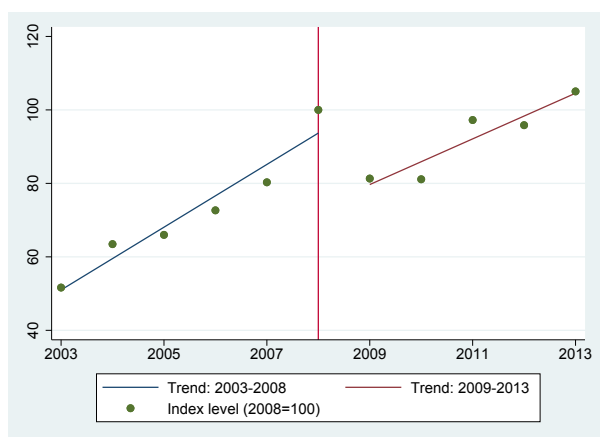

(e) $\omega$

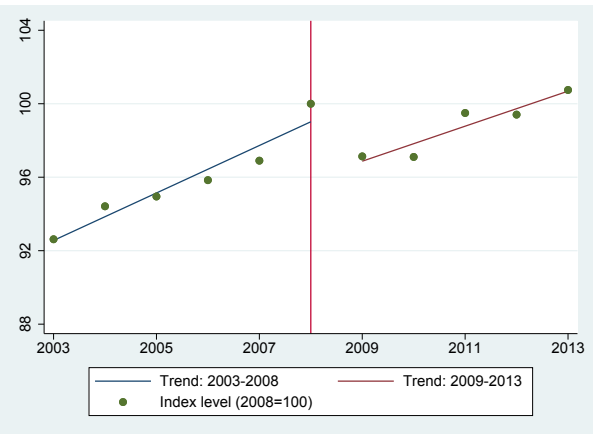

(f) $\mu$

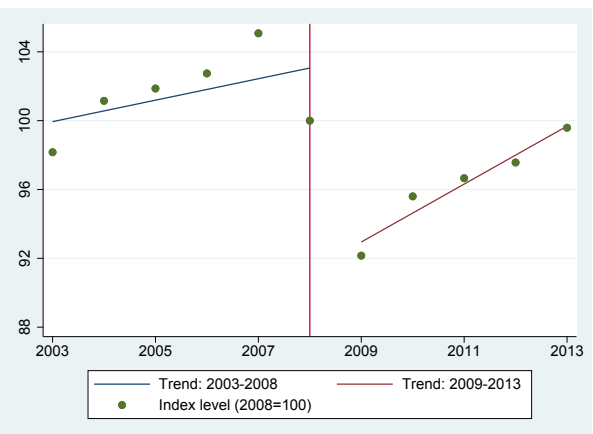

(g) scale 
Figure B-8: Services. Evolution of revenue TFP and its components over the period 20032013. Within sample, employment-weighted

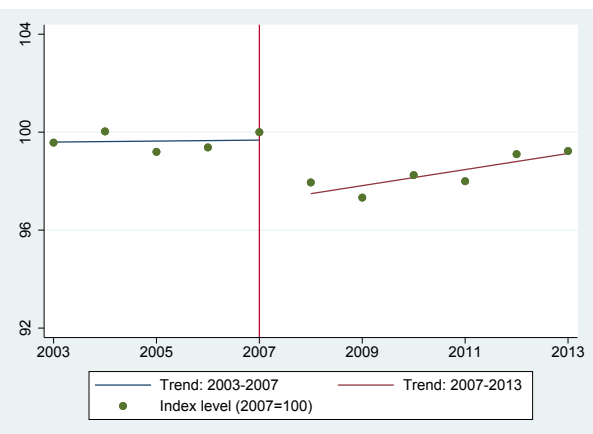

(a) WLD rev TFP

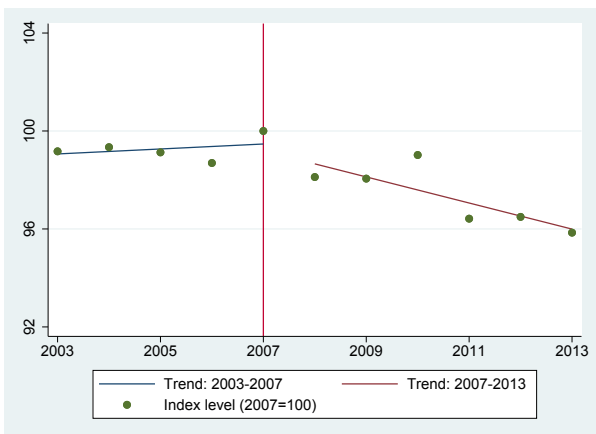

(c) $\mu$

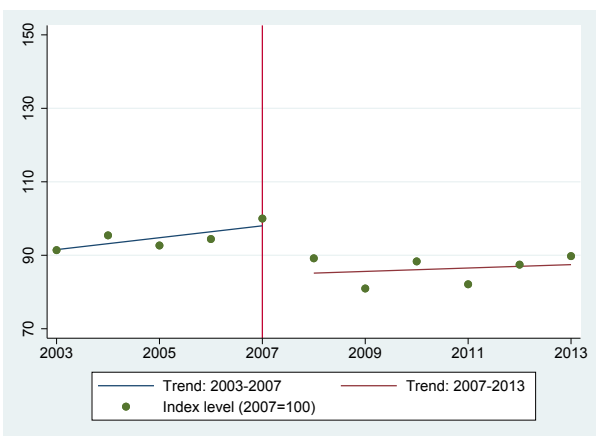

(e) adjusted $\omega$

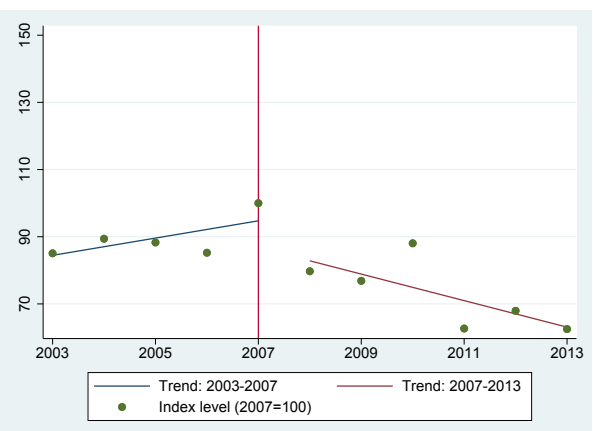

(b) $\omega$

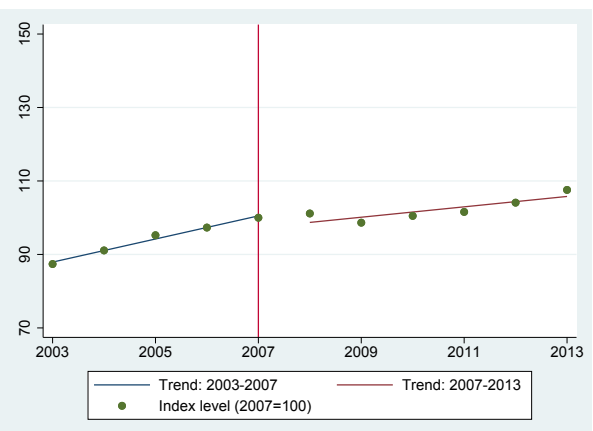

(d) scale

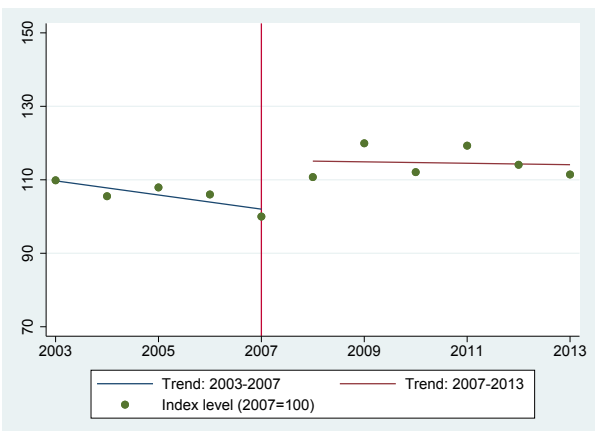

(f) adjusted scale 
Table B-11: Manufacturing. Changes of revenue TFP and its components over the period 2003-2013. FMMM estimation procedure, within sample, revenue-weighted

\begin{tabular}{lcccccccc}
\hline & $\begin{array}{c}\Delta \text { TFP-R } \\
\text { (WLD) }\end{array}$ & $\begin{array}{c}\Delta \text { TFP-R } \\
(\text { FMMM })\end{array}$ & $\Delta a$ & $\Delta \lambda$ & $\Delta \omega$ & $\Delta \mu$ & $\Delta$ scale & Obs \\
& 0.007 & 0.024 & 0.011 & 0.123 & 0.133 & 0.012 & 0.031 & 576 \\
2004 & 0.011 & -0.011 & -0.012 & 0.026 & 0.014 & 0.003 & 0.022 & 498 \\
2005 & 0.018 & 0.046 & 0.039 & 0.060 & 0.099 & 0.006 & -0.016 & 548 \\
2006 & 0.012 & 0.025 & 0.015 & -0.004 & 0.010 & 0.001 & 0.026 & 519 \\
2007 & 0.028 & 0.032 & 0.064 & 0.149 & 0.213 & 0.016 & -0.045 & 355 \\
2008 & -0.025 & -0.000 & -0.046 & -0.096 & -0.142 & -0.015 & -0.093 & 364 \\
2009 & 0.031 & 0.031 & 0.003 & 0.005 & 0.008 & 0.001 & 0.032 & 435 \\
2010 & 0.023 & 0.038 & 0.050 & 0.168 & 0.217 & 0.017 & 0.003 & 387 \\
2011 & -0.008 & -0.015 & -0.021 & 0.005 & -0.016 & 0.000 & 0.018 & 405 \\
2012 & 0.013 & 0.012 & -0.012 & 0.094 & 0.082 & 0.007 & 0.025 & 417 \\
2013 & 0.015 & 0.024 & 0.023 & 0.070 & 0.094 & 0.007 & 0.004 & 2,496 \\
$2003-2008$ & 0.007 & 0.013 & -0.005 & 0.035 & 0.030 & 0.002 & -0.003 & 2,008 \\
$2008-2013$ & & & & & & & & \\
\hline
\end{tabular}

Table B-12: Services. Changes of revenue TFP and its components over the period 2003-2013. FMMM estimation procedure, within sample, revenue-weighted

\begin{tabular}{lccccccc}
\hline & $\begin{array}{c}\Delta \text { TFP-R } \\
(\text { FMMM })\end{array}$ & $\Delta \omega$ & $\Delta \mu$ & $\Delta$ scale & $\Delta$ adjusted $\omega$ & $\begin{array}{c}\Delta \text { adjusted } \\
\text { scale }\end{array}$ & Obs \\
\hline 2004 & -0.004 & 0.083 & 0.007 & 0.052 & 0.050 & -0.054 & 8,387 \\
2005 & -0.012 & -0.034 & -0.002 & 0.049 & -0.017 & 0.006 & 7,813 \\
2006 & 0.008 & -0.017 & -0.002 & 0.035 & 0.026 & -0.017 & 6,438 \\
2007 & -0.001 & 0.166 & 0.014 & 0.051 & 0.113 & -0.114 & 6,266 \\
2008 & -0.014 & -0.159 & -0.012 & 0.010 & -0.124 & 0.110 & 5,674 \\
2009 & -0.027 & -0.018 & 0.001 & -0.016 & 0.011 & -0.038 & 6,493 \\
2010 & 0.011 & 0.097 & 0.008 & 0.014 & 0.079 & -0.068 & 6,079 \\
2011 & 0.018 & -0.132 & -0.013 & -0.002 & -0.108 & 0.126 & 5,966 \\
2012 & 0.030 & 0.101 & 0.006 & 0.009 & 0.088 & -0.058 & 6,404 \\
2013 & 0.004 & -0.022 & -0.002 & 0.024 & -0.012 & 0.016 & 6,626 \\
$2003-2007$ & -0.002 & 0.051 & 0.004 & 0.047 & 0.044 & -0.046 & 28,904 \\
$2007-2013$ & 0.004 & -0.019 & -0.002 & 0.007 & -0.008 & 0.012 & 37,242 \\
\hline
\end{tabular}


Figure B-9: Manufacturing. Evolution of revenue TFP and its components over the period 2003-2013. FMMM estimation procedure, within sample, revenue-weighted

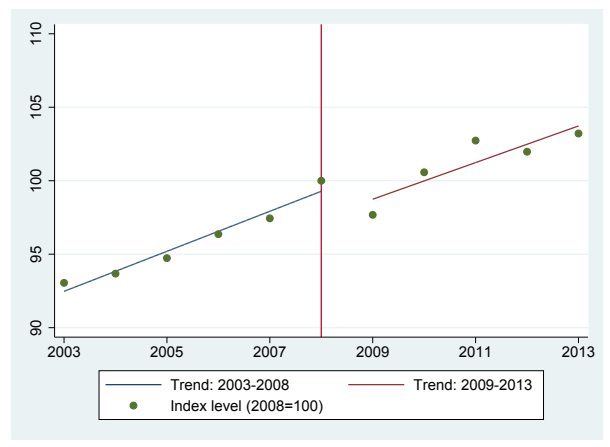

(a) WLD rev TFP

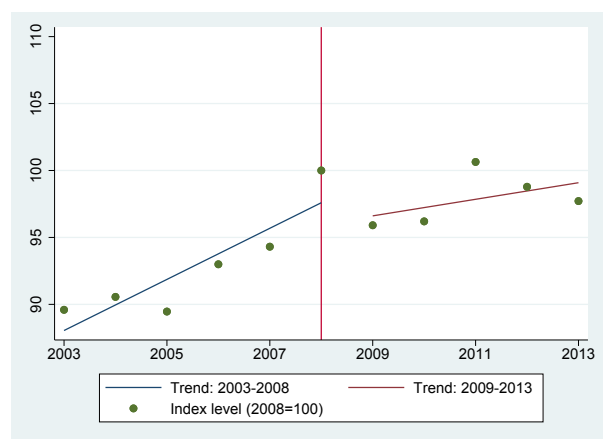

(c) a

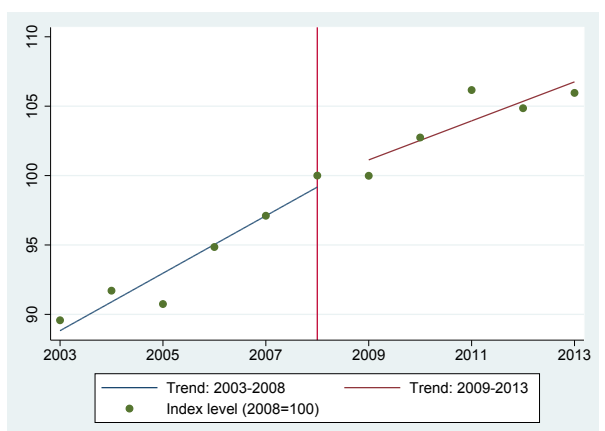

(b) FMMM rev TFP

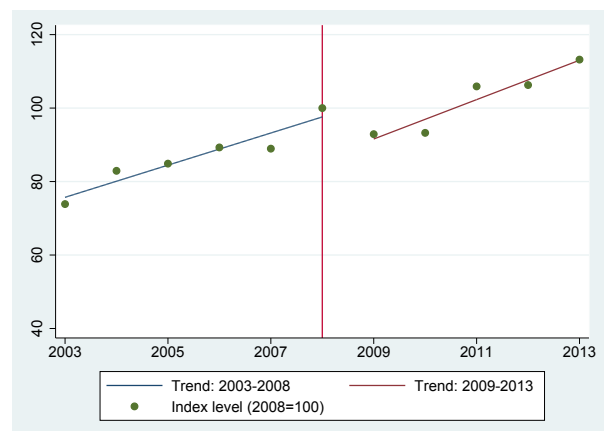

(d) $\lambda$

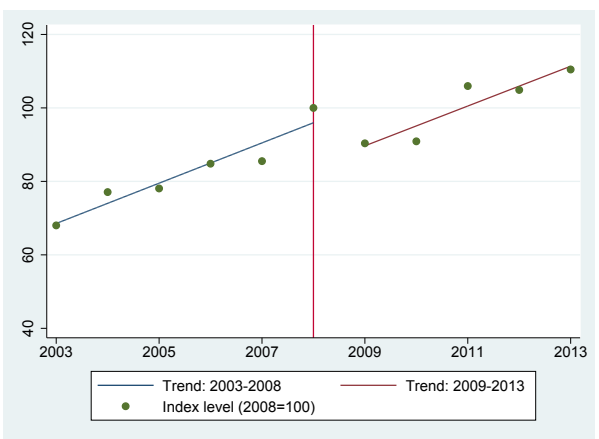

(e) $\omega$

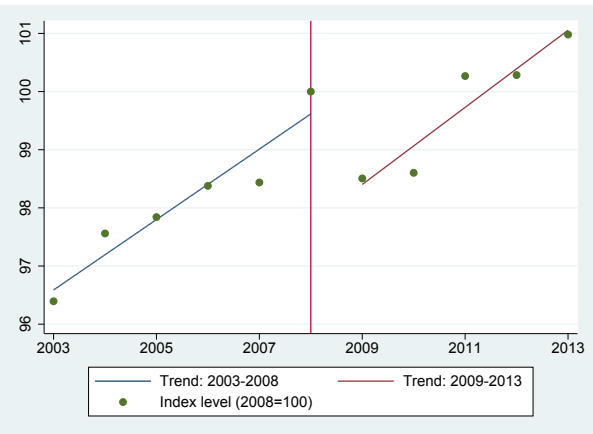

(f) $\mu$

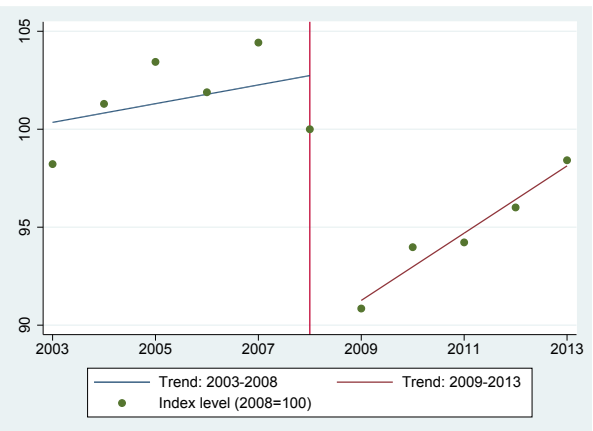

(g) scale 
Figure B-10: Services. Evolution of revenue TFP and its components over the period 20032013. FMMM estimation procedure, within sample, revenue-weighted

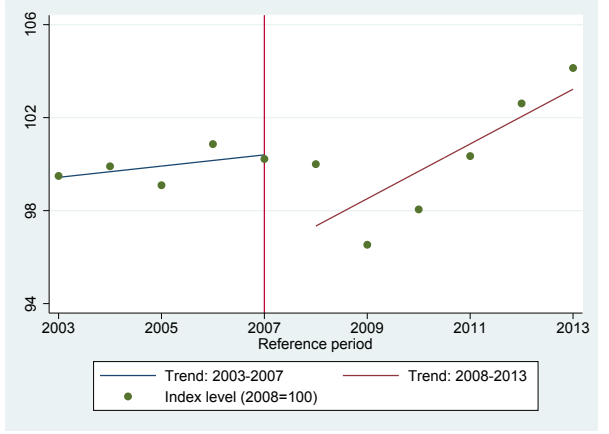

(a) FMMM rev TFP

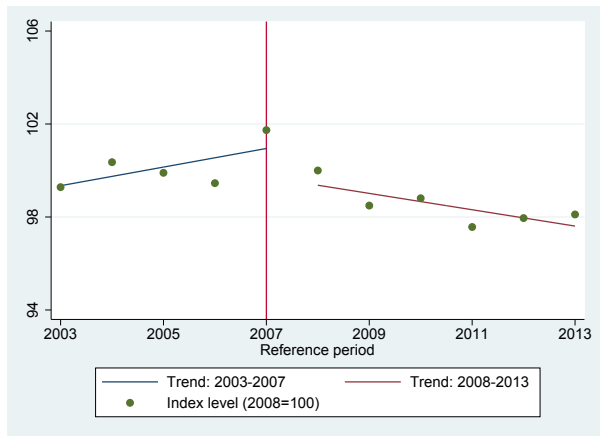

(c) $\mu$

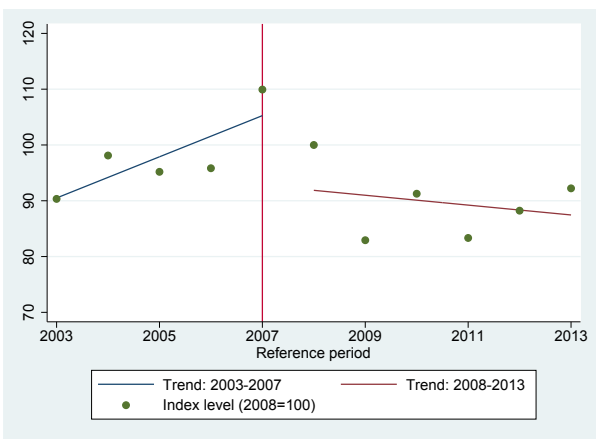

(e) adjusted $\omega$

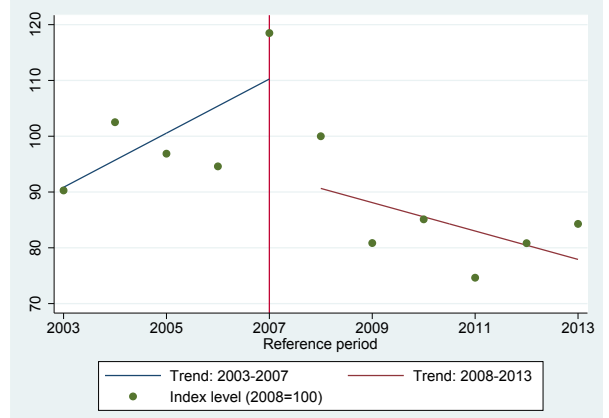

(b) $\omega$

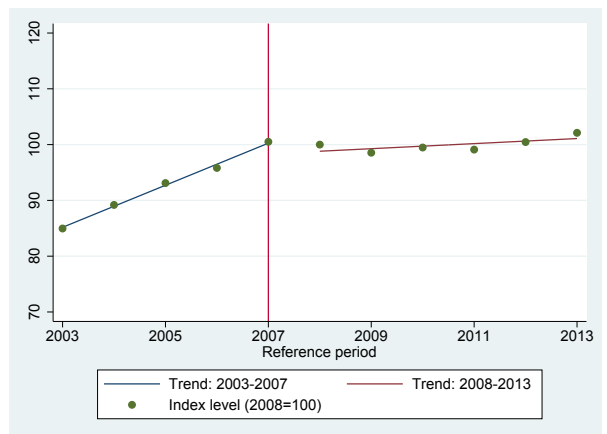

(d) scale

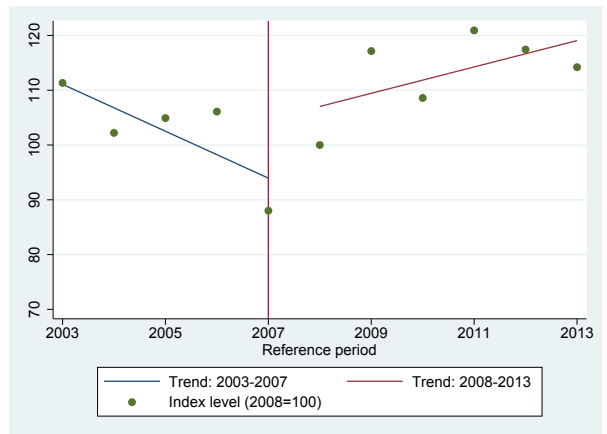

(f) adjusted scale 
Table B-13: Manufacturing. Changes of revenue TFP and its components over the period 2003-2013. Translog production function, within sample, revenue-weighted

\begin{tabular}{lcccccccc}
\hline & $\begin{array}{c}\Delta \text { TFP-R } \\
\text { (WLD) }\end{array}$ & $\begin{array}{c}\Delta \text { TFP-R } \\
\text { (DGKP) }\end{array}$ & $\Delta a$ & $\Delta \lambda$ & $\Delta \omega$ & $\Delta \mu$ & $\Delta$ scale & Obs \\
\hline 2004 & 0.006 & 0.021 & 0.012 & 0.227 & 0.240 & 0.020 & 0.040 & 659 \\
2005 & 0.012 & -0.002 & -0.015 & -0.005 & -0.020 & -0.001 & 0.018 & 572 \\
2006 & 0.018 & 0.015 & 0.005 & 0.134 & 0.140 & 0.011 & 0.024 & 624 \\
2007 & 0.008 & 0.016 & 0.000 & 0.222 & 0.222 & 0.017 & 0.033 & 605 \\
2008 & 0.025 & 0.015 & 0.047 & 0.144 & 0.191 & 0.016 & -0.036 & 396 \\
2009 & -0.018 & -0.018 & -0.051 & -0.210 & -0.261 & -0.022 & -0.059 & 434 \\
2010 & 0.023 & 0.023 & 0.013 & 0.318 & 0.332 & 0.028 & 0.039 & 504 \\
2011 & 0.024 & 0.024 & 0.022 & 0.277 & 0.299 & 0.024 & 0.021 & 457 \\
2012 & -0.004 & -0.008 & -0.014 & -0.127 & -0.141 & -0.012 & 0.015 & 485 \\
2013 & 0.009 & 0.013 & -0.004 & 0.197 & 0.194 & 0.015 & 0.024 & 484 \\
$2003-2008$ & 0.013 & 0.013 & 0.009 & 0.149 & 0.158 & 0.013 & 0.017 & 2,856 \\
$2008-2013$ & 0.007 & 0.007 & -0.006 & 0.093 & 0.087 & 0.007 & 0.009 & 2,364 \\
\hline
\end{tabular}


Figure B-11: Manufacturing. Changes of revenue TFP and its components over the period 2003-2013. Translog production function, within sample, revenue-weighted

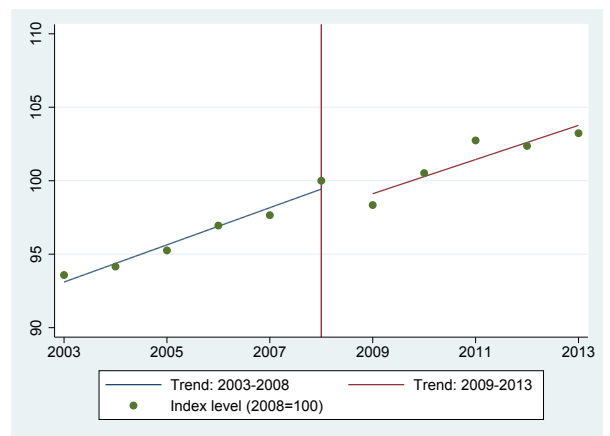

(a) WLD rev TFP

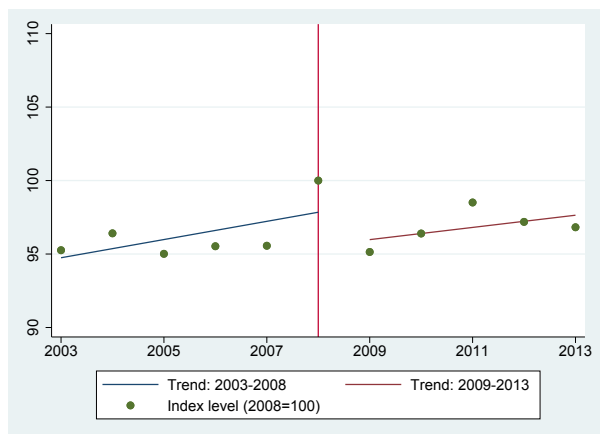

(c) a

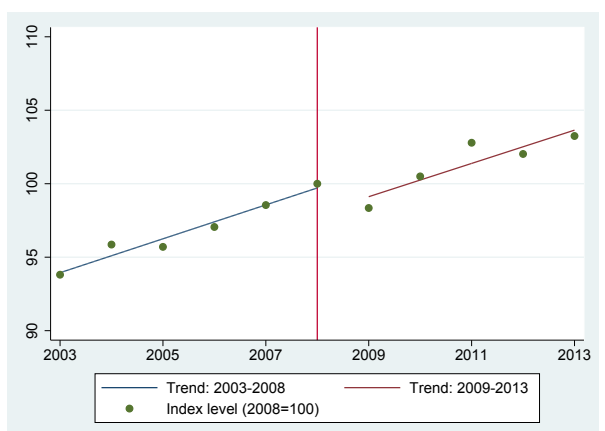

(b) DGKP rev TFP

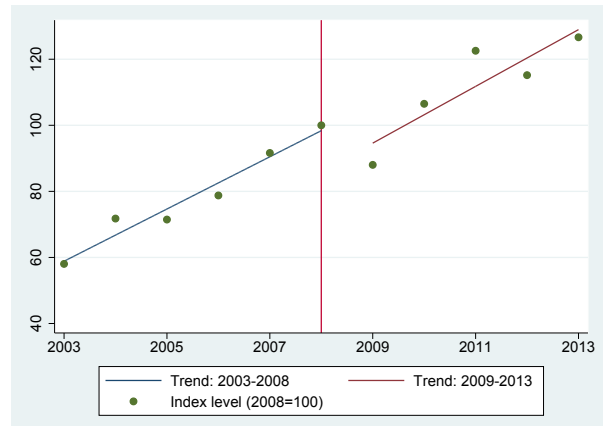

(d) $\lambda$

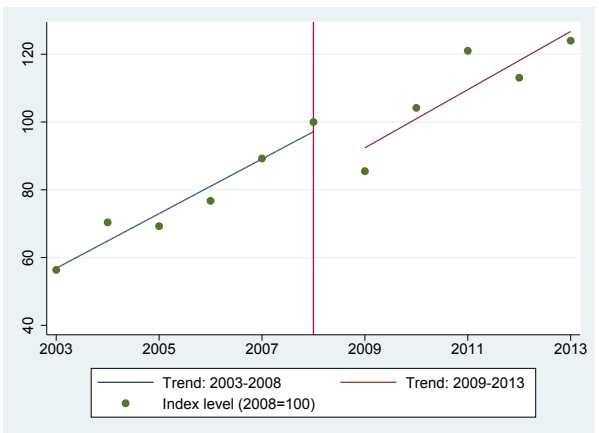

(e) $\omega$

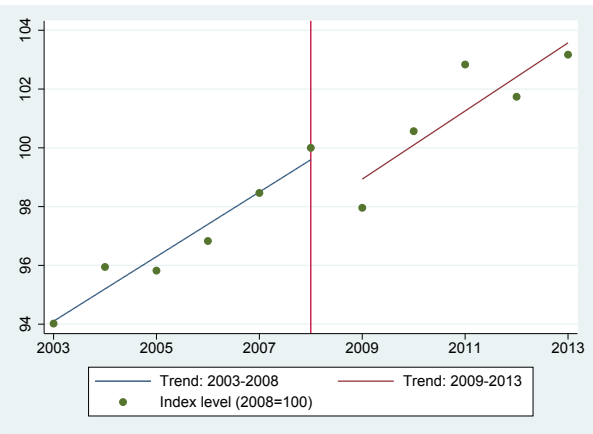

(f) $\mu$

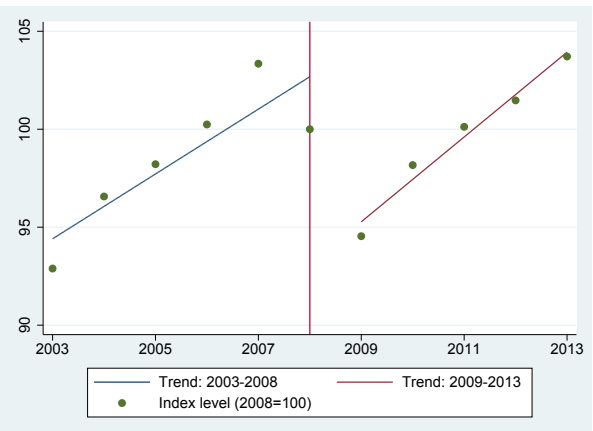

(g) scale 
CENTRE FOR ECONOMIC PERFORMANCE

Recent Discussion Papers

\begin{tabular}{|c|c|c|}
\hline 1736 & $\begin{array}{l}\text { Gabriel M. Ahlfeldt } \\
\text { Fabian Bald } \\
\text { Duncan Roth } \\
\text { Tobias Seidel }\end{array}$ & Quality of life in a dynamic spatial model \\
\hline 1735 & Kilian Huber & $\begin{array}{l}\text { Are bigger banks better? Firm-level evidence } \\
\text { from Germany }\end{array}$ \\
\hline 1734 & $\begin{array}{l}\text { César Ducruet } \\
\text { Réka Juhász } \\
\text { Dávid Krisztián Nagy } \\
\text { Claudia Steinwender }\end{array}$ & All aboard: the effects of port development \\
\hline 1733 & $\begin{array}{l}\text { Jonathan Colmer } \\
\text { John Voorheis }\end{array}$ & $\begin{array}{l}\text { The grandkids aren't alright: the } \\
\text { intergenerational effects of prenatal pollution } \\
\text { exposure }\end{array}$ \\
\hline 1732 & $\begin{array}{l}\text { Kabir Dasgupta } \\
\text { André Diegmann } \\
\text { Tom Kirchmaier } \\
\text { Alexander Plum }\end{array}$ & $\begin{array}{l}\text { Heterogeneity in criminal behavior after child } \\
\text { birth: the role of ethnicity }\end{array}$ \\
\hline 1731 & $\begin{array}{l}\text { Andreas Diemer } \\
\text { Tanner Regan }\end{array}$ & $\begin{array}{l}\text { No inventor is an island: social connectedness } \\
\text { and the geography of knowledge flows in the } \\
\text { US }\end{array}$ \\
\hline 1730 & $\begin{array}{l}\text { Hanming Fang } \\
\text { Chunmian Ge } \\
\text { Hanwei Huang } \\
\text { Hongbin Li }\end{array}$ & $\begin{array}{l}\text { Pandemics, global supply chains, and local } \\
\text { labor demand: evidence from } 100 \text { million } \\
\text { posted jobs in China }\end{array}$ \\
\hline 1729 & $\begin{array}{l}\text { Ria Ivandić } \\
\text { Tom Kirchmaier } \\
\text { Ben Linton }\end{array}$ & $\begin{array}{l}\text { Changing patterns of domestic abuse during } \\
\text { COVID-19 lockdown }\end{array}$ \\
\hline 1728 & $\begin{array}{l}\text { Jonathan Colmer } \\
\text { Ralf Martin } \\
\text { Mirabelle Muûls } \\
\text { Ulrich J. Wagner }\end{array}$ & $\begin{array}{l}\text { Does pricing carbon mitigate climate change? } \\
\text { Firm-level evidence from the European Union } \\
\text { emissions trading scheme }\end{array}$ \\
\hline
\end{tabular}




\begin{tabular}{|c|c|c|}
\hline 1727 & $\begin{array}{l}\text { Tony Beatton } \\
\text { Michael P. Kidd } \\
\text { Matteo Sandi }\end{array}$ & School indiscipline and crime \\
\hline 1726 & $\begin{array}{l}\text { Maximilian v. Ehrlich } \\
\text { Henry G. Overman }\end{array}$ & $\begin{array}{l}\text { Place-based policies and spatial disparities } \\
\text { across European cities }\end{array}$ \\
\hline 1725 & $\begin{array}{l}\text { Gabriel M. Ahlfeldt } \\
\text { Thilo N. H. Albers } \\
\text { Kristian Behrens }\end{array}$ & Prime Locations \\
\hline 1724 & $\begin{array}{l}\text { Benjamin Handel } \\
\text { Jonathan Kolstad } \\
\text { Thomas Minten } \\
\text { Johannes Spinnewijn }\end{array}$ & $\begin{array}{l}\text { The Social Determinants of Choice Quality: } \\
\text { Evidence from Health Insurance in the } \\
\text { Netherlands }\end{array}$ \\
\hline 1723 & $\begin{array}{l}\text { Claudia Hupkau } \\
\text { Barbara Petrongolo }\end{array}$ & $\begin{array}{l}\text { Work, Care and Gender During the Covid-19 } \\
\text { Crisis }\end{array}$ \\
\hline 1722 & $\begin{array}{l}\text { Ross Levine } \\
\text { Yona Rubinstein }\end{array}$ & $\begin{array}{l}\text { Selection Into Entrepreneurship and Self- } \\
\text { Employment }\end{array}$ \\
\hline 1721 & Sandra McNally & $\begin{array}{l}\text { Gender Differences in Tertiary Education: } \\
\text { What Explains STEM Participation? }\end{array}$ \\
\hline 1720 & $\begin{array}{l}\text { Edoardo di Porto } \\
\text { Paolo Naticchioni } \\
\text { Vincenzo Scrutinio }\end{array}$ & $\begin{array}{l}\text { Partial Lockdown and the Spread of Covid- } \\
\text { 19: Lessons From the Italian Case }\end{array}$ \\
\hline 1719 & $\begin{array}{l}\text { Swati Dhingra } \\
\text { Stephen Machin }\end{array}$ & The Crisis and Job Guarantees in Urban India \\
\hline 1718 & Stephen J. Redding & Trade and Geography \\
\hline
\end{tabular}

The Centre for Economic Performance Publications Unit

Tel: +44 (0)207955 7673 Email info@cep.lse.ac.uk

Website: http://cep.lse.ac.uk Twitter: @CEP_LSE 